\title{
High-Throughput Screening of Sensory and Nutritional Characteristics for Cultivar Selection in Commercial Hydroponic Greenhouse Crop Production
}

\author{
Atef M. K. Nassar, ${ }^{1,2,3}$ Stan Kubow, ${ }^{2}$ and Danielle J. Donnelly ${ }^{1}$ \\ ${ }^{1}$ Plant Science Department, Macdonald Campus of McGill University, 21111 Lakeshore Road, Sainte Anne de Bellevue, \\ QC, Canada H9X 3 V9 \\ ${ }^{2}$ School of Dietetics and Human Nutrition, Macdonald Campus of McGill University, 21111 Lakeshore Road, Sainte Anne de Bellevue, \\ QC, Canada H9X 3V9 \\ ${ }^{3}$ Plant Protection Department, Faculty of Agriculture, Damanhour University, Damanhour, Albeheira 22516, Egypt
}

Correspondence should be addressed to Danielle J. Donnelly; danielle.donnelly@mcgill.ca

Received 11 May 2015; Revised 6 October 2015; Accepted 5 November 2015

Academic Editor: Kent Burkey

Copyright (C) 2015 Atef M. K. Nassar et al. This is an open access article distributed under the Creative Commons Attribution License, which permits unrestricted use, distribution, and reproduction in any medium, provided the original work is properly cited.

\begin{abstract}
Hydroponic greenhouse-grown and store-bought cultivars of tomato (cherry and beefsteak), cucumbers, bibb lettuce, and arugula were investigated to see if they could be distinguished based on sensory qualities and phytonutrient composition. Only the more dominant sensory criteria were sufficiently robust to distinguish between cultivars and could form the core of a consolidated number of criteria in a more discriminating sensory evaluation test. Strong determinants for cultivar selection within each crop included the following: mineral analysis (particularly $\mathrm{Cu}, \mathrm{Fe}, \mathrm{K}, \mathrm{Mg}$, and $\mathrm{P}$ ); total carotenoids (particularly $\beta$-carotene, lycopene, and lutein); total carbohydrate (except in arugula); organic acids; total phenolics and total anthocyanins (except in cucumber). Hydroponically grown and store-bought produce were of similar quality although individual cultivars varied in quality. Storage at $4^{\circ} \mathrm{C}$ for up to 6 days did not affect phytonutrient status. From this, we conclude that "freshness," while important, has a longer duration than the 6 days used in our study. Overall, the effect of cultivar was more important than the effect of growing method or short-term storage at $4^{\circ} \mathrm{C}$ under ideal storage conditions.
\end{abstract}

\section{Introduction}

Modern agriculture aims to maximize yield and quality of plants with efficient use of resources and labor. Growing plants in a soilless environment on a supportive substrate (e.g., coir, peat, or rockwool) conserves water, nutrients, and space and is defined as hydroponics [1,2]. Hydroponics has long been considered a powerful method of commercial vegetable and fruit production where growing conditions (light, temperature, medium composition, etc.) are fully controlled. More recently, advances in biocontrol technology have enabled pesticide-free produce. The acreage of hydroponic greenhouses ranges from 3,000 to 4,000 in the United States and Canada [2]. Canadians consume large amounts of vegetables $\sim 337 \mathrm{~g} / \mathrm{d}$, about $123 \mathrm{~kg} /$ capita/yr [3].
Important considerations for hydroponically grown greenhouse $(\mathrm{GH})$ produce are microclimate and fertigation components that could potentially affect various plant characteristics. It is our contention that if these are held constant, selection of nutritionally optimal cultivars can be performed, based on a combination of sensory and phytonutrient characteristics. The latter includes biochemical composition and proximate traits. Fruits and vegetables are rich in phytonutrients including anthocyanins, carotenoids, minerals, organic acids, polyphenolics, and vitamins (e.g., vitamins $\mathrm{C}$ and E) $[4,5]$. Phytonutrients contribute to the general acceptability of any food as they influence taste, color, odor, and nutritional quality. Consumption of fruits and vegetables increases the intake of antioxidant compounds. These dietary antioxidants act as scavengers of reactive 
oxygen and nitrogen species and prevent lipid oxidation. This decreases DNA damage related to oxidative stress, implicated in causing metabolic diseases that can lead to cancer, as well as cardiovascular and other diseases $[6,7]$.

Four salad crops were examined in this study including tomato, cucumber, and the leafy greens arugula and bibb lettuce. Tomato consumption in Canada in 2007 was $87 \mathrm{~g} /$ capita/d or $32 \mathrm{~kg} /$ capita/yr [3]. Canadian consumption of cucumber and lettuce were 4.76 and $9.98 \mathrm{~kg} /$ capita/yr, respectively, in 2009 [8] while statistics on Canadian arugula consumption could not be located. Tomato contains phytochemicals including carotenoids (especially $\beta$-carotene and lycopene), flavonoids, folate, minerals, polyphenols, and vitamins ( $\mathrm{C}$ and E) [9]. Epidemiological studies showed that tomato phytochemicals (especially lycopene) reduce cancer (e.g., prostate cancer), act as in vivo antioxidants, enhance cell-to-cell communication, modulate cell-cycle progression, and alter xenobiotic metabolism [9]. Regular consumption of tomato has been related to reduced incidence of both prostate cancer and heart diseases (e.g., myocardial infarction) [1012], as well as promotion of healthy eye function [1316]. Cucumbers contain significant amounts of triterpenoid cucurbitacins that possess antioxidant, anti-inflammatory, and anticancer properties [17]. In particular, leafy salad vegetables (arugula and lettuce) provide antioxidant compounds, fiber, polyphenolics, and vitamin C [18-20]. Green leafy vegetables are also recommended as a source of the provitamin A carotenoids [21].

Few studies have been conducted on the phytonutrient composition of hydroponically produced vegetables. As these are grown under defined conditions of light, temperature, and fertigation, the nutritional content of specific cultivars may not vary widely from crop to crop. Although there may be some differences in nutritional composition related to season, differences are primarily related to light effects [22, 23]. Nutritional differences based on cultivar were explored for a range of crops grown in the Macdonald Campus Greenhouse and harvested fresh for comparison with storebought produce of the same species.

Selection of the most pleasing and nutritious cultivars for each food species would contribute to maximum consumer satisfaction and health. Following sensory characterization and phytonutrient analysis, a method was developed to highlight the most revealing factors for high-throughput cultivar selection within each species (cherry and beefsteak tomato, cucumber, arugula, and bibb lettuce). A range of complex statistical methods was considered. Among the methods examined for data classification and mining were partial least squares or projection to latent structures (PLS), principal component analysis (PCA), variable clustering, classification trees, linear and quadratic discriminant analysis, neural networks, and support vector machines [24]. Following comparative study, a decision was made to use a combination of PLS and PCA, which yield much richer results than other methods [24-26] and combine them with VARCLUS (SAS procedure for division of variables into hierarchical clusters) to verify decision-making.

So the objectives of this research were to (1) utilize taste panels to assess the appearance, taste, and texture acceptability of different cultivars of GH tomato (cherry and beefsteak types), cucumber, and two leafy green crops (arugula and bibb lettuce), (2) compare the phytonutrient composition of different cultivars of these fresh $\mathrm{GH}$ crops with store-bought (SB) produce, and (3) identify the most revealing factors (including sensory and phytonutrient data) that could be used in a high-throughput screening of a large number of cultivars, within each crop species, to expediently identify the most appealing and nutritious ones.

\section{Materials and Methods}

2.1. Plant Materials. Six cherry tomato cultivars including 'Apero', 'Favorita', and 'Juanita' were grown hydroponically in the greenhouse. Seeds of 'Apero' and 'Favorita' were bought from Johnny's Selected Seeds (ME, USA) while seeds of 'Juanita' were bought from De Ruiter Seeds (Monsanto; Montreal, QC, Canada). Fruit of three cherry tomato cultivars were purchased from local stores and tested under their trade names: Jardino (product of EU; from an IGA store on LouisMenard St.), Fruiterie (product of Mexico; from Inter-Marche on Cote Vertu Blvd.), and Cherries (product of Mexico; from Inter-Marche on Saint Laurence St.).

Four cultivars of beefsteak tomato including 'Arbason', 'Caramba, 'Geronimo,' and 'Trust' were grown hydroponically in the greenhouse. Seeds of 'Arbason,' 'Geronimo,' and 'Trust' were bought from Johnny's Selected Seeds and seeds of 'Caramba' were bought from De Ruiter Seeds. Fruit of three beef steak tomatoes were bought from local grocery stores and tested under their trade names: Kaliroy (produced in Mexico; from IGA on Louis-Menard St.), BionatureL (produced in Mexico; from Loblaws on Jean-Talon St.), and BionatureP (produced in Mexico; from Provigo on St. Urbain St.). 'Diva' Mini Cucumber was hydroponically grown in the greenhouse from seed bought from Johnny's Selected Seed. Three SB cultivars were tested under their trade names: Cool Cukes, Lebanese, and Mini cucumber.

Four cultivars of arugula and three of bibb lettuce were evaluated. The arugula 'Astro' was grown hydroponically from seeds bought from Johnny's Selected Seeds. Three arugula were SB and tested under their trade names: ADO (bought from Adonis) and BW and PRO (bought from Provigo). The bibb lettuce 'RexMT0' was grown in the greenhouse from seeds purchased from Johnny's Selected Seeds. Two store-bought bibb lettuce were tested under their trade names: ADO (bought from Adonis) and IGA (bought from IGA).

Hydroponically grown cherry tomato, cucumber, and leafy vegetables were stored in a household fridge $\left(4^{\circ} \mathrm{C}\right)$ for 0,3 , and/or $6 \mathrm{~d}$ (based on produce availability). This enabled comparison of "fresh" and cold-stored produce.

2.2. Panelists and Taste Tests. Taste tests were carried out at McGill University in a taste test laboratory (McGill University Research Ethics Board Approval \# 953-1110). Fifty persons were recruited and went through two rounds of training, and then individuals with consistent ratings were selected. Panelists included 25 males and females from 18 to 52 years of age with no known allergies to any of the tested fruits 
and vegetables. They tested hydroponic greenhouse grown and store-purchased produce, including tomato, cucumber, arugula, and lettuce. Before each taste test session, panelists were instructed regarding terminology, test procedures, and the nature of the samples. The sensory analysis taste test for each crop was conducted over several sessions during $1 \mathrm{~d}$, with a variable number of 10-20 panelists per session and results were subjected to statistical analysis.

2.2.1. Sample Preparation for Sensory Evaluation. Hydroponically grown and SB tomato, cucumber, arugula, and bibb lettuce were rinsed well under tap water and air-dried for at least $15 \mathrm{~min}$. Tomatoes were cut into thin round slices about $6 \mathrm{~mm}$ thick and then into halves, just before serving. Cucumber samples were cross-sliced (2-3 mm) just before serving. Panelists were served a plate containing, in the following order, 2-3 whole fruit of each cherry tomato cultivar, 2-3 slices of each cucumber cultivar, 2-3 half slices of each beefsteak tomato cultivar, and finally 2-3 leaves of each leafy green cultivar. Panelists were individually supplied with plain soda crackers and directed to have a bite after sampling and then sip some water to rinse their palate between each sample. More samples were given upon request and retasting was conducted when necessary.

2.2.2. Panelist Responses. Panelists scored their responses onto a print-out paper sheet that was prepared specifically for each crop. After sensory evaluation, panelists were asked to answer demographic questions (multiple choice), which included age, gender, and frequency of fresh vegetable consumption. Tomato ripeness, sweetness/saltiness, juiciness, and general acceptability of cherry or beefsteak varieties were scored on 9-point hedonic scales, where 9: ripe, 5: neutral, 1: unripe. The same scale was used for sweetness/saltiness and responses were scored: 1: salty; 5: not salty or sweet; 9: sweet. Juiciness was scored on a 9-point score where 1: dislike; 5: neutral; and 9: like. General acceptability also was given scores from 1 to 9, where 1: dislike and 9: like.

Cucumber sensory characteristics including flesh color and firmness, aroma of the fruit, and flesh taste sweetness/bitterness traits were scored on a 9-point scale, where 1 : dislike and 9: like for flesh color, firmness, and fresh aroma of the fruit. Sweetness/bitterness were scored on a 9-point scale, where 1: bitter, 5: not bitter or sweet, and 9: sweet. Arugula sensory characteristics including green/grassy, intensity of bitterness, astringent, and overall liking were rated on a 9point hedonic scale, where 1 was the lowest and 9 was the strongest taste and liking. Bibb lettuce was evaluated for color, sogginess/freshness, off-odor, and overall quality. Sensory evaluation of lettuce was done using the same hedonic 9point scale.

2.3. Mineral Analysis Using ICP-OES. Greenhouse and SB produce were hand-rinsed under running tap water and then blotted onto paper towels and air-dried for 1-2 h. Samples consisted of $1 \mathrm{~g}$ cross-sectional slices from the middle of each of 7-12 whole fruit or up to 20 leaves of leafy vegetables. These were incubated overnight in $3 \mathrm{~mL}$ nitric acid (trace metal analysis grade, Fisher Scientific Co., ON, Canada) in a $10 \mathrm{~mL}$ Oak Ridge centrifuge tube (Thermo Scientific, NY, USA) placed in a fume hood. On the following day, samples were digested using a heating block (Thermolyne heater type 16500 Dri Bath model DB16525; Thermolyne, Dubuque, IA 52001, USA). The samples were heated to $105^{\circ} \mathrm{C}$ until no nitrous oxide gases (brown gases) were evolved. Samples were diluted $(1: 4)$ with Type- 1 water $(18 \Omega \mathrm{cm})$ and mixed thoroughly (flipping tubes over) prior to injection into the ICP-OES apparatus for analysis. Control elemental stock standard solution (J. T. Baker, St. Louis, MO, USA) was used to calibrate the instrument before sample injection. The inductively coupled argon plasma optical emission spectrometer (ICP-OES) used for mineral analysis in this study was a model VISTA-MPX CCD Simultaneous ICP-OES (Varian Australia PTY Ltd., Australia). The settings were as follows: power $1.2 \mathrm{~kW}$, plasma flow $15 \mathrm{Lmin}^{-1}$, argon pressure $32 \mathrm{~L} \mathrm{~min}^{-1}(600 \mathrm{kPa})$, nebulizer flow $0.75 \mathrm{Lmin}^{-1}$, auxiliary flow $1.5 \mathrm{~L} \mathrm{~min}^{-1}$, pump rate $15 \mathrm{rpm}$, viewing height $10 \mathrm{~mm}$, replicate reading time $10 \mathrm{~s}$, and instrument stabilization delay $15 \mathrm{~s}$ [27]. Mineral contents were expressed as $\mathrm{g}$ or $\mathrm{mg}$ of macro- or microminerals, respectively, per $100 \mathrm{~g} \mathrm{DW}$ based on the dry matter content of each variety.

\subsection{Sample Preparation for Phytonutrient Analyses}

2.4.1. Freeze-Drying and Grinding of Plant Samples. Plant samples (about $1 \mathrm{~kg}$ of beef-steak, cherry tomato, or cucumber and $0.5 \mathrm{~kg}$ of arugula and bibb-lettuce leafy vegetables; all randomly selected, 3 replicates/variety) were homogenized and cut into thin slices $(0.5-1 \mathrm{~cm})$ and fast-frozen on aluminum plates (diameter of $25 \mathrm{~cm}$ ) using liquid nitrogen and then freeze-dried at -60 to $-70^{\circ} \mathrm{C}$ for up to $4 \mathrm{~d}$ in a freezedryer (Christ Freeze-Dryer, Gamma 1-16 LSC, Osterode, Germany). Freeze-dried samples (2 samples/replicate) were ground into a fine powder in liquid nitrogen and stored in a -80 C Freezer (Thermo Electron Corporation, OH, USA). Sample weights were recorded before (fresh weight) and after (dry weight) freeze-drying to calculate the sample dry matter content. Freeze-dried samples were used for phytonutrient analyses.

\subsubsection{Preparation of Crude Extracts for Phytonutrient Measure-} ments. About $100 \mathrm{mg}$ of freeze-dried powder was extracted with $2 \mathrm{~mL}$ of $90 \%$ methanol $(\mathrm{MeOH})$. Samples were vortexed at maximum speed for $60 \mathrm{~s}$, sonicated (Branson 2200, Branson Ultrasonics Corporation, CT, USA) for $30 \mathrm{~min}$, and centrifuged at 3,500 rpm for $15 \mathrm{~min}$ at $4^{\circ} \mathrm{C}$. Supernatants were collected into $15 \mathrm{~mL}$ Falcon tubes. The remaining pellet was reextracted with $1 \mathrm{~mL}$ of $90 \% \mathrm{MeOH}$ and supernatants were combined. Crude extract was used to measure total soluble phenolics (Folin Ciocalteu or FC test), the antioxidant scavenging capacity using 2,2-diphenyl-1-picrylhydrazyl (DPPH), and 2,2' -azino-bis-3-ethylbenzothiazoline-6-sulphonic acid (ABTS) (hydrophilic phase) [28]. The remaining pellet was reextracted twice, each time with $1 \mathrm{~mL}$ hexane, and supernatants were combined. This extract was dried in a Speed-Vac (Thermo Savant, Waltham, MA, USA) and the residues resolubilized in $2 \mathrm{~mL}$ of $95 \%$ ethanol and used for the evaluation 
of antioxidant scavenging capacity using ABTS (lipophilic phase).

2.5. Total Phenolics. Total extractable phenolic contents of $\mathrm{GH}$ or SB produce were evaluated with Folin-Ciocalteu (FC) reagent according to [29] using gallic acid (GA) as a standard. A $100 \mu \mathrm{L}$ sample aliquot of extract or standard dilution was mixed with $2 \mathrm{~mL}$ water followed by $200 \mu \mathrm{L}$ FC reagent $(2 \mathrm{~N})$. Tubes were vortexed and incubated at room temperature (RT) for $5 \mathrm{~min}$; then $1 \mathrm{~mL}$ of aqueous sodium carbonate solution (20\%) was added. Samples were vortexed and kept at RT for $1 \mathrm{~h}$. Absorbance was measured at $765 \mathrm{~nm}$ in a Beckman DU 640 spectrophotometer (Beckman Instruments, Fullerton, CA, USA) using $1 \mathrm{~cm}$ disposable cells. All measurements were replicated 2 times. Total phenolic content was expressed as milligrams of gallic acid equivalent (mg GAE) per $100 \mathrm{~g} \mathrm{DW}$.

2.6. Antioxidant Capacity via ABTS (Hydrophilic and Lipophilic Phases). ABTS $(7 \mathrm{mM})$ stock solution was prepared in $18 \Omega \mathrm{cm}^{-1}$ water. Radical cation of ABTS $\left(\mathrm{ABTS}^{\circ+}\right.$ ) was produced by reacting ABTS solution with potassium persulfate $\left(\mathrm{K}_{2} \mathrm{~S}_{2} \mathrm{O}_{8}\right)(2.45 \mathrm{mM})$ in the dark at RT for $12-16 \mathrm{~h}$ before use for complete oxidation of ABTS [30]. Oxidation of ABTS starts immediately after adding the $\mathrm{K}_{2} \mathrm{~S}_{2} \mathrm{O}_{8}$ but absorbance is not maximal or stable until after period more than $6 \mathrm{~h}$. The radical is stable in this form for more than $2 \mathrm{~d}$ when stored in the dark at room temperature. The $\mathrm{ABTS}^{\circ+}$ solution was diluted with $95 \%$ ethanol to an absorbance of $0.70 \pm 0.02$ at $734 \mathrm{~nm}$. About $1.2 \mathrm{~mL}$ of diluted ABTS $^{*+}$ solution $(\mathrm{A} 734 \mathrm{~nm}=0.700 \pm 0.020)$ was added to $100 \mu \mathrm{L}$ of sample extracts (hydrophilic or lipophilic) or Trolox standards $(0-15 \mu \mathrm{M})$ in ethanol and absorbance was reported $1 \mathrm{~min}$ after initial mixing and up to $5 \mathrm{~min}$. Antioxidant scavenging activity was expressed as $\mu \mathrm{g}$ Trolox equivalent (TE)/100 g DW [28].

2.7. Antioxidant Capacity Using DPPH Radical Scavenging Capacity. Radical scavenging capacity assay was performed as described by [28]. About $100 \mu \mathrm{L}$ of methanolic crude extract was added to $1.5 \mathrm{~mL}$ of DPPH $(2.5 \mu \mathrm{M}$ in methanol) and shaken vigorously. After incubation at RT for $30 \mathrm{~min}$, the absorbance of the remaining DPPH molecules was determined at $517 \mathrm{~nm}$ in a Beckman DU 640 spectrophotometer using $1 \mathrm{~cm}$ disposable cells. The mean values were obtained from triplicate determinations. Antioxidant activity was expressed as mg GAE/100 $\mathrm{g}$ DW.

2.8. Total Anthocyanin Content (TAC). Total anthocyanin content was extracted following the method previously described [31-33]. One hundred micrograms of each freezedried sample was mixed with $4 \mathrm{~mL}$ acetone and the extracted material was separated from the cake by filtration on a Buchner funnel. The filter cake remnant was reextracted with $70 \%(\mathrm{v} / \mathrm{v})$ aqueous acetone twice. Filtrates were combined and partitioned with chloroform (1:2 acetone: chloroform, $\mathrm{v} / \mathrm{v}$ ) and stored overnight at $1^{\circ} \mathrm{C}$. The aqueous portion containing the TAC was recovered and separated from the residual acetone at $40^{\circ} \mathrm{C}$ and resolubilized in $0.01 \% \mathrm{HCl}$. Extractions were repeated two times. All extracts were stored at $-70^{\circ} \mathrm{C}$ until being analyzed. The TAC in plant produce extracts were determined by using the $\mathrm{pH}$ differential method [34]. Absorbance was measured at 510 and $700 \mathrm{~nm}$ in a Beckman DU 640 spectrophotometer in potassium chloride (0.025 M, pH 1.0) and sodium acetate (0.4 M, pH 4.5) buffers. A molar extinction coefficient of $26,900 \mathrm{~L} \mathrm{~cm}^{-1} \mathrm{~mol}^{-1}$ and a molecular weight of 449.2 were used for calculation of total monomeric anthocyanin. Results were expressed as mg of cyanidin-3-glucoside equivalents (mg CGE)/100 g DW.

\subsection{Total Carotenoids in Hexane and Ethanol Extracts}

2.9.1. Hexane Extraction. Total carotenoids were extracted using hexane as described by [35]. A freeze-dried sample of $0.2 \mathrm{~g}$ was weighed into an amber vial and $5 \mathrm{~mL}$ of $0.05 \%(\mathrm{w} / \mathrm{v})$ butylated hydroxyl toluene (BHT) in acetone and then $5 \mathrm{~mL}$ of $95 \%$ ethanol and $10 \mathrm{~mL}$ of hexane were added. Samples were stirred on a magnetic stirring plate, placed on ice, and transferred onto an orbital shaker (Lab-Line Instruments Inc., Illinois, USA) at $180 \mathrm{rpm}$ for $15 \mathrm{~min}$. After shaking, $3 \mathrm{~mL}$ of deionized water was added and shaking was resumed for an additional $5 \mathrm{~min}$ (still on ice). Sample vials were left at RT for $5 \mathrm{~min}$ to allow for phase-separation. Absorbance of the upper hexane layer was recorded at $450 \mathrm{~nm}$ in a $1 \mathrm{~cm}$ path length quartz cuvette with a hexane blank in a Beckman DU 640 spectrophotometer. Total carotenoid content was calculated for sample weight using the absorbance at $450 \mathrm{~nm}$ based on a standard $\beta$-carotene curve [36].

2.9.2. Ethanol Extraction. Total carotenoids were assayed following the method of [37] to exclude the chlorophyll content. Approximately $0.2 \mathrm{mg}$ of freeze-dried sample was extracted in $5 \mathrm{~mL}$ of $95 \%$ ethanol. Extracts were vortexed for $60 \mathrm{~s}$ and sonicated for $30 \mathrm{~min}$ and then centrifuged at $3,700 \mathrm{rpm}$ for $10 \mathrm{~min}$ at $4^{\circ} \mathrm{C}$ before transfer to $1 \mathrm{~cm}$ disposable cells. Absorbance of supernatants was read at 470, 648.6, and $664.1 \mathrm{~nm}$ in a Beckman DU 640 spectrophotometer. Concentrations of total carotenoids (including xanthophylls) were determined by the following equations:

$$
\begin{aligned}
& \operatorname{Chl}_{a}(\mu \mathrm{g} / \mathrm{mL})=\left(13.36 * A_{664.1}-5.19 * A_{648.6}\right) \\
& \operatorname{Chl}_{b}(\mu \mathrm{g} / \mathrm{mL})=\left(27.43 * A_{648.6}-8.12 * A_{664.1}\right) \\
& \text { Total Carotenoid }(\mu \mathrm{g} / \mathrm{mL}) \\
& \quad=\frac{\left(1000 * A_{470}-2.13 * \mathrm{Chl}_{a}-97.64 * \mathrm{Chl}_{b}\right)}{209} .
\end{aligned}
$$

2.10. $\beta$-Carotene, Lutein, and Lycopene Measurements. The carotenoid compounds in freeze-dried produce samples were extracted using a modified method from [38]. A freeze-dried sample of $0.1 \mathrm{~g}$ was extracted with $5 \mathrm{~mL}$ of extraction solvent (hexane/acetone/ethanol: $50: 25: 25 \mathrm{v} / \mathrm{v} / \mathrm{v}$ ) in dark glass vials. The extracts were vortexed for $30 \mathrm{~min}$ and $1 \mathrm{~mL}$ of water was added. The upper layer was collected and the extract was evaporated to dryness in a Speed-Vac. The residue was dissolved to a final volume of $0.5 \mathrm{~mL}$ of ethanol/acetone $65: 35(\mathrm{v} / \mathrm{v})$. The extract was passed through a $0.20 \mu \mathrm{m}$ nylon membrane filter and $20 \mu \mathrm{L}$ was injected for HPLC analysis. 
Solvents and the HPLC running method under isocratic conditions were as described by [38]. Analysis was performed using a reverse phase Varian 9012 HPLC Gemini$\mathrm{NX}(5 \mu \mathrm{m}, 100 \mathrm{~mm} \times 4.6 \mathrm{~mm}) \mathrm{C}-18$ column equipped with a tertiary pump, refrigerated autosampler, and single variable UV wavelength detector. The mobile phase consisted of methanol (solvent A) and acetonitrile with triethylamine $(9 \mu \mathrm{M})$ (solvent B) at $90: 10$ at a flow rate of $0.9 \mathrm{~mL} \mathrm{~min} \mathrm{~m}^{-1}$. The column temperature was $30^{\circ} \mathrm{C}$ and the absorbance was read at $475 \mathrm{~nm}$.

2.11. Measurement of Organic Acids. The organic acids, ascorbic, citric, fumaric, and malic, were determined following [39] using a HPLC (Varian 9012, Varian Chromatography Systems, CA, USA) equipped with a tertiary pump, refrigerated autosampler, and single variable UV wavelength detector. A $100 \mathrm{mg}$ freeze-dried sample was extracted with $5 \mathrm{~mL}$ of $0.008 \mathrm{~N} \mathrm{H}_{2} \mathrm{SO}_{4}$ in type-1 water $(18 \Omega \mathrm{cm})$. Samples were shaken for $1 \mathrm{~min}$ on an orbital shaker (Lab-Line Instruments Inc., Illinois, USA) and centrifuged at 3,000 rpm for $10 \mathrm{~min}$ at $4^{\circ} \mathrm{C}$. Supernatant was collected and filtered through a $20 \mu \mathrm{m}$ nylon syringe filter (Fisher brand, Fisher Scientific, ON, Canada). Extracts were analyzed using a reverse phase HPLC Gemini-NX $(5 \mu \mathrm{m}, 100 \mathrm{~mm} \times 4.6 \mathrm{~mm})$ C-18 column (Phenomenex Inc., CA, USA) and a $4.6 \mathrm{~mm} \times 2.0 \mathrm{~mm}$ guard column. The mobile phase was $0.008 \mathrm{~N} \mathrm{H}_{2} \mathrm{SO}_{4}$ in water at $1.0 \mathrm{~mL} \mathrm{~min}^{-1}$ under isocratic conditions at $245 \mathrm{~nm}$ for ascorbic acid and at $210 \mathrm{~nm}$ for malic, citric, and fumaric acids. Extraction was repeated twice for each sample. The data obtained was expressed as mg of organic acid per $100 \mathrm{~g} \mathrm{DW}$.

2.12. Determination of Total Carbohydrates. About $20 \mathrm{mg}$ of freeze-dried sample was added to $5 \mathrm{~mL}$ of $1 \mathrm{M} \mathrm{HCl}$ and placed into a preheated shaker water bath at $100^{\circ} \mathrm{C}$ for $2 \mathrm{~h}$ [40]. Digested supernatant was collected and used for total carbohydrate measurements. Total carbohydrates were determined using the phenol-sulfuric acid colorimetric method described by Nelsen [41]. One $\mathrm{mL}$ of $5 \% \mathrm{w} / \mathrm{w}$ phenol and $5 \mathrm{~mL}$ of concentrated sulfuric acid were added to $1 \mathrm{~mL}$ of aciddigested sample in a $15 \mathrm{~mL}$ glass tube. Tubes were allowed to stand for $30 \mathrm{~min}$ in a shaker $(180 \mathrm{rpm})$ water bath at $30^{\circ} \mathrm{C}$. The absorption was read at $485 \mathrm{~nm}$ in a $1 \mathrm{~cm}$ quartz cell against a blank consisting of $1 \mathrm{~mL}$ of $5 \% \mathrm{w} / \mathrm{w}$ phenol, $5 \mathrm{~mL}$ of concentrated sulfuric acid, and $1 \mathrm{~mL}$ of deionized water. Standard solutions of glucose from $10-100 \mathrm{mg} \mathrm{L}^{-1}$ were used for preparation of a standard curve.

2.13. Total Dietary Fiber. Freeze-dried samples were analyzed for soluble and insoluble fiber using the method of AOAC (1995) $[42,43]$. The method includes enzymatic hydrolysis with $\alpha$-amylase (heat stable, Sigma A3306), protease (from Bacillus licheniformis, Sigma P3910), and amyloglucosidase (from Aspergillus niger, Sigma A9913). A $1 \mathrm{~g}$ quantity of freeze-dried sample was suspended in $50 \mathrm{~mL}$ phosphate buffer and a series of enzymes were added in the following sequence in a water bath (Reciprocal Shaking Bath Model 25, Precision Scientific, Il, USA): (1) $50 \mu \mathrm{L}$ of thermo-resistant $\alpha$ amylase at $95-100^{\circ} \mathrm{C}$ for $35 \mathrm{~min},(2) 100 \mu \mathrm{L}$ of protease at $60^{\circ} \mathrm{C}$ for $30 \mathrm{~min}$, and then following $\mathrm{pH}$ correction to 4.0-4.7, (3) $300 \mu \mathrm{L}$ of amyloglucosidase at $60^{\circ} \mathrm{C}$ for $30 \mathrm{~min}$. After soluble fiber precipitation with ethanol $(95 \% \mathrm{v} / \mathrm{v})$ at $60^{\circ} \mathrm{C}$, the sample was filtered. The crucibles containing the residues were dried at $105^{\circ} \mathrm{C}$, then cooled in a desiccator, and weighed. Residue was divided into two portions. The first part was used for estimation of protein content using a LECO nitrogen analyzer and a $\% \mathrm{~N} \times 6.25$ conversion factor to estimate the total protein content. The second part was incinerated at $525^{\circ} \mathrm{C}$ overnight to measure the ash content. Total dietary fiber was calculated using the following equation:

$$
\begin{aligned}
& \text { Total Dietary Fiber } \% \\
& =\left[\frac{(\text { weight of residue }- \text { protein }- \text { ash }- \text { blank })}{\text { sample weight }}\right] \\
& \quad \times 100 .
\end{aligned}
$$

2.14. Statistical Analyses. Statistical analysis was performed using the statistical analysis systems (SAS) software (version 9.2, 2009). Analysis of variance (ANOVA) was used to detect significant differences between varieties for individual attributes. Sensory evaluations were analyzed using the general linear model (GLM) procedure of SAS (Version 9.2, Cary, NC, USA). The data were first analyzed to determine panelist's age and gender effects in a randomized complete block design (RCBD). Least square means of panelists' responses were separated when effects were significant in the ANOVA table $(P \leq 0.05)$. Panelist, panelist's age, gender, and crop varieties were analyzed as main factors and were studied for their interactions. When effects of panelists were not significant they were pooled. The means were compared using Scheffe's Multiple Comparison Procedure $(P \leq 0.05)$.

Phytonutrients were analyzed using the GLM procedure of SAS (Version 9.2, Cary, NC, USA, 2011). Analysis of variance (ANOVA) was used to differentiate between main factors for cultivars within each crop and between crops for individual phytonutrient characteristics. The data were first analyzed for normality using PROC UNIVARIATE. When effects were significant in the ANOVA table $(P \leq 0.05)$ least square means of measurements were separated and compared using Scheffe's Multiple Comparison Test $(P \leq 0.05)$.

2.14.1. Identification of the Dominant (Useful) Variables. Identification of the dominant variables was done after running the variable cluster analysis (VARCLUS), principal component analysis (PCA), and partial least square (PLS) statistical analysis. Based on the hierarchical clustering patterns, classification of variables in nonoverlapping clusters was estimated by analyzing the correlation or the covariance matrices subsequently.

Cluster analysis is a separation method that divides the data set into a number of groups or clusters (tree dendrogram; tree leaves and leaflets) based on similarity. The data points within each group (cluster; one major leaf with one or several leaflets) are more similar to one another than they are to the data points within other clusters. The distance between clusters on the $x$-axis (horizontal axis) indicates how similar 
to one another the elements of a cluster are. The more distinct a cluster is, the longer the branch along the $x$-axis that connects it to a larger cluster is.

Then PCA and PLS were run to confirm and visualize in space the cluster (group) classification of variables based on the weight of each variable in relation to the variance (PLS) and covariance (PLS and PCA) matrices [24, 26, 44]. Clustering of variables based on their contribution to the overall variance was done using the VARCLUS procedure. VARCLUS output mainly classified variables based on their $R^{2}$ values. Three $R^{2}$ values were compared for better selection of variables: $R^{2}$ with own (the greater the better clustering), $R^{2}$ with nearest cluster (the lower the better), and $1-R^{2}$ ratio (the lower the better).

Correlation loading plot is a circular graph showing the variation accounted for by each extracted factor (of one or more variable(s)) and is generated by partial least square (PLS) analysis. The amount of variation in the data points is relative to their distance from the origin. So, the outside circle shows the data points that are most similar and grouped together (highly correlated). Each successive circle working from the outside to the inside indicates decreasing levels of explained variation. The correlation between any two variables is relative to the length of the projection of the point corresponding to one variable on a line through the origin passing through the other variable. The sign of the correlation (negative or positive) corresponds to which side of the origin the projected point falls on.

Multidimensional preference analysis is another mapping technique for the two principal components that show most of the variance and is generated by the principal component analysis (PCA). A biplot displays the independent and dependent variables in a single plot by projecting them onto the plane that accounts for the most variance. Points that are tightly clustered and point in the same direction share the most attributes in common. Pointing in the opposite direction suggests negative correlation. The longer the projection, the relatively more important the variable.

For data mining and discriminant analysis, statistical analysis was done on two steps: (1) significant variation among the 34 variables was identified (based on MANOVA table) and the nondiscriminant variables were identified for a drop-list. (2) Variable clustering analysis was done according to the contribution of each variable to the overall variance using the VARCLUS procedure. Then, their possible interrelationships were studied through visualization of a network structure using both principal component analysis (PCA) and partial least squares regression (PLS).

\section{Results and Discussion}

\subsection{Sensory Traits of Fruits and Vegetables}

3.1.1. Sensory Traits of Cherry and Beef Steak Tomatoes. Data presented in Table 1 show sensory traits of cherry and beefsteak tomato from the greenhouse and Montreal area grocery stores. Tomato ripeness was expressed by fruit firmness and color. Unripe tomatoes are firmer. As they ripen, they soften until they reach the fully ripe state where their color (red or orange) is most intense and the fruit are slightly soft to the touch [45].

There was no effect of panelist gender or age on cherry tomato ripening classification. No differences occurred in ripeness score between the GH cherry tomatoes 'Apero,' 'Favorita,' 'Juanita,' and the SB Fruiterie while SB Jardino was scored as less ripe than the others. Sweetness or saltiness of tomato is a trait related to soluble sugars and mineral content of tomato $[39,46]$. Juiciness represents the amount of juice/moisture perceived in the mouth. Mouth feeling is a measure of granularity of tomato texture. GH 'Apero' and 'Favorita' and SB Fruiterie had significantly sweeter taste, were juicier, and had a better mouth feel and greater general acceptance compared with both GH 'Juanita' and SB Jardino (Table 1). There was no effect of age or gender on panelist response.

No differences in sensory traits were found between GH beefsteak tomato cultivars (Table 1). The GH beefsteak tomatoes all scored similarly for juiciness and mouth feel but were significantly firmer than both the SB varieties (CHS and Plain Jane). Firmness also was reported to be highly correlated with general acceptability of field-grown tomato [45, 47]. GH 'Arbason,' 'Caramba,' and SB 'Plain Jane' were considered riper and more generally acceptable than the other cultivars. No differences were discerned in sweetness/saltiness and all of them were considered more sweet than salty. Sex, but not age, was important to determination of sensory traits of beefsteak tomato. Male panelists gave greater scores than females for ripeness, sweetness, juiciness, mouth feel, and general acceptability.

3.1.2. Sensory Traits of Cucumber. Results of sensory characterization of cucumber cultivars were presented in Table 2. Hydroponic greenhouse-grown 'Diva' was ranked above the two SB cucumber cultivars. Flesh color and fruit firmness of 'Diva' were more accepted compared with SB cucumbers. 'Diva' and Lebanese were sweeter than Mini Cucumber but all three were similar for fruit aroma. Panelists scored sensory characteristics of cucumber similarly without apparent age or gender bias.

3.1.3. Sensory Traits of Arugula. Results of sensory characterization of arugula (Rocket salad) cultivars are presented in Table 3. All arugula cultivars scored similarly for overall quality and greeny/grassy trait (a measure of freshness). The $\mathrm{GH}$ arugula cultivar had an intensely bitter and astringent taste compared with the SB cultivars. Although all participants in this test had never eaten arugula before, their gender and age significantly affected their responses. Male panelists had greater scores for greeny/grassy compared with female participants. Age of participants affected sensory traits of arugula with no obvious trend. For example, panelists, 21-41 years old, had greater scores for overall quality than panelists of the age of 19-20 ( 3 panelists) and $\geq 43$ ( 2 participants) years. For the intensity of bitterness, only one panelist (a 29 years old) scored less than all other participants. Also, only 2 panelists (49 years old) had greater scores of greeny/grassy trait than 2 panelists (43 years old). Similarly, four panelists 
TABLE 1: LS mean score values ${ }^{1} \pm$ SE of panelist responses to different sensory traits and general acceptability of greenhouse-grown ('Apero,' 'Favorita,' and 'Juanita') and store-bought (Fruterie and Jardino) cherry tomato and greenhouse-grown ('Arbason,' 'Caramba,' 'Geronimo,' and 'Trust') and store-bought (CHS, del Campo, and Plain Jane) beefsteak tomato.

\begin{tabular}{|c|c|c|c|c|c|}
\hline Cultivar & Ripeness* & Sweetness/saltiness & Juiciness & Mouth feeling & General acceptability \\
\hline \multicolumn{6}{|c|}{ Cherry tomato } \\
\hline Apero & $8.36 \pm 0.183^{\mathrm{a}}$ & $8.08 \pm 0.197^{\mathrm{a}}$ & $8.27 \pm 0.185^{\mathrm{a}}$ & $8.02 \pm 0.209^{\mathrm{a}}$ & $8.22 \pm 0.204^{\mathrm{a}}$ \\
\hline Favorita & $8.15 \pm 0.183^{\mathrm{a}}$ & $7.50 \pm 0.192^{\mathrm{ab}}$ & $7.81 \pm 0.185^{\mathrm{a}}$ & $7.35 \pm 0.209^{\mathrm{ab}}$ & $7.83 \pm 0.204^{\mathrm{ab}}$ \\
\hline Juanita & $8.11 \pm 0.183^{\mathrm{a}}$ & $6.94 \pm 0.193^{\mathrm{b}}$ & $6.64 \pm 0.196^{\mathrm{b}}$ & $6.96 \pm 0.222^{\mathrm{b}}$ & $6.94 \pm 0.215^{\mathrm{c}}$ \\
\hline Fruterie & $7.99 \pm 0.183^{\mathrm{a}}$ & $7.49 \pm 0.198^{\mathrm{ab}}$ & $8.31 \pm 0.185^{\mathrm{a}}$ & $7.12 \pm 0.225^{\mathrm{b}}$ & $7.42 \pm 0.220^{\mathrm{bc}}$ \\
\hline Jardino & $6.81 \pm 0.197^{\mathrm{b}}$ & $5.80 \pm 0.192^{c}$ & $6.07 \pm 0.218^{\mathrm{b}}$ & $5.59 \pm 0.226^{\mathrm{c}}$ & $5.82 \pm 0.215^{\mathrm{d}}$ \\
\hline \multicolumn{6}{|c|}{ Beefsteak tomato } \\
\hline Arbason & $8.27 \pm 0.287^{\mathrm{a}}$ & $5.37 \pm 0.292^{\mathrm{a}}$ & $6.27 \pm 0.280^{\mathrm{ab}}$ & $5.82 \pm 0.297^{\mathrm{ab}}$ & $5.96 \pm 0.303^{\mathrm{b}}$ \\
\hline Caramba & $6.72 \pm 0.287^{\mathrm{bc}}$ & $5.72 \pm 0.292^{\mathrm{a}}$ & $6.87 \pm 0.280^{\mathrm{ab}}$ & $6.07 \pm 0.297^{\mathrm{ab}}$ & $6.26 \pm 0.303^{\mathrm{a}}$ \\
\hline Geronimo & $7.77 \pm 0.287^{\mathrm{ab}}$ & $5.77 \pm 0.292^{\mathrm{a}}$ & $6.32 \pm 0.280^{\mathrm{b}}$ & $6.12 \pm 0.297^{\mathrm{a}}$ & $6.41 \pm 0.303^{\mathrm{a}}$ \\
\hline Trust & $7.77 \pm 0.287^{\mathrm{ab}}$ & $5.82 \pm 0.292^{\mathrm{a}}$ & $7.07 \pm 0.280^{\mathrm{a}}$ & $6.62 \pm 0.297^{\mathrm{a}}$ & $6.66 \pm 0.303^{\mathrm{a}}$ \\
\hline CHS & $7.92 \pm 0.287^{\mathrm{ab}}$ & $6.57 \pm 0.292^{\mathrm{a}}$ & $7.37 \pm 0.280^{\mathrm{a}}$ & $6.42 \pm 0.297^{\mathrm{a}}$ & $6.71 \pm 0.303^{\mathrm{a}}$ \\
\hline del Campo & $6.17 \pm 0.287^{\mathcal{C}}$ & $6.02 \pm 0.292^{\mathrm{a}}$ & $6.47 \pm 0.280^{\mathrm{ab}}$ & $6.22 \pm 0.297^{\mathrm{a}}$ & $6.01 \pm 0.303^{\mathrm{ab}}$ \\
\hline Plain Jane & $4.97 \pm 0.287^{\mathcal{C}}$ & $5.17 \pm 0.292^{\mathrm{a}}$ & $5.32 \pm 0.280^{c}$ & $5.32 \pm 0.297^{\mathrm{b}}$ & $4.91 \pm 0.303^{\mathrm{c}}$ \\
\hline
\end{tabular}

${ }^{1}$ LS means were compared using Scheffe's Multiple Comparison Procedure. Superscripts not sharing the same letter within each column are significantly different $(P \leq 0.05) .{ }^{*}$ Tomato ripeness was scored on 9-point hedonic scales, where 9: ripe, 5: neutral, 1 : unripe. Sweetness/saltiness responses were scored as 1: salty, 5: not salty or sweet, and 9: sweet. Juiciness was scored on a 9-point scale, where 1: dislike, 5: neutral, and 9: like. General acceptability also was given scores from 1 to 9 , where 1: dislike and 9: like.

TABLE 2: LS mean score values ${ }^{1} \pm$ SE of panelist responses to different sensory traits of greenhouse-grown ('Diva') and store-bought (Lebanese and Mini Cucumber) cucumbers.

\begin{tabular}{lcccc}
\hline Cultivar & Flesh color $^{*}$ & Firmness & Aroma & Sweetness/bitterness \\
\hline Diva & $7.50 \pm 0.253^{\mathrm{a}}$ & $7.81 \pm 0.260^{\mathrm{a}}$ & $6.77 \pm 0.319^{\mathrm{a}}$ & $6.80 \pm 0.276^{\mathrm{a}}$ \\
Lebanese & $5.99 \pm 0.267^{\mathrm{b}}$ & $6.69 \pm 0.304^{\mathrm{b}}$ & $6.47 \pm 0.308^{\mathrm{a}}$ & $6.14 \pm 0.304^{\mathrm{a}}$ \\
Mini Cucumber & $5.61 \pm 0.257^{\mathrm{b}}$ & $5.54 \pm 0.276^{\mathrm{c}}$ & $6.33 \pm 0.324^{\mathrm{a}}$ & $5.51 \pm 0.305^{\mathrm{b}}$ \\
\hline
\end{tabular}

${ }^{1}$ LS means were compared using Scheffe's Multiple Comparison Procedure. Superscripts not sharing the same letter within each column are significantly different $(P \leq 0.05) .{ }^{*}$ Cucumber flesh color and firmness, aroma of the fruit, and flesh taste sweetness/bitterness traits were scored on 9-point scales, where 1: dislike and 9: like for flesh color, firmness, and fresh aroma of the fruit. Sweetness/bitterness were scored on a 9-point scale, where 1: bitter, 5: not bitter or sweet, and 9: sweet.

TABLE 3: LS mean score values ${ }^{1} \pm \mathrm{SE}$ of panelist responses to different sensory traits of greenhouse-grown ('Astro') and store-bought (ADO, BW, and PRO) arugula.

\begin{tabular}{lcccc}
\hline Cultivar & Overall quality $^{*}$ & Intensity of bitterness & Green/grassy & Astringency \\
\hline Astro & $6.07 \pm 0.262^{\mathrm{a}}$ & $6.40 \pm 0.378^{\mathrm{a}}$ & $7.47 \pm 0.225^{\mathrm{a}}$ & $6.40 \pm 0.309^{\mathrm{a}}$ \\
ADO & $6.92 \pm 0.255^{\mathrm{a}}$ & $4.27 \pm 0.370^{\mathrm{b}}$ & $7.42 \pm 0.229^{\mathrm{ab}}$ & $4.35 \pm 0.308^{\mathrm{b}}$ \\
BW & $6.91 \pm 0.258^{\mathrm{a}}$ & $4.09 \pm 0.402^{\mathrm{b}}$ & $6.74 \pm 0.212^{\mathrm{ab}}$ & $3.61 \pm 0.315^{\mathrm{b}}$ \\
PRO & $6.62 \pm 0.274^{\mathrm{a}}$ & $5.10 \pm 0.369^{\mathrm{b}}$ & $6.63 \pm 0.231^{\mathrm{b}}$ & $4.07 \pm 0.288^{\mathrm{b}}$ \\
\hline
\end{tabular}

${ }^{1}$ LS means were compared using Scheffe's Multiple Comparison Procedure. Superscripts not sharing the same letter within each column are significantly different $(P \leq 0.05) .{ }^{*}$ Arugula sensory characteristics including green/grassy, intensity of bitterness, astringency, and overall liking, were rated on 9-point hedonic scales, where 1 was the lowest and 9 was the strongest taste and liking.

(18 years old) scored the astringent characteristic greater than 1 participant, 25 years old. Mixed responses of panelists to the flavor of arugula could be due to the presence of glucosinolates/isothiocyanates, which give both positive and negative sensory properties [48].

3.1.4. Sensory Traits of Bibb Lettuce. Overall quality and freshness were not different between GH 'RexMT0' and the SB bibb lettuce cultivars and all had acceptable odor (Table 4). Panelists liked the color of 'RexMT0' and the IGA bibb lettuce but not ADO. No age or sex bias was apparent for panelist response to overall quality of bibb lettuce. However, for lettuce color only, males had greater scores compared with female participants.

\subsection{Mineral Content of Fruits and Vegetables}

3.2.1. Mineral Content of Cherry Tomato. Least squares means results for the macro mineral $(\mathrm{Ca}, \mathrm{Mg}, \mathrm{K}$, and $\mathrm{P}$; $\mathrm{g} / 100 \mathrm{~g} \mathrm{FW}$ ) contents of three hydroponically grown $\mathrm{GH}$ and 
TABLE 4: LS mean score values ${ }^{1} \pm$ SE of panelist responses to different sensory traits of greenhouse-grown ('RexMT0') and store-bought (ADO and IGA) bibb lettuce.

\begin{tabular}{lcccc}
\hline Cultivar & Overall quality $^{*}$ & Color & Sogginess/freshness & Off-odor \\
\hline RexMT0 & $6.75 \pm 0.237^{\mathrm{a}}$ & $7.19 \pm 0.212^{\mathrm{a}}$ & $3.23 \pm 0.348^{\mathrm{b}}$ & $1.59 \pm 0.163^{\mathrm{a}}$ \\
ADO & $6.51 \pm 0.235^{\mathrm{a}}$ & $5.86 \pm 0.226^{\mathrm{b}}$ & $4.32 \pm 0.325^{\mathrm{a}}$ & $1.67 \pm 0.170^{\mathrm{a}}$ \\
IGA & $7.23 \pm 0.212^{\mathrm{a}}$ & $7.11 \pm 0.198^{\mathrm{a}}$ & $3.67 \pm 0.311^{\mathrm{ab}}$ & $1.38 \pm 0.159^{\mathrm{a}}$ \\
\hline
\end{tabular}

${ }^{1}$ LS means were compared using Scheffe's Multiple Comparison Procedure. Superscripts not sharing the same letter within each column are significantly different $(P \leq 0.05)$. ${ }^{*}$ Bibb lettuce was evaluated for color, sogginess/freshness, off-odor, and overall quality. Sensory evaluation of lettuce was done using the same hedonic 9-point scales where 1 was the lowest and 9 was the strongest taste and liking.

three SB cherry tomato varieties are presented in Table 5. There were no clear distinctions in overall macro mineral content between $\mathrm{GH}$ and SB cherry tomato. However, the GH 'Apero' had the greatest overall content of macrominerals. In particular, it had greater $\mathrm{K}$ content but similar $\mathrm{Mg}$ content compared with 'Juanita.' Also, GH 'Apero' and 'Juanita' (but not 'Favorita') had greater $\mathrm{Mg}$ and $\mathrm{P}$ content compared to all of the SB varieties. The SB varieties 'Cherries' and 'Fruiterie' (but not 'Jardino') had greater Ca levels compared with the GH cultivars.

Levels of microminerals $\mathrm{Cu}, \mathrm{Fe}$, and $\mathrm{Na}$ (Table 5) and $\mathrm{Al}$, As, Cr, Se, and $\mathrm{Zn}$ (mg/100 g FW) (Table 6) varied widely in $\mathrm{GH}$ and SB cherry tomato. As with the macrominerals, there were no clear distinctions in overall micro mineral content between GH and SB cherry tomato. However, 'Apero' had the greatest $\mathrm{Fe}$ and $\mathrm{Na}$ contents compared with other $\mathrm{GH}$ and SB varieties but similar Cu levels to 'Cherries.' Storebought cherry tomato also showed less $\mathrm{Na}$ content compared with GH varieties. Cd was detected only in the GH 'Apero' and 'Juanita' (but not 'Favorita') with no differences between them. Hydroponically grown GH cherry tomato showed consistently less Al content compared with SB varieties while the $\mathrm{SB}$ variety cherries were uniquely high in $\mathrm{Al}$ content among all of the cherry and beefsteak tomato cultivars. Overall mineral content was not affected by fridge-storage of cherry tomato cultivars for $6 \mathrm{~d}$ (Tables 5 and 6). However, storage resulted in increased Fe levels in 'Juanita' and As content in 'Apero' while levels of Se were dramatically reduced in 'Favorita' and 'Juanita.'

3.2.2. Mineral Content of Beefsteak Tomato. Concentrations of macrominerals ( $\mathrm{Ca}, \mathrm{K}, \mathrm{Mg}$, and $\mathrm{P} ; \mathrm{g} / 100 \mathrm{~g} \mathrm{FW}$ ) of the four $\mathrm{GH}$ beefsteak tomato cultivars (Arbason, Caramba, Geronimo, and Trust) and the three SB varieties (Kaliroy, BionatureL, and BionatureP) are presented in Table 5. Overall, the GH cultivars were superior in macromineral content to $\mathrm{SB}$ varieties. However, clear cultivar differences were apparent among both the GH and the SB beefsteak tomato groups. The cultivars with the greatest tissue concentrations of all macrominerals were 'Caramba' (greatest in all except $\mathrm{Ca}$ and P) and 'Geronimo' and 'Trust' (greatest in Ca, and less than 'Caramba', but greater than the other cultivars for other macrominerals).

Microminerals (mg/100 g FW), Cu, Fe, and Na (Table 5) and $\mathrm{Al}, \mathrm{As}, \mathrm{Cd}, \mathrm{Cr}, \mathrm{Pb}, \mathrm{Se}$, and $\mathrm{Zn}$ (Table 6), varied between $\mathrm{GH}$ and SB beefsteak tomato varieties. 'Caramba' had the greatest $\mathrm{Cu}, \mathrm{Fe}$, and $\mathrm{Na}$ compared with other beefsteak tomato cultivars. The $\mathrm{GH}$ group had the least $\mathrm{Al}$ concentrations and As and Cd were detected only in 'Arbason.' 'Geronimo' showed the least Cr content but this was similar in the other GH cultivars. Also, 'Geronimo' had the greatest $\mathrm{Pb}$ level but this was similar in several other cultivars, both $\mathrm{GH}$ and SB. Selenium was detected, at similar concentrations, only in two cultivars, Caramba and Geronimo. Very high $\mathrm{Zn}$ content occurred in three of the four GH beefsteak cultivars. These $\mathrm{Zn}$ levels were much greater than in the other crops tested. 'Caramba' had the greatest $\mathrm{Zn}$ content followed by 'Geronimo' and 'Trust.' The other beefsteak cultivars (Arbason, Kaliroy, BionatureL, and BionatureP) had relatively low tissue levels of $\mathrm{Zn}$.

3.2.3. Mineral Content of Cucumber. Results of least square means of $\mathrm{Ca}, \mathrm{K}, \mathrm{Mg}$, and P (g/100 g FW) of one GH cultivar (Diva) and three SB cultivars of cucumber are presented in Table 5. No differences were found for $\mathrm{Ca}$ and $\mathrm{Mg}$ levels among $\mathrm{GH}$ and SB cucumber. Similar K concentrations were reported for 'Diva,' 'Lebanese', and 'Mini Cucumber.' 'Diva' had greater P content than 'Mini Cucumber' and 'Cool Cukes' but was not different from 'Lebanese.' Hydroponically grown $\mathrm{GH}$ 'Diva' led the SB varieties in $\mathrm{Cu}$ content but had similar Fe content to 'Cool Cukes' (Tables 5 and 6). Na level was greater in 'Diva' compared with cultivars Mini Cucumber and Cool Cukes but was not different from 'Lebanese.' 'Diva' had greater concentrations of $\mathrm{Zn}$ and $\mathrm{Al}$ compared to the $\mathrm{SB}$ varieties and $\mathrm{Cr}$ and $\mathrm{Pb}$ concentrations were similar for $\mathrm{GH}$ and SB cucumbers. Overall, it was apparent that fridgestorage of the cucumber 'Diva' for 3 or $6 \mathrm{~d}$ somewhat affected its mineral content (Table 5). While storage did not affect $\mathrm{Ca}$, $\mathrm{Cu}, \mathrm{K}$, and $\mathrm{Fe}$, it increased $\mathrm{Mg}, \mathrm{Na}, \mathrm{P}$, and $\mathrm{Zn}$ and reduced $\mathrm{Al}$ levels, compared with fresh cucumber (Table 6). Also, both As and Cd were detected, at similar concentrations for both storage intervals, only after 3 and $6 \mathrm{~d}$ storage but were not detected in the fresh sample. The rationale for differences in mineral content before and after storage is unclear, but the results may reflect reduced moisture content after storage, difficulty in complete extraction of minerals from fresh cucumber tissue, and/or potential matrix interferences.

3.2.4. Mineral Content of Arugula. Arugula from the GH (1 cultivar) and SB (3 cultivars) were similar in both macro- and micromineral content, except for $\mathrm{Fe}, \mathrm{Na}$, and $\mathrm{Al}$, where all of the SB cultivars had consistently greater levels (Tables 5 and 6). Fridge-storage for $6 \mathrm{~d}$ of $\mathrm{GH}$ 'Astro' did not have a great impact on mineral content (Tables 5 and 6). Fresh 'Astro' was 
TABLE 5: LS mean values ${ }^{1}$ of macrominerals (Ca, K, Mg, and P; g/100 g DW) and microminerals (Cu, Fe, and Na; mg/100 g DW) in hydroponically grown $(\mathrm{GH})$ and store-bought $(\mathrm{SB})$ cherry and beefsteak tomato, cucumber, arugula, and lettuce cultivars.

\begin{tabular}{|c|c|c|c|c|c|c|c|c|}
\hline \multirow{2}{*}{ Crops } & \multirow{2}{*}{ Varieties } & \multicolumn{4}{|c|}{ Macrominerals } & \multicolumn{3}{|c|}{ Microminerals } \\
\hline & & $\mathrm{Ca}$ & $\mathrm{K}$ & $\mathrm{Mg}$ & $\mathrm{P}$ & $\mathrm{Cu}$ & $\mathrm{Fe}$ & $\mathrm{Na}$ \\
\hline \multicolumn{9}{|c|}{ Cherry tomato } \\
\hline $\mathrm{GH}$ & Apero & $0.08^{\mathrm{b}}$ & $5.51^{\mathrm{ab}}$ & $0.40^{\mathrm{a}}$ & $1.14^{\mathrm{a}}$ & $1.93^{\mathrm{a}}$ & $13.81^{\mathrm{a}}$ & $65.90^{\mathrm{ab}}$ \\
\hline GH & Apero- $6^{*}$ & $0.09^{\mathrm{b}}$ & $6.10^{\mathrm{a}}$ & $0.41^{\mathrm{a}}$ & $1.11^{\mathrm{a}}$ & $1.72^{\mathrm{ab}}$ & $12.35^{\mathrm{ab}}$ & $73.86^{\mathrm{a}}$ \\
\hline $\mathrm{GH}$ & Favorita & $0.03^{\mathrm{c}}$ & $2.92^{\mathrm{c}}$ & $0.15^{\mathrm{d}}$ & $0.50^{\mathrm{b}}$ & $0.71^{\mathrm{c}}$ & $5.48^{\mathrm{d}}$ & $23.98^{\mathrm{f}}$ \\
\hline GH & Favorita-6 & $0.03^{\mathrm{c}}$ & $2.95^{\mathrm{c}}$ & $0.16^{\mathrm{d}}$ & $0.50^{\mathrm{b}}$ & $0.72^{\mathrm{c}}$ & $5.12^{\mathrm{de}}$ & $26.23^{\mathrm{ef}}$ \\
\hline GH & Juanita & $0.07^{\mathrm{b}}$ & $4.88^{\mathrm{b}}$ & $0.31^{\mathrm{abc}}$ & $1.03^{\mathrm{a}}$ & $1.37^{\mathrm{b}}$ & $10.08^{b c}$ & $38.13^{\mathrm{de}}$ \\
\hline GH & Juanita-6 & $0.08^{\mathrm{b}}$ & $5.25^{\mathrm{ab}}$ & $0.35^{\mathrm{ab}}$ & $1.14^{\mathrm{a}}$ & $1.61^{\mathrm{ab}}$ & $13.86^{\mathrm{a}}$ & $47.54^{\mathrm{cd}}$ \\
\hline SB & Jardino & $0.08^{\mathrm{b}}$ & $1.20^{\mathrm{d}}$ & $0.11^{\mathrm{d}}$ & $0.16^{\mathrm{b}}$ & $0.51^{\mathrm{c}}$ & $1.35^{\mathrm{e}}$ & $20.96^{\mathrm{f}}$ \\
\hline SB & Cherries & $0.17^{\mathrm{a}}$ & $2.33^{\mathrm{cd}}$ & $0.24^{\mathrm{bcd}}$ & $0.54^{\mathrm{b}}$ & $1.45^{\mathrm{ab}}$ & $7.20^{\mathrm{cd}}$ & $52.24^{\mathrm{bc}}$ \\
\hline \multirow[t]{2}{*}{ SB } & Fruiterie & $0.15^{\mathrm{a}}$ & $3.21^{\mathrm{c}}$ & $0.18^{\mathrm{cd}}$ & $0.42^{\mathrm{b}}$ & $0.17^{\mathrm{c}}$ & $4.27^{\mathrm{de}}$ & $19.83^{\mathrm{f}}$ \\
\hline & Mean & $0.09^{\mathrm{D}}$ & $3.82^{\mathrm{A}}$ & $0.26^{\mathrm{C}}$ & $0.73^{\mathrm{B}}$ & $1.13^{\mathrm{B}}$ & $8.17^{\mathrm{A}}$ & $40.96^{\mathrm{CD}}$ \\
\hline \multicolumn{9}{|c|}{ Beefsteak tomato } \\
\hline $\mathrm{GH}$ & Arbason & $0.11^{\mathrm{b}}$ & $3.50^{\mathrm{c}}$ & $0.28^{\mathrm{c}}$ & $0.57^{\mathrm{a}}$ & $1.16^{\mathrm{c}}$ & $6.97^{\mathrm{c}}$ & $23.81^{\mathrm{cd}}$ \\
\hline GH & Caramba & $0.14^{\mathrm{b}}$ & $7.94^{\mathrm{a}}$ & $1.07^{\mathrm{a}}$ & $0.22^{\mathrm{b}}$ & $6.67^{\mathrm{a}}$ & $22.04^{\mathrm{a}}$ & $144.00^{\mathrm{a}}$ \\
\hline GH & Geranimo & $0.23^{\mathrm{a}}$ & $5.49^{\mathrm{b}}$ & $0.67^{\mathrm{b}}$ & $0.22^{\mathrm{b}}$ & $4.92^{\mathrm{b}}$ & $15.34^{\mathrm{b}}$ & $90.58^{\mathrm{b}}$ \\
\hline GH & Trust & $0.21^{\mathrm{a}}$ & $5.80^{\mathrm{b}}$ & $0.64^{\mathrm{b}}$ & $0.30^{\mathrm{b}}$ & $4.66^{\mathrm{b}}$ & $12.68^{\mathrm{b}}$ & $75.23^{b c}$ \\
\hline SB & Kaliroy & $0.10^{\mathrm{b}}$ & $1.64^{\mathrm{cd}}$ & $0.07^{\mathrm{c}}$ & $0.24^{\mathrm{b}}$ & $0.27^{\mathcal{C}}$ & $1.69^{c}$ & $19.26^{\mathrm{cd}}$ \\
\hline SB & BionatureL & $0.11^{\mathrm{b}}$ & $1.39^{\mathrm{d}}$ & $0.07^{\mathrm{c}}$ & $0.22^{\mathrm{b}}$ & $0.02^{\mathrm{c}}$ & $1.63^{\mathrm{c}}$ & $18.04^{\mathrm{d}}$ \\
\hline \multirow[t]{2}{*}{ SB } & BionatureP & $0.11^{\mathrm{b}}$ & $1.79^{\mathrm{cd}}$ & $0.06^{\mathrm{c}}$ & $0.16^{\mathrm{b}}$ & $0.04^{\mathrm{c}}$ & $1.34^{\mathrm{c}}$ & $11.97^{\mathrm{d}}$ \\
\hline & Mean & $0.14^{\mathrm{CD}}$ & $3.94^{\mathrm{A}}$ & $0.41^{\mathrm{A}}$ & $0.28^{\mathrm{D}}$ & $2.53^{\mathrm{A}}$ & $8.81^{\mathrm{A}}$ & $54.70^{\mathrm{C}}$ \\
\hline \multicolumn{9}{|c|}{ Cucumber } \\
\hline $\mathrm{GH}$ & Diva & $0.20^{\mathrm{a}}$ & $2.70^{\mathrm{a}}$ & $0.14^{\mathrm{b}}$ & $0.53^{\mathrm{b}}$ & $0.65^{\mathrm{a}}$ & $3.27^{\mathrm{ab}}$ & $24.51^{\mathrm{b}}$ \\
\hline GH & Diva-3 & $0.23^{\mathrm{a}}$ & $2.52^{\mathrm{a}}$ & $0.24^{\mathrm{a}}$ & $0.75^{\mathrm{a}}$ & $0.61^{\mathrm{a}}$ & $3.51^{\mathrm{ab}}$ & $40.46^{\mathrm{a}}$ \\
\hline GH & Diva-6 & $0.22^{\mathrm{a}}$ & $2.70^{\mathrm{a}}$ & $0.24^{\mathrm{a}}$ & $0.85^{\mathrm{a}}$ & $0.75^{\mathrm{a}}$ & $4.12^{\mathrm{a}}$ & $38.99^{\mathrm{a}}$ \\
\hline SB & Cool Cukes & $0.18^{\mathrm{a}}$ & $1.56^{\mathrm{c}}$ & $0.11^{\mathrm{b}}$ & $0.25^{\mathrm{d}}$ & $0.11^{\mathrm{b}}$ & $1.28^{\mathrm{c}}$ & $15.60^{\mathrm{c}}$ \\
\hline SB & Lebanese & $0.25^{\mathrm{a}}$ & $2.09^{\mathrm{ab}}$ & $0.14^{\mathrm{b}}$ & $0.39^{\mathrm{bc}}$ & $0.04^{\mathrm{b}}$ & $2.68^{\mathrm{b}}$ & $20.55^{\mathrm{b}}$ \\
\hline \multirow[t]{2}{*}{ SB } & Mini Cucumber & $0.24^{\mathrm{a}}$ & $1.96^{\mathrm{ab}}$ & $0.11^{\mathrm{b}}$ & $0.32^{\text {cd }}$ & $0.12^{\mathrm{b}}$ & $2.48^{\mathrm{b}}$ & $16.01^{c}$ \\
\hline & Mean & $0.22^{\mathrm{C}}$ & $2.25^{\mathrm{B}}$ & $0.17^{\mathrm{D}}$ & $0.52^{\mathrm{C}}$ & $0.38^{\mathrm{D}}$ & $2.89^{\mathrm{C}}$ & $26.02^{\mathrm{D}}$ \\
\hline \multicolumn{9}{|c|}{ Arugula } \\
\hline $\mathrm{GH}$ & Astro & $2.21^{\mathrm{a}}$ & $3.61^{\mathrm{a}}$ & $0.28^{\mathrm{a}}$ & $0.62^{\mathrm{a}}$ & $0.47^{\mathrm{bc}}$ & $6.23^{\mathrm{b}}$ & $70.25^{\mathrm{c}}$ \\
\hline $\mathrm{GH}$ & Astro-6 & $1.45^{\mathrm{b}}$ & $3.80^{\mathrm{a}}$ & $0.34^{\mathrm{a}}$ & $0.54^{\mathrm{ab}}$ & $0.31^{c}$ & $4.06^{\mathrm{c}}$ & $49.35^{\mathrm{c}}$ \\
\hline SB & ADO & $2.18^{\mathrm{a}}$ & $2.67^{\mathrm{b}}$ & $0.42^{\mathrm{a}}$ & $0.64^{\mathrm{a}}$ & $0.69^{\mathrm{b}}$ & $10.89^{\mathrm{a}}$ & $573.67^{\mathrm{ab}}$ \\
\hline SB & BW & $1.57^{\mathrm{ab}}$ & $2.67^{\mathrm{b}}$ & $0.29^{\mathrm{a}}$ & $0.61^{\mathrm{a}}$ & $1.22^{\mathrm{a}}$ & $10.63^{\mathrm{a}}$ & $637.72^{\mathrm{a}}$ \\
\hline \multirow[t]{2}{*}{ SB } & PRO & $1.62^{\mathrm{ab}}$ & $2.45^{\mathrm{b}}$ & $0.30^{\mathrm{a}}$ & $0.38^{\mathrm{b}}$ & $0.47^{\mathrm{bc}}$ & $10.00^{\mathrm{a}}$ & $459.03^{\mathrm{b}}$ \\
\hline & Mean & $1.81^{\mathrm{A}}$ & $3.04^{\mathrm{B}}$ & $0.33^{\mathrm{B}}$ & $0.56^{\mathrm{C}}$ & $0.63^{\mathrm{CD}}$ & $8.36^{\mathrm{A}}$ & $358.00^{\mathrm{A}}$ \\
\hline \multicolumn{9}{|c|}{ Bibb lettuce } \\
\hline $\mathrm{GH}$ & RexMT0 & $0.42^{\mathrm{ab}}$ & $3.90^{\mathrm{a}}$ & $0.24^{\mathrm{b}}$ & $0.96^{\mathrm{b}}$ & $0.71^{\mathrm{b}}$ & $5.34^{\mathrm{b}}$ & $31.45^{\mathrm{b}}$ \\
\hline $\mathrm{GH}$ & RexMT0-6 & $0.35^{\mathrm{b}}$ & $3.26^{\mathrm{a}}$ & $0.16^{\mathrm{c}}$ & $0.76^{\mathrm{b}}$ & $0.52^{\mathrm{b}}$ & $3.16^{\mathrm{b}}$ & $36.41^{\mathrm{b}}$ \\
\hline SB & ADO & $0.46^{\mathrm{a}}$ & $3.71^{\mathrm{a}}$ & $0.31^{\mathrm{a}}$ & $1.40^{\mathrm{a}}$ & $1.85^{\mathrm{a}}$ & $13.14^{\mathrm{a}}$ & $243.60^{\mathrm{a}}$ \\
\hline \multirow[t]{2}{*}{ SB } & IGA & $0.42^{\mathrm{ab}}$ & $4.08^{\mathrm{a}}$ & $0.18^{b c}$ & $0.84^{\mathrm{b}}$ & $0.39^{\mathrm{b}}$ & $3.79^{\mathrm{b}}$ & $37.66^{\mathrm{b}}$ \\
\hline & Mean & $0.41^{\mathrm{B}}$ & $3.74^{\mathrm{A}}$ & $0.22^{\mathrm{CD}}$ & $0.99^{\mathrm{A}}$ & $0.87^{\mathrm{C}}$ & $6.36^{\mathrm{B}}$ & $87.28^{\mathrm{B}}$ \\
\hline
\end{tabular}

${ }^{1}$ LS means were compared using Scheffe's Multiple Comparison Procedure. Small case superscripts within species and large case superscripts between species not sharing the same letter are significantly different $(P \leq 0.05)$. ${ }^{*}$ Produce (based on availability) was fridge-stored $\left(4^{\circ} \mathrm{C}\right)$ for 3 and/or 6 days.

similar in mineral content to Astro after $6 \mathrm{~d}$ storage except for greater $\mathrm{Ca}$ and $\mathrm{Fe}$ (levels reduced by 34.39 and $34.83 \%$, resp.; Table 5) and $\mathrm{Cr}$ and $\mathrm{Pb}$ (not detected in stored produce) (Table 6).
3.2.5. Mineral Content of Bibb Lettuce. Data presented in Tables 5 and 6 showed no differences between GH and SB bibb lettuce in $\mathrm{K}(\mathrm{g} / 100 \mathrm{~g} \mathrm{FW})$ and As (mg/100 $\mathrm{g} \mathrm{FW}$ ) mineral concentrations. However, the SB variety ADO had greater $\mathrm{Mg}$ 
TABLE 6: LS mean values ${ }^{1}$ of microminerals, including Al, As, Cd, Cr, Pb, Se, and $\mathrm{Zn}$ (mg/100 g DW) of greenhouse-grown (GH) and storebought (SB) cherry tomato, beefsteak tomato, cucumber, arugula, and bibb lettuce.

\begin{tabular}{|c|c|c|c|c|c|c|c|c|}
\hline Crops & Varieties & $\mathrm{Al}$ & As & $\mathrm{Cd}$ & $\mathrm{Cr}$ & $\mathrm{Pb}$ & $\mathrm{Se}$ & $\mathrm{Zn}$ \\
\hline \multicolumn{9}{|c|}{ Cherry tomato } \\
\hline $\mathrm{GH}$ & Apero & $2.51^{\mathrm{d}}$ & $0.24^{\mathrm{b}}$ & $0.02^{\mathrm{ab}}$ & $0.05^{\mathrm{a}}$ & $0.29^{\mathrm{a}}$ & $11.32^{\mathrm{bc}}$ & $4.90^{\mathrm{a}}$ \\
\hline GH & Apero- $6^{*}$ & $3.57^{\mathrm{d}}$ & $1.29^{\mathrm{a}}$ & $0.04^{\mathrm{a}}$ & $0.08^{\mathrm{a}}$ & $0.34^{\mathrm{a}}$ & $0.79^{c}$ & $4.35^{\mathrm{ab}}$ \\
\hline $\mathrm{GH}$ & Favorita & $2.30^{\mathrm{d}}$ & $0.32^{\mathrm{b}}$ & - & $0.05^{\mathrm{a}}$ & $0.25^{\mathrm{a}}$ & $41.64^{\mathrm{a}}$ & $1.96^{\mathrm{c}}$ \\
\hline $\mathrm{GH}$ & Favorita-6 & $3.46^{\mathrm{d}}$ & $0.03^{\mathrm{b}}$ & - & $0.04^{\mathrm{a}}$ & $0.27^{\mathrm{a}}$ & $0.94^{\mathrm{c}}$ & $1.87^{\mathrm{c}}$ \\
\hline GH & Juanita & $3.70^{\mathrm{d}}$ & $0.86^{\mathrm{ab}}$ & $0.02^{\mathrm{ab}}$ & $0.06^{\mathrm{a}}$ & $0.23^{\mathrm{a}}$ & $36.73^{\mathrm{a}}$ & $4.26^{\mathrm{ab}}$ \\
\hline GH & Juanita-6 & $3.05^{\mathrm{b}}$ & $0.67^{\mathrm{ab}}$ & $0.01^{\mathrm{b}}$ & $0.05^{\mathrm{a}}$ & $0.21^{\mathrm{a}}$ & $0.91^{c}$ & $5.03^{\mathrm{a}}$ \\
\hline SB & Jardino & $10.22^{\mathrm{c}}$ & $-\$$ & - & $0.03^{\mathrm{a}}$ & $0.20^{\mathrm{a}}$ & $24.59^{\mathrm{ab}}$ & $1.16^{\mathrm{c}}$ \\
\hline SB & Cherries & $34.91^{\mathrm{a}}$ & - & - & $0.06^{\mathrm{a}}$ & $0.16^{\mathrm{a}}$ & - & $2.73^{b c}$ \\
\hline \multirow[t]{2}{*}{ SB } & Fruiterie & $24.67^{\mathrm{b}}$ & - & - & $0.03^{\mathrm{a}}$ & $0.32^{\mathrm{a}}$ & $23.10^{\mathrm{ab}}$ & $1.18^{\mathrm{c}}$ \\
\hline & Mean & $9.82^{\mathrm{B}}$ & $0.57^{\mathrm{A}}$ & $0.02^{\mathrm{B}}$ & $0.05^{\mathrm{B}}$ & $0.25^{\mathrm{B}}$ & $17.50^{\mathrm{B}}$ & $3.05^{\mathrm{C}}$ \\
\hline \multicolumn{9}{|c|}{ Beefsteak tomato } \\
\hline $\mathrm{GH}$ & Arbason & $4.31^{\mathrm{c}}$ & $0.41^{\mathrm{a}}$ & $0.01^{\mathrm{a}}$ & $0.12^{\mathrm{ab}}$ & $0.17^{\mathrm{ab}}$ & - & $2.70^{c}$ \\
\hline $\mathrm{GH}$ & Caramba & $3.10^{\mathrm{c}}$ & - & - & $0.08^{\mathrm{ab}}$ & $0.23^{\mathrm{ab}}$ & $19.93^{\mathrm{a}}$ & $43.29^{\mathrm{a}}$ \\
\hline $\mathrm{GH}$ & Geronimo & $2.32^{\mathrm{c}}$ & - & - & $0.04^{\mathrm{b}}$ & $0.37^{\mathrm{a}}$ & $23.68^{\mathrm{a}}$ & $29.74^{\mathrm{b}}$ \\
\hline GH & Trust & $2.23^{\mathrm{c}}$ & - & - & $0.12^{\mathrm{ab}}$ & $0.13^{\mathrm{b}}$ & - & $28.39^{\mathrm{b}}$ \\
\hline SB & Kaliroy & $13.96^{\mathrm{ab}}$ & - & - & $0.16^{\mathrm{a}}$ & $0.17^{\mathrm{ab}}$ & - & $0.71^{\mathrm{c}}$ \\
\hline SB & BionatureL & $11.33^{\mathrm{b}}$ & - & - & $0.14^{\mathrm{a}}$ & $0.22^{\mathrm{ab}}$ & - & $0.68^{\mathrm{c}}$ \\
\hline \multirow[t]{2}{*}{ SB } & BionatureP & $16.95^{\mathrm{a}}$ & - & - & $0.18^{\mathrm{a}}$ & $0.11^{\mathrm{b}}$ & - & $0.50^{c}$ \\
\hline & Mean & $7.74^{\mathrm{C}}$ & $0.41^{\mathrm{AB}}$ & $0.01^{\mathrm{B}}$ & $0.12^{\mathrm{A}}$ & $0.20^{\mathrm{B}}$ & $21.81^{\mathrm{AB}}$ & $15.15^{\mathrm{A}}$ \\
\hline \multicolumn{9}{|c|}{ Cucumber } \\
\hline $\mathrm{GH}$ & Diva & $28.55^{\mathrm{a}}$ & - & - & $0.04^{\mathrm{a}}$ & $0.19^{\mathrm{a}}$ & - & $2.83^{\mathrm{b}}$ \\
\hline GH & Diva-3 & $2.72^{\mathrm{d}}$ & $0.54^{\mathrm{a}}$ & $0.03^{\mathrm{a}}$ & $0.06^{\mathrm{a}}$ & $0.14^{\mathrm{a}}$ & $32.99^{\mathrm{a}}$ & $3.41^{\mathrm{ab}}$ \\
\hline $\mathrm{GH}$ & Diva-6 & $2.11^{\mathrm{d}}$ & $0.38^{\mathrm{a}}$ & - & $0.03^{\mathrm{a}}$ & $0.09^{\mathrm{a}}$ & $28.60^{\mathrm{ab}}$ & $4.02^{\mathrm{a}}$ \\
\hline SB & Cool Cukes & $10.24^{\mathrm{c}}$ & - & - & $0.03^{\mathrm{a}}$ & $0.15^{\mathrm{a}}$ & $21.66^{\mathrm{b}}$ & $1.21^{\mathrm{c}}$ \\
\hline SB & Lebanese & $19.82^{\mathrm{b}}$ & - & - & $0.03^{\mathrm{a}}$ & $0.16^{\mathrm{a}}$ & $24.53^{\mathrm{ab}}$ & $1.73^{\mathrm{c}}$ \\
\hline \multirow[t]{2}{*}{ SB } & Mini Cucumber & $16.95^{\mathrm{b}}$ & - & - & $0.02^{\mathrm{a}}$ & $0.19^{\mathrm{a}}$ & $13.80^{\mathrm{b}}$ & $1.08^{\mathrm{c}}$ \\
\hline & Mean & $13.40^{\mathrm{A}}$ & $0.50^{\mathrm{AB}}$ & $0.03^{\mathrm{B}}$ & $0.04^{\mathrm{B}}$ & $0.15^{\mathrm{B}}$ & $24.32^{\mathrm{A}}$ & $2.38^{\mathrm{C}}$ \\
\hline \multicolumn{9}{|c|}{ Arugula } \\
\hline $\mathrm{GH}$ & Astro & $5.76^{\mathrm{b}}$ & $0.25^{\mathrm{ab}}$ & - & $0.02^{\mathrm{a}}$ & $0.34^{\mathrm{a}}$ & $28.36^{\mathrm{a}}$ & $3.44^{\mathrm{c}}$ \\
\hline $\mathrm{GH}$ & Astro-6 & $5.54^{\mathrm{b}}$ & $0.15^{\mathrm{b}}$ & - & - & - & - & $2.36^{\mathrm{c}}$ \\
\hline SB & $\mathrm{ADO}$ & $13.38^{\mathrm{a}}$ & $0.56^{\mathrm{a}}$ & - & $0.03^{\mathrm{a}}$ & $0.42^{\mathrm{a}}$ & $34.77^{\mathrm{a}}$ & $6.74^{\mathrm{b}}$ \\
\hline SB & BW & $11.26^{\mathrm{a}}$ & $0.14^{\mathrm{b}}$ & - & $0.04^{\mathrm{a}}$ & $0.47^{\mathrm{a}}$ & $40.09^{\mathrm{a}}$ & $13.07^{\mathrm{a}}$ \\
\hline \multirow[t]{2}{*}{ SB } & PRO & $9.80^{\mathrm{a}}$ & - & $0.04^{\mathrm{a}}$ & - & $0.47^{\mathrm{a}}$ & $22.92^{\mathrm{a}}$ & $3.13^{\mathrm{c}}$ \\
\hline & Mean & $9.15^{\mathrm{BC}}$ & $0.27^{\mathrm{B}}$ & $0.04^{\mathrm{AB}}$ & $0.03^{\mathrm{B}}$ & $0.43^{\mathrm{A}}$ & $31.54^{\mathrm{A}}$ & $5.75^{\mathrm{B}}$ \\
\hline \multicolumn{9}{|c|}{ Bibb lettuce } \\
\hline $\mathrm{GH}$ & RexMT0 & $2.87^{b c}$ & $0.81^{\mathrm{a}}$ & $0.03^{b c}$ & - & - & - & $6.78^{\mathrm{b}}$ \\
\hline $\mathrm{GH}$ & RexMT0-6 & $2.24^{\mathrm{c}}$ & $0.42^{\mathrm{a}}$ & $0.01^{\mathrm{c}}$ & - & - & - & $4.63^{c}$ \\
\hline SB & $\mathrm{ADO}$ & $8.58^{\mathrm{a}}$ & $0.57^{\mathrm{a}}$ & $0.16^{\mathrm{a}}$ & - & - & - & $9.08^{\mathrm{a}}$ \\
\hline \multirow[t]{2}{*}{ SB } & IGA & $4.90^{\mathrm{b}}$ & $0.88^{\mathrm{a}}$ & $0.07^{\mathrm{b}}$ & - & - & - & $3.61^{\mathrm{c}}$ \\
\hline & Mean & $4.64^{\mathrm{D}}$ & $0.67^{\mathrm{A}}$ & $0.07^{\mathrm{A}}$ & - & - & - & $6.03^{\mathrm{B}}$ \\
\hline
\end{tabular}

${ }^{1}$ LS means were compared using Scheffe's Multiple Comparison Procedure. Small case superscripts within species and large case superscripts between species not sharing the same letter are significantly different $(P \leq 0.05)$. ${ }^{*}$ Produce (based on availability) was fridge-stored $\left(4^{\circ} \mathrm{C}\right)$ for 3 and/or 6 days. $-\$$ : not detected.

and P contents compared with both GH 'RexMT0' and the SB variety IGA. Similar Ca content was found in GH 'RexMT0' and the SB 'ADO' and IGA. Store-bought variety ADO had greater $\mathrm{Al}, \mathrm{Cd}, \mathrm{Cu}, \mathrm{Fe}$, and $\mathrm{Na}$ levels compared with both GH 'RexMT0' and the SB variety IGA. Few differences were observed in mineral content between fresh and fridge-stored
(6 d) GH 'RexMT0.' Storage did not alter the concentrations of $\mathrm{Ca}, \mathrm{Cu}, \mathrm{K}, \mathrm{Fe}, \mathrm{Na}$, and $\mathrm{P}$ but reduced $\mathrm{Al}, \mathrm{Cd}, \mathrm{Mg}$, and $\mathrm{Zn}$ levels.

3.3. Dry Matter (\%) of Fruit and Vegetables. Cherry tomato cultivars had the greatest dry matter percentages $(9.22 \%)$ 
TABLE 7: LS mean values ${ }^{1}$ of dry matter content (\%), total dietary fiber (\%), and total carbohydrate content mg glucose/100 g DW equivalents of greenhouse-grown $(\mathrm{GH})$ and store-bought $(\mathrm{SB})$ cherry tomato, beefsteak tomato, cucumber, arugula, and bibb lettuce.

\begin{tabular}{|c|c|c|c|c|}
\hline Crops & Varieties & Dry matter (\%) & Total carbohydrates & Total dietary fiber (\%) \\
\hline \multicolumn{5}{|c|}{ Cherry tomato } \\
\hline $\mathrm{GH}$ & Apero & $11.02^{\mathrm{a}}$ & $55.48^{\mathrm{bc}}$ & $1.37^{\mathrm{a}}$ \\
\hline $\mathrm{GH}$ & Apero- $6^{*}$ & $11.06^{\mathrm{a}}$ & $52.27^{\mathrm{c}}$ & $1.79^{\mathrm{a}}$ \\
\hline GH & Favorita & $9.57^{\mathrm{b}}$ & $53.81^{\mathrm{bc}}$ & $1.35^{\mathrm{a}}$ \\
\hline $\mathrm{GH}$ & Favorita-6 & $10.14^{\mathrm{ab}}$ & $60.87^{\mathrm{abc}}$ & $1.46^{\mathrm{a}}$ \\
\hline $\mathrm{GH}$ & Juanita & $10.28^{\mathrm{ab}}$ & $64.10^{\mathrm{abc}}$ & $1.80^{\mathrm{a}}$ \\
\hline GH & Juanita-6 & $10.16^{\mathrm{ab}}$ & $49.76^{\mathrm{c}}$ & $1.88^{\mathrm{a}}$ \\
\hline SB & Jardino & $6.00^{\mathrm{d}}$ & $78.80^{\mathrm{a}}$ & $1.70^{\mathrm{a}}$ \\
\hline SB & Cherries & $6.28^{\mathrm{d}}$ & $57.06^{\mathrm{abc}}$ & $1.82^{\mathrm{a}}$ \\
\hline \multirow[t]{2}{*}{ SB } & Fruiterie & $8.50^{\mathrm{c}}$ & $76.92^{\mathrm{ab}}$ & $1.65^{\mathrm{a}}$ \\
\hline & Mean & $9.22^{\mathrm{A}}$ & $61.00^{\mathrm{B}}$ & $1.65^{\mathrm{C}}$ \\
\hline \multicolumn{5}{|c|}{ Beefsteak tomato } \\
\hline $\mathrm{GH}$ & Arbason & $6.45^{\mathrm{a}}$ & $49.02^{\mathrm{ab}}$ & $2.14^{\mathrm{a}}$ \\
\hline $\mathrm{GH}$ & Caramba & $5.79^{\mathrm{a}}$ & $49.01^{\mathrm{a}}$ & $2.08^{\mathrm{a}}$ \\
\hline GH & Geronimo & $4.91^{\mathrm{a}}$ & $62.71^{\mathrm{a}}$ & $1.72^{\mathrm{a}}$ \\
\hline GH & Trust & $4.65^{\mathrm{a}}$ & $41.68^{\mathrm{b}}$ & $1.65^{\mathrm{a}}$ \\
\hline SB & Kaliroy & $5.18^{\mathrm{a}}$ & $50.24^{\mathrm{ab}}$ & $1.66^{\mathrm{a}}$ \\
\hline SB & BionatureL & $2.81^{\mathrm{a}}$ & $55.14^{\mathrm{ab}}$ & $1.90^{\mathrm{a}}$ \\
\hline \multirow[t]{2}{*}{ SB } & BionatureP & $5.95^{\mathrm{a}}$ & $55.76^{\mathrm{ab}}$ & $1.84^{\mathrm{a}}$ \\
\hline & Mean & $5.11^{\mathrm{C}}$ & $51.94^{\mathrm{C}}$ & $1.86^{\mathrm{BC}}$ \\
\hline \multicolumn{5}{|c|}{ Cucumber } \\
\hline $\mathrm{GH}$ & Diva & $5.20^{\mathrm{a}}$ & $75.03^{\mathrm{ab}}$ & $2.68^{\mathrm{a}}$ \\
\hline $\mathrm{GH}$ & Diva-3 & $4.69^{\mathrm{a}}$ & $70.18^{\mathrm{ab}}$ & $1.87^{\mathrm{a}}$ \\
\hline GH & Diva-6 & $5.10^{\mathrm{a}}$ & $66.72^{\mathrm{b}}$ & $1.64^{\mathrm{a}}$ \\
\hline SB & Cool Cukes & $4.81^{\mathrm{a}}$ & $92.07^{\mathrm{a}}$ & $1.65^{\mathrm{a}}$ \\
\hline SB & Lebanese & $5.00^{\mathrm{a}}$ & $81.89^{\mathrm{ab}}$ & $1.70^{\mathrm{a}}$ \\
\hline \multirow[t]{2}{*}{ SB } & Mini Cucumber & $4.64^{\mathrm{a}}$ & $60.75^{\mathrm{b}}$ & $1.67^{\mathrm{a}}$ \\
\hline & Mean & $4.91^{\mathrm{C}}$ & $74.44^{\mathrm{A}}$ & $1.87^{\mathrm{BC}}$ \\
\hline \multicolumn{5}{|c|}{ Arugula } \\
\hline $\mathrm{GH}$ & Astro & $8.47^{\mathrm{a}}$ & $24.95^{\mathrm{a}}$ & $3.12^{\mathrm{a}}$ \\
\hline $\mathrm{GH}$ & Astro-6 & $7.64^{\mathrm{a}}$ & $13.54^{\mathrm{b}}$ & $2.69^{a}$ \\
\hline SB & $\mathrm{ADO}$ & $8.32^{\mathrm{a}}$ & $10.65^{\mathrm{b}}$ & $2.92^{\mathrm{a}}$ \\
\hline SB & BW & $8.55^{\mathrm{a}}$ & $9.80^{\mathrm{b}}$ & $3.43^{\mathrm{a}}$ \\
\hline \multirow[t]{2}{*}{ SB } & PRO & $5.79^{\mathrm{b}}$ & $9.38^{\mathrm{ab}}$ & $2.07^{\mathrm{a}}$ \\
\hline & Mean & $7.79^{\mathrm{B}}$ & $13.67^{\mathrm{E}}$ & $2.85^{\mathrm{A}}$ \\
\hline \multicolumn{5}{|c|}{ Bibb lettuce } \\
\hline $\mathrm{GH}$ & RexMT0 & $4.57^{\mathrm{b}}$ & $32.53^{\mathrm{ab}}$ & $2.03^{\mathrm{a}}$ \\
\hline GH & RexMT0-6 & $4.65^{\mathrm{b}}$ & $42.21^{\mathrm{ab}}$ & $2.14^{\mathrm{a}}$ \\
\hline SB & $\mathrm{ADO}$ & $5.25^{\mathrm{a}}$ & $44.53^{\mathrm{a}}$ & $2.19^{\mathrm{a}}$ \\
\hline \multirow[t]{2}{*}{ SB } & IGA & $4.39^{\mathrm{b}}$ & $27.49^{\mathrm{b}}$ & $2.16^{\mathrm{a}}$ \\
\hline & Mean & $4.71^{\mathrm{C}}$ & $36.69^{\mathrm{D}}$ & $2.23^{\mathrm{B}}$ \\
\hline
\end{tabular}

${ }^{1}$ LS means were compared using Scheffe's Multiple Comparison Test. Small case superscripts within species and large case superscripts between species not sharing the same letter are significantly different $(P \leq 0.05)$. ${ }^{*}$ Produce (based on availability) was fridge-stored $\left(4^{\circ} \mathrm{C}\right)$ for 3 and/or 6 days.

followed by arugula (7.79\%), then beefsteak tomato $(5.11 \%)$, cucumber $(4.91 \%)$, and bibb lettuce $(4.71 \%)$ (Table 7$)$. For cherry tomato, the GH 'Apero' and 'Juanita' but not 'Favorita' had greater dry matter percentages than the three SB cultivars. There were no differences in dry matter content between $\mathrm{GH}$ and SB cultivars for the other crops. There was no effect of storage duration ( 3 or $6 \mathrm{~d}$ ) on the dry matter content of any crop.

3.4. Total Carbohydrates. Total carbohydrates of GH and SB crops were expressed as mg glucose equivalent/100 g DW (Table 7). Total carbohydrate levels varied with crop. 
Cucumber (74.44) had the greatest total carbohydrate content followed by cherry tomato (61.00) and then beefsteak tomato (51.94) and bibb lettuce (36.69), while arugula (13.67) had the least content. Hydroponically grown $\mathrm{GH}$ and SB crops were similar in their carbohydrate content. No differences in total carbohydrate contents occurred between fresh $\mathrm{GH}$ cherry tomato, bibb lettuce, and cucumber compared with produce that was fridge-stored for $6 \mathrm{~d}$. However, storage of arugula 'Astro' for $6 \mathrm{~d}$ decreased the total carbohydrate levels compared with fresh 'Astro.'

3.5. Total Dietary Fiber (\%). Percentages of total dietary fiber (TDF) of GH and SB produce are presented in Table 7. TDF\% ranged from 2.07 to 3.43 (arugula), 2.03 to 2.19 (bibb lettuce), 1.64 to 2.68 (cucumber), 1.65 to 2.14 (beefsteak tomato), and 1.37 to 1.88 (cherry tomato), with no differences between GH or SB produce. Fridge-storage $(6 \mathrm{~d})$ had no effect on produce TDF\%.

\subsection{Antioxidant Assays for Fruits and Vegetables}

3.6.1. Antioxidant Scavenging Activity (ABTS (Hydrophilic and Lipophilic) and DPPH). Antioxidant scavenging capacity of $\mathrm{GH}$ and $\mathrm{SB}$ vegetables was evaluated using two oxidizing agents: 2,2'-azino-bis(3-ethylbenzothiazoline-6-sulphonic acid) (ABTS) and 2,2-diphenyl-1-picrylhydrazyl (DPPH) (Table 8). Hydroponically grown GH and SB cherry tomato cultivars had similar ABTS and DPPH antioxidant activity. Similarly, no differences were found between GH and SB beefsteak varieties in the hydrophilic and total ABTS and the DPPH scavenging activities except for GH 'Geronimo' that showed less ABTS lipophilic antioxidant activity than the SB variety BionatureL. However, 'Geronimo' showed similar antioxidant capacity to all other varieties. The GH cucumber 'Diva' had the greatest hydrophilic and total ABTS activity compared with the three SB varieties. No differences were found between Mini Cucumber, Cool Cukes, and Lebanese cucumber in antioxidant scavenging capacity. There were no differences in antioxidant capacity observed between GH arugula 'Astro' and the three SB varieties. For bibb lettuce, the SB variety ADO had greater hydrophilic ABTS antioxidant activity (TE/100 g DW) compared with all other lettuce varieties. Also, GH and SB bibb lettuce showed similar antioxidant activity based on lipophilic and total ABTS and DPPH assays (Table 8).

Antioxidant activity based on ABTS (hydrophilic) (mg TE/100 g DW) showed that, overall, arugula, beefsteak tomato, and cherry tomato had greater activity than bibb lettuce and cucumber. Bibb lettuce showed greater antioxidant activity than cucumber (Table 8). Cherry tomato was reported to contain higher antioxidant scavenging activity compared to beefsteak tomato [49]. ABTS (lipophilic) scavenging activity was greatest for arugula followed by bibb lettuce and beef-steak tomato, cherry tomato, and cucumber varieties. In direct contrast, the DPPH free radical test (mg AAE/100 g DW) showed that, overall, cucumber had greater antioxidant activity than all other crops, while beefsteak tomato, bibb lettuce, and arugula had greater activity than cherry tomato but arugula and cherry tomato were similar in their antioxidant scavenging capacity. Fridge-storage of three GH cherry tomato cultivars, one arugula, and one bibb lettuce cultivar for $6 \mathrm{~d}$ did not affect their antioxidant scavenging activity based on either method used (Table 4). For cucumber, fresh samples of 'Diva' had greater hydrophilic and total ABTS activity but similar lipophilic ABTS and $\mathrm{DPPH}$ antioxidant scavenging activity compared with fridge-stored ( 3 or $6 \mathrm{~d}$ ) produce. Using the ORAC technique, Song et al. [7] reported no differences in the antioxidant capacity among tomato, cucumber, and lettuce.

3.6.2. Total Phenolic Content. Total phenolic content of GH and SB vegetables was expressed as $\mathrm{mg}$ of gallic acid equivalent (GAE) per $100 \mathrm{~g}$ DW (Table 9). Most cultivars of cherry tomatoes (Apero, Favorita, Juanita, and Jardino), whether $\mathrm{GH}$ or SB, had similar total phenolic levels. However, the SB variety Cherries had the least content compared with all other cherry tomato cultivars. Total phenolic content of the GH beefsteak tomatoes was similar to that of the SB varieties.

The only GH cucumber, 'Diva,' had greater total phenolic content compared with the three SB varieties. Similar content of total phenolics was found in GH and SB arugula and bibb lettuce cultivars. Vegetable crops, arranged in descending order based on their total phenolic contents (mg/100 g GAE), were arugula, cherry tomato, beefsteak tomato and cucumber, and bibb lettuce and cucumber, respectively. Lettuce was also reported to have greater content of total phenolics than cucumber by Chu et al. [6]. There was no effect of storage on total phenolic levels of any of the tested vegetable crops (Table 9). Generally, tomato cherry or beefsteak tomato showed similar total phenolics content to cucumber, arugula, and bibb lettuce. This was not in agreement with Song et al. [7]; they reported that tomato cultivars had higher total phenolics than both cucumber and lettuce that had similar content.

3.7. Total Anthocyanin Content (TAC). Comparing between crops revealed that arugula had the greatest TAC content followed by cherry tomato and cucumber, which had TAC similar to beefsteak tomato while bibb lettuce had the least TAC content (Table 9). For cherry tomato, TAC content of GH 'Favorita' was greater than 'Apero' and 'Cherries' but similar to 'Juanita,' 'Jardino', and 'Fruiterie.' For beefsteak tomato, the GH cultivars generally had greater TAC compared with the SB ones. However, 'Arbason' and 'Trust' had similar TAC content to 'Kaliroy' and 'BionatureL.' Storebought cucumber 'Lebanese' had greater TAC content than the GH 'Diva' and the other two SB cultivars. Arugula 'Astro' had greater TAC content compared to SB varieties. For bibb lettuce, GH 'RexMT0' had greater TAC content compared with the SB 'ADO' but was similar to 'IGA' (Table 9).

Fridge-storage affected TAC content of the crops in different ways. For example, storage of GH cherry tomato did not affect TAC content of 'Favorita' and 'Juanita' but increased the TAC of 'Apero.' Storage $(3 \mathrm{~d})$ increased the TAC of cucumber 'Diva' but it was decreased again after $6 \mathrm{~d}$ storage (Table 9). Storage of $\mathrm{GH}$ arugula for $6 \mathrm{~d}$ decreased the TAC content. There was no difference in TAC content between fresh and stored bibb lettuce 'RexMT0.' The mechanism for 
TABLE 8: LS mean values ${ }^{1}$ of antioxidant scavenging capacity of hydrophilic and lipophilic phases using oxidizing agents ABTS (mg trolox equivalent (TE)/100 g DW) and DPPH (hydrophilic phase) (mg ascorbic acid equivalent (AAE)/100 g DW) of hydroponically grown (GH) and store-bought (SB) cherry tomato, beefsteak tomato, cucumber, arugula, and bibb lettuce.

\begin{tabular}{|c|c|c|c|c|c|}
\hline \multirow{2}{*}{ Crops } & \multirow{2}{*}{ Varieties } & \multicolumn{3}{|c|}{ ABTS } & \multirow{2}{*}{ DPPH } \\
\hline & & Hydrophilic & Lipophilic & Total & \\
\hline \multicolumn{6}{|c|}{ Cherry tomato } \\
\hline $\mathrm{GH}$ & Apero & $0.67^{\mathrm{a}}$ & $0.29^{\mathrm{a}}$ & $0.96^{\mathrm{a}}$ & $11.71^{\mathrm{a}}$ \\
\hline GH & Apero- $6^{*}$ & $0.69^{\mathrm{a}}$ & $0.30^{\mathrm{a}}$ & $0.99^{\mathrm{a}}$ & $14.20^{\mathrm{a}}$ \\
\hline GH & Favorita & $0.71^{\mathrm{a}}$ & $0.32^{\mathrm{a}}$ & $1.04^{\mathrm{a}}$ & $13.33^{\mathrm{a}}$ \\
\hline $\mathrm{GH}$ & Favorita-6 & $0.69^{\mathrm{a}}$ & $0.30^{\mathrm{a}}$ & $0.99^{\mathrm{a}}$ & $11.57^{\mathrm{a}}$ \\
\hline GH & Juanita & $0.68^{\mathrm{a}}$ & $0.31^{\mathrm{a}}$ & $0.99^{\mathrm{a}}$ & $11.75^{\mathrm{a}}$ \\
\hline GH & Juanita-6 & $0.69^{\mathrm{a}}$ & $0.29^{\mathrm{a}}$ & $0.99^{\mathrm{a}}$ & $12.12^{\mathrm{a}}$ \\
\hline SB & Jardino & $0.71^{\mathrm{a}}$ & $0.32^{\mathrm{a}}$ & $1.03^{\mathrm{a}}$ & $12.82^{\mathrm{a}}$ \\
\hline SB & Cherries & $0.69^{\mathrm{a}}$ & $0.31^{\mathrm{a}}$ & $0.99^{\mathrm{a}}$ & $12.21^{\mathrm{a}}$ \\
\hline \multirow[t]{2}{*}{ SB } & Fruiterie & $0.70^{\mathrm{a}}$ & $0.31^{\mathrm{a}}$ & $1.01^{\mathrm{a}}$ & $12.53^{\mathrm{a}}$ \\
\hline & Mean & $0.69^{\mathrm{A}}$ & $0.31^{\mathrm{C}}$ & $1.00^{\mathrm{B}}$ & $12.47^{\mathrm{C}}$ \\
\hline \multicolumn{6}{|c|}{ Beefsteak tomato } \\
\hline $\mathrm{GH}$ & Arbason & $0.69^{\mathrm{a}}$ & $0.30^{\mathrm{ab}}$ & $0.99^{\mathrm{a}}$ & $15.55^{\mathrm{a}}$ \\
\hline GH & Caramba & $0.68^{\mathrm{a}}$ & $0.31^{\mathrm{ab}}$ & $0.99^{\mathrm{a}}$ & $14.81^{\mathrm{a}}$ \\
\hline GH & Geronimo & $0.69^{\mathrm{a}}$ & $0.27^{\mathrm{b}}$ & $0.96^{\mathrm{a}}$ & $14.82^{\mathrm{a}}$ \\
\hline $\mathrm{GH}$ & Trust & $0.69^{\mathrm{a}}$ & $0.31^{\mathrm{ab}}$ & $1.00^{\mathrm{a}}$ & $14.57^{\mathrm{a}}$ \\
\hline SB & Kaliroy & $0.63^{\mathrm{a}}$ & $0.30^{\mathrm{ab}}$ & $0.93^{\mathrm{a}}$ & $14.86^{\mathrm{a}}$ \\
\hline SB & BionatureL & $0.68^{\mathrm{a}}$ & $0.33^{\mathrm{a}}$ & $1.01^{\mathrm{a}}$ & $15.50^{\mathrm{a}}$ \\
\hline \multirow[t]{2}{*}{$\mathrm{SB}$} & BionatureP & $0.69^{\mathrm{a}}$ & $0.29^{\mathrm{ab}}$ & $0.97^{\mathrm{a}}$ & $12.03^{\mathrm{a}}$ \\
\hline & Mean & $0.68^{\mathrm{A}}$ & $0.30^{\mathrm{C}}$ & $0.98^{\mathrm{B}}$ & $14.59^{\mathrm{B}}$ \\
\hline \multicolumn{6}{|c|}{ Cucumber } \\
\hline GH & Diva & $0.47^{\mathrm{a}}$ & $0.30^{\mathrm{a}}$ & $0.77^{\mathrm{a}}$ & $17.22^{\mathrm{a}}$ \\
\hline $\mathrm{GH}$ & Diva-3 & $0.36^{\mathrm{b}}$ & $0.32^{\mathrm{a}}$ & $0.68^{\mathrm{ab}}$ & $17.83^{\mathrm{a}}$ \\
\hline GH & Diva-6 & $0.30^{\mathrm{bc}}$ & $0.29^{\mathrm{a}}$ & $0.59^{\mathrm{bc}}$ & $17.22^{\mathrm{a}}$ \\
\hline SB & Cool Cukes & $0.30^{\mathrm{bc}}$ & $0.30^{\mathrm{a}}$ & $0.60^{\mathrm{bc}}$ & $18.15^{\mathrm{a}}$ \\
\hline SB & Lebanese & $0.25^{\mathrm{c}}$ & $0.30^{\mathrm{a}}$ & $0.55^{\mathrm{c}}$ & $17.07^{\mathrm{a}}$ \\
\hline \multirow[t]{2}{*}{ SB } & Mini Cucumber & $0.33^{\mathrm{bc}}$ & $0.30^{\mathrm{a}}$ & $0.63^{\mathrm{bc}}$ & $17.48^{\mathrm{a}}$ \\
\hline & Mean & $0.34^{\mathrm{C}}$ & $0.30^{\mathrm{C}}$ & $0.64^{\mathrm{D}}$ & $17.50^{\mathrm{A}}$ \\
\hline \multicolumn{6}{|c|}{ Arugula } \\
\hline $\mathrm{GH}$ & Astro & $0.70^{\mathrm{a}}$ & $0.49^{\mathrm{a}}$ & $1.19^{\mathrm{a}}$ & $15.52^{\mathrm{a}}$ \\
\hline $\mathrm{GH}$ & Astro-6 & $0.67^{\mathrm{a}}$ & $0.47^{\mathrm{a}}$ & $1.14^{\mathrm{a}}$ & $14.51^{\mathrm{ab}}$ \\
\hline SB & $\mathrm{ADO}$ & $0.67^{\mathrm{a}}$ & $0.47^{\mathrm{a}}$ & $1.14^{\mathrm{a}}$ & $9.94^{\mathrm{b}}$ \\
\hline SB & BW & $0.72^{\mathrm{a}}$ & $0.43^{\mathrm{a}}$ & $1.14^{\mathrm{a}}$ & $11.46^{\mathrm{ab}}$ \\
\hline \multirow[t]{2}{*}{ SB } & PRO & $0.74^{\mathrm{a}}$ & $0.52^{\mathrm{a}}$ & $1.26^{\mathrm{a}}$ & $14.81^{\mathrm{ab}}$ \\
\hline & Mean & $0.70^{\mathrm{A}}$ & $0.48^{\mathrm{A}}$ & $1.18^{\mathrm{A}}$ & $13.25^{\mathrm{BC}}$ \\
\hline \multicolumn{6}{|c|}{ Bibb lettuce } \\
\hline GH & RexMT0 & $0.41^{\mathrm{b}}$ & $0.43^{\mathrm{a}}$ & $0.84^{\mathrm{a}}$ & $15.06^{\mathrm{a}}$ \\
\hline GH & RexMT0-6 & $0.39^{\mathrm{b}}$ & $0.28^{\mathrm{a}}$ & $0.68^{\mathrm{a}}$ & $14.70^{\mathrm{a}}$ \\
\hline SB & ADO & $0.67^{\mathrm{a}}$ & $0.29^{\mathrm{a}}$ & $0.95^{\mathrm{a}}$ & $12.70^{\mathrm{a}}$ \\
\hline \multirow[t]{2}{*}{ SB } & IGA & $0.48^{\mathrm{ab}}$ & $0.44^{\mathrm{a}}$ & $0.92^{\mathrm{a}}$ & $15.35^{\mathrm{a}}$ \\
\hline & Mean & $0.49^{\mathrm{B}}$ & $0.36^{\mathrm{B}}$ & $0.85^{\mathrm{C}}$ & $14.45^{\mathrm{B}}$ \\
\hline
\end{tabular}

${ }^{1}$ LS means were compared using Scheffe's Multiple Comparison Test. Small case superscripts within species and large case superscripts between species not sharing the same letter are significantly different $(P \leq 0.05)$. ${ }^{*}$ Produce (based on availability) was fridge-stored $\left(4^{\circ} \mathrm{C}\right)$ for 3 and/or 6 days.

variations in TAC between fresh and stored material or the TAC fluctuations during storage needs further study; however, such changes may be related to synthesis and degradation of anthocyanin pigments during storage.
3.8. Total Carotenoid Levels. Total carotenoid levels of GH and SB varieties were estimated in two different extracts: hexane or ethanol (Table 9). Overall, for the hexane extracts, there were no differences between $\mathrm{GH}$ and SB vegetables 
TABLE 9: LS mean values ${ }^{1}$ of total phenolics (mg/100 g DW gallic acid (GAE) equivalent), total carotenoids (mg/100 g DW $\beta$-carotene), and total anthocyanins (mg/100 g DW cyanidin-3-glucoside) of hydroponically grown (GH) and store-bought (SB) cherry tomato, beefsteak tomato, cucumber, arugula, and bibb lettuce.

\begin{tabular}{|c|c|c|c|c|c|}
\hline \multirow{2}{*}{ Crops } & \multirow{2}{*}{ Varieties } & \multirow{2}{*}{ Total phenolics } & \multirow{2}{*}{ Total anthocyanins } & \multicolumn{2}{|c|}{ Total carotenoids } \\
\hline & & & & Hexane & Ethanol \\
\hline \multicolumn{6}{|c|}{ Cherry tomato } \\
\hline $\mathrm{GH}$ & Apero & $10.60^{\mathrm{ab}}$ & $4.91^{b c}$ & $1170.88^{\mathrm{a}}$ & $8.17^{\mathrm{b}}$ \\
\hline $\mathrm{GH}$ & Apero- $6^{*}$ & $11.00^{\mathrm{ab}}$ & $16.04^{\mathrm{ab}}$ & $1420.39^{\mathrm{a}}$ & $8.92^{\mathrm{b}}$ \\
\hline GH & Favorita & $11.06^{\mathrm{ab}}$ & $18.42^{\mathrm{a}}$ & $1332.90^{\mathrm{a}}$ & $9.72^{\mathrm{b}}$ \\
\hline $\mathrm{GH}$ & Favorita-6 & $12.11^{\mathrm{ab}}$ & $12.24^{\mathrm{abc}}$ & $1157.47^{\mathrm{a}}$ & $7.44^{\mathrm{b}}$ \\
\hline GH & Juanita & $10.43^{\mathrm{ab}}$ & $10.37^{\mathrm{abc}}$ & $1175.16^{\mathrm{a}}$ & $8.51^{\mathrm{b}}$ \\
\hline GH & Juanita-6 & $13.60^{\mathrm{a}}$ & $3.81^{\mathrm{c}}$ & $1212.27^{\mathrm{a}}$ & $8.71^{\mathrm{b}}$ \\
\hline SB & Jardino & $11.10^{\mathrm{ab}}$ & $10.96^{\mathrm{abc}}$ & $1282.42^{\mathrm{a}}$ & $14.82^{\mathrm{a}}$ \\
\hline SB & Cherries & $8.59^{\mathrm{b}}$ & $6.43^{\mathrm{bc}}$ & $1221.45^{\mathrm{a}}$ & $14.87^{\mathrm{a}}$ \\
\hline \multirow[t]{2}{*}{ SB } & Fruiterie & $9.91^{\mathrm{ab}}$ & $10.52^{\mathrm{abc}}$ & $1252.70^{\mathrm{a}}$ & $11.27^{\mathrm{ab}}$ \\
\hline & Mean & $10.99^{\mathrm{B}}$ & $10.41^{\mathrm{B}}$ & $1247.30^{\mathrm{C}}$ & $10.27^{\mathrm{A}}$ \\
\hline \multicolumn{6}{|c|}{ Beefsteak tomato } \\
\hline $\mathrm{GH}$ & Arbason & $8.31^{\mathrm{a}}$ & $4.93^{\mathrm{abc}}$ & $1554.79^{\mathrm{a}}$ & $11.83^{\mathrm{ab}}$ \\
\hline $\mathrm{GH}$ & Caramba & $7.23^{\mathrm{a}}$ & $11.47^{\mathrm{a}}$ & $1480.51^{\mathrm{a}}$ & $14.35^{\mathrm{a}}$ \\
\hline $\mathrm{GH}$ & Geronimo & $8.26^{\mathrm{a}}$ & $11.03^{\mathrm{a}}$ & $1481.94^{\mathrm{a}}$ & $11.73^{\mathrm{ab}}$ \\
\hline GH & Trust & $9.29^{\mathrm{a}}$ & $10.48^{\mathrm{ab}}$ & $1457.40^{\mathrm{a}}$ & $12.51^{\mathrm{ab}}$ \\
\hline SB & Kaliroy & $9.55^{\mathrm{a}}$ & $4.97^{\mathrm{abc}}$ & $1486.47^{\mathrm{a}}$ & $8.73^{\mathrm{b}}$ \\
\hline SB & BionatureL & $8.90^{\mathrm{a}}$ & $3.29^{\mathrm{bc}}$ & $1549.62^{\mathrm{a}}$ & $9.11^{\mathrm{b}}$ \\
\hline \multirow[t]{2}{*}{ SB } & BionatureP & $9.26^{\mathrm{a}}$ & $2.17^{\mathrm{c}}$ & $1203.18^{\mathrm{a}}$ & $8.49^{\mathrm{b}}$ \\
\hline & Mean & $8.68^{\mathrm{C}}$ & $6.91^{\mathrm{C}}$ & $1459.13^{\text {B }}$ & $10.96^{\mathrm{A}}$ \\
\hline \multicolumn{6}{|c|}{ Cucumber } \\
\hline $\mathrm{GH}$ & Diva & $9.65^{\mathrm{a}}$ & $3.90^{\mathrm{cd}}$ & $1721.66^{\mathrm{a}}$ & $3.84^{\mathrm{bc}}$ \\
\hline GH & Diva-3 & $8.72^{\mathrm{ab}}$ & $11.13^{\mathrm{ab}}$ & $1782.82^{\mathrm{a}}$ & $3.46^{\mathrm{c}}$ \\
\hline GH & Diva-6 & $9.87^{\mathrm{a}}$ & $2.22^{\mathrm{d}}$ & $1722.46^{\mathrm{a}}$ & $4.73^{\mathrm{abc}}$ \\
\hline SB & Cool Cukes & $6.69^{b c}$ & $9.95^{\mathrm{bc}}$ & $1815.45^{\mathrm{a}}$ & $7.90^{\mathrm{a}}$ \\
\hline SB & Lebanese & $6.99^{b c}$ & $16.66^{\mathrm{a}}$ & $1707.20^{\mathrm{a}}$ & $6.95^{\mathrm{ab}}$ \\
\hline \multirow[t]{2}{*}{ SB } & Mini Cucumber & $6.38^{\mathrm{c}}$ & $7.24^{\mathrm{bcd}}$ & $1748.34^{\mathrm{a}}$ & $6.05^{\mathrm{abc}}$ \\
\hline & Mean & $8.05^{\mathrm{CD}}$ & $8.52^{\mathrm{BC}}$ & $1749.66^{\mathrm{A}}$ & $5.49^{\mathrm{C}}$ \\
\hline \multicolumn{6}{|c|}{ Arugula } \\
\hline $\mathrm{GH}$ & Astro & $12.33^{\mathrm{ab}}$ & $59.56^{\mathrm{a}}$ & $1552.25^{\mathrm{a}}$ & $1.23^{\mathrm{ab}}$ \\
\hline $\mathrm{GH}$ & Astro-6 & $11.01^{\mathrm{b}}$ & $31.63^{\mathrm{bc}}$ & $1450.70^{\mathrm{ab}}$ & $1.48^{\mathrm{ab}}$ \\
\hline SB & ADO & $13.06^{\mathrm{ab}}$ & $38.26^{b c}$ & $994.12^{\mathrm{b}}$ & $0.97^{\mathrm{b}}$ \\
\hline SB & BW & $15.92^{\mathrm{a}}$ & $27.40^{c}$ & $1145.93^{\mathrm{ab}}$ & $1.99^{\mathrm{ab}}$ \\
\hline \multirow[t]{2}{*}{ SB } & PRO & $15.68^{\mathrm{a}}$ & $40.84^{\mathrm{b}}$ & $1480.76^{\mathrm{ab}}$ & $3.16^{\mathrm{a}}$ \\
\hline & Mean & $13.60^{\mathrm{A}}$ & $39.54^{\mathrm{A}}$ & $1324.75^{\mathrm{BC}}$ & $1.77^{\mathrm{D}}$ \\
\hline \multicolumn{6}{|c|}{ Bibb lettuce } \\
\hline $\mathrm{GH}$ & RexMT0 & $6.59^{\mathrm{a}}$ & $2.72^{\mathrm{a}}$ & $1505.92^{\mathrm{a}}$ & $2.82^{\mathrm{b}}$ \\
\hline GH & RexMT0-6 & $7.06^{\mathrm{a}}$ & $1.60^{\mathrm{ab}}$ & $1469.75^{\mathrm{a}}$ & $5.80^{\mathrm{b}}$ \\
\hline SB & $\mathrm{ADO}$ & $7.78^{\mathrm{a}}$ & $0.69^{\mathrm{b}}$ & $1270.19^{a}$ & $13.79^{\mathrm{a}}$ \\
\hline \multirow[t]{2}{*}{ SB } & IGA & $7.47^{\mathrm{a}}$ & $1.63^{\mathrm{ab}}$ & $1534.99^{\mathrm{a}}$ & $5.28^{\mathrm{b}}$ \\
\hline & Mean & $7.22^{\mathrm{D}}$ & $1.66^{\mathrm{D}}$ & $1445.21^{\mathrm{B}}$ & $6.92^{\mathrm{B}}$ \\
\hline
\end{tabular}

${ }^{1}$ LS means were compared using Scheffe's Multiple Comparison Test. Small case superscripts within species and large case superscripts between species not sharing the same letter are significantly different $(P \leq 0.05)$. ${ }^{*}$ Produce (based on availability) was fridge-stored $\left(4^{\circ} \mathrm{C}\right)$ for 3 and/or 6 days.

(cherry tomato, beefsteak tomato, cucumber, and bibb lettuce), except for arugula 'Astro' that had greater total carotenoid content than one (ADO) but not the other two SB varieties. No differences were found among the GH 'Astro', SB
'BW, and SB 'PRO' varieties and no differences were observed between the three $\mathrm{SB}$ varieties.

For the ethanol extract, GH cherry tomato had lesser concentrations of carotenoids compared with the SB cultivars 
(Table 9). All GH varieties had similar total carotenoids. The opposite results occurred for beefsteak tomatoes. Cultivar Caramba had greater carotenoid content compared with the SB cultivars but was not different from the other GH cultivars, Arbason, Geronimo, and Trust. For arugula, the SB 'PRO' had greater total carotenoids than 'ADO' but was not different from 'Astro' and 'BW.' For bibb lettuce, the SB 'ADO' had greater carotenoid levels compared with 'RexMT0' and 'IGA.' There were no distinctions between carotenoid content in fresh or stored cultivars. Fresh and stored cultivars of all vegetables showed similar total carotenoid levels from both hexane and ethanol extracts. Lettuce had lactucaxanthin $(7.5 \mathrm{mg} / \mathrm{g} \mathrm{FM})$ as the main carotenoid compound while tomato was rich in the lycopene $(35.4 \mathrm{mg} / \mathrm{g} \mathrm{FM})$, lutein $(1.0 \mathrm{mg} / \mathrm{g} \mathrm{FM})$, and $\beta$-carotene $(3.2 \mathrm{mg} / \mathrm{g} \mathrm{FM})$ carotenoids [50].

3.9. HPLC Analysis of Major Carotenoids. The HPLC analysis of the major carotenoid compounds ( $\beta$-carotene, lutein (xanthophyll), and lycopene) in vegetable produce is summarized in Table 10.

3.9.1. $\beta$-Carotene. $\beta$-Carotene levels among cherry tomato cultivars ranged from 107.43 to $390.34 \mathrm{mg} / 100 \mathrm{~g}$ DW. The SB 'Cherries' had the greatest content of $\beta$-carotene followed by 'Fruiterie.' GH cherry tomato cultivars showed less $\beta$ carotene contents than the SB cultivars but similar to 'Jardino.' 'Favorita' showed greater content compared with 'Apero' and 'Juanita', which had similar levels of $\beta$-carotene. The average content of $\beta$-carotene for cherry tomato varieties was greater than that of the beefsteak tomatoes. Beefsteak tomato cultivars had $\beta$-carotene levels that ranged from 54.25 to $153.32 \mathrm{mg} / 100 \mathrm{gDW}$. GH 'Caramba' and the SB 'BionatureP' and 'BionatureL' showed the greatest $\beta$-carotene levels compared with all other cultivars. 'Arbason' and 'Trust' showed the least concentrations of $\beta$-carotene. No differences were noted among 'Caramba,' 'Geronimo,' and 'BionatureL.' Also, 'Kaliroy,' 'Trust,' and 'Arbason' had similar contents of $\beta$-carotene.

Store-bought cucumber variety Mini Cucumber showed greater $\beta$-carotene content $(139.05 \mathrm{mg} / 100 \mathrm{~g} \mathrm{DW})$ compared with the other two SB varieties and the GH 'Diva' (Table 10). Cultivar Diva had the least $\beta$-carotene level compared with the SB varieties but had similar content to 'Cool Cukes.' Arugula varieties contained great amounts of $\beta$-carotene that ranged from 445.22 to $1,365.03 \mathrm{mg} / 100 \mathrm{~g} \mathrm{DW}$. However, there was a huge variation in $\beta$-carotene content among arugula varieties where 'ADO' had greater content compared with 'Astro' but was not different from the other SB varieties BW and PRO. No differences were found between the GH 'Astro' and the SB varieties BW and PRO. For bibb lettuce, the SB 'IGA' had greater content of $\beta$-carotene compared with 'RexMT0' and 'ADO.' The GH 'RexMT0' had greater $\beta$ carotene level than 'ADO.'

Fridge-storage of GH vegetables depressed the content of $\beta$-carotene in cherry tomato and bibb lettuce varieties but did not significantly affect cucumber and arugula varieties (Table 10). Storage of cherry tomato cultivars for $6 \mathrm{~d}$ decreased the $\beta$-carotene contents of 'Apero' (35.35\%) and
'Favorita' (35.28\%) but not 'Juanita.' Storage of cucumber 'Diva' for 3 and $6 \mathrm{~d}$ at $4^{\circ} \mathrm{C}$ did not change the $\beta$-carotene content. Storage of arugula 'Astro' for $6 \mathrm{~d}$ did not affect $\beta$ carotene compared with the fresh sample. Storage of greenhouse bibb lettuce 'RexMT0' for $6 \mathrm{~d}$ significantly decreased $\beta$-carotene levels compared with fresh produce.

3.9.2. Lutein. Lutein concentration in arugula was the greatest among tested crops and ranged from 33.76 to $95.22 \mathrm{mg} / 100 \mathrm{~g} \mathrm{DW}$ : manyfold greater than in the other vegetables (Table 10). Cherry tomato and beefsteak tomato cultivars were similar in lutein concentrations. The SB 'Cherries' had greater lutein content compared with other cherry tomato cultivars but was not different from 'Fruiterie' (SB) and 'Favorita' (GH). Cultivars Apero, Favorita, Juanita, Jardino, and Fruiterie had similar lutein levels. Beefsteak tomato that was either $\mathrm{GH}$ or SB had similar lutein levels (2.85-5.79 mg/100 g DW). For cucumber, no differences were found in lutein levels between the GH 'Diva' and the SB 'Cool Cukes,' 'Mini Cucumber,' and 'Lebanese.' Store-bought arugula cultivars were similar in lutein content but greater than that of the GH 'Astro' (Table 10). Arugula was reported to be a rich source of lutein when eaten fresh or processed $[21,51]$. Also, the SB bibb lettuce 'IGA' had greater lutein content compared with 'ADO' and 'RexMT0', which had similar lutein levels. There was no effect of fridge-storage on the lutein content of any of the GH vegetables. Similarly, hydroponic lettuce has previously been shown to contain significantly lower lutein, $\alpha$-carotene, violaxanthin, and neoxanthin content than the conventionally produced lettuce [22].

3.9.3. Lycopene. Lycopene is the most predominant carotenoid pigment in tomatoes (about 83\%) [49]. Lycopene was detected only in tomato varieties and not in cucumber, arugula, or bibb lettuce varieties (Table 10). A wide range of lycopene concentrations was detected in cherry tomato varieties (60.74-139.74 mg/100 g DW). Store-bought 'Cherries' showed the greatest lycopene level but this was similar to GH 'Favorita.' Cultivars Favorita and Fruiterie were similar in lycopene content. No differences occurred in lycopene levels of 'Apero,' 'Juanita,' and 'Jardino.' Beefsteak tomato cultivars had levels of lycopene that ranged from 32.03 to $67.00 \mathrm{mg} / 100 \mathrm{~g} \mathrm{DW}$ : about half the levels of cherry tomatoes. Hydroponically GH grown 'Trust' and 'Caramba' had the greatest lycopene levels compared with other cultivars. No differences occurred in lycopene levels between 'Arbason,' 'Geronimo,' 'Kaliroy,' 'BionatureL,' and 'BionatureP.' Fridgestorage of cherry tomato varieties for $6 \mathrm{~d}$ decreased lycopene content of 'Favorita' but not 'Apero' or 'Juanita'.

\subsection{HPLC Analysis of Organic Acids}

3.10.1. Ascorbic Acid (Vitamin C). Concentrations of ascorbic acid were similar for GH and SB cherry tomato (Table 11). A different trend was noticed for beefsteak tomato, where SB cultivars had greater vitamin $\mathrm{C}$ content compared with $\mathrm{GH}$ cultivars. The SB 'Kaliroy' had the greatest vitamin C content and the GH 'Geronimo' had the least concentration. Hydroponically grown GH cucumber 'Diva' had greater ascorbic 
TABLE 10: LS mean values ${ }^{1}$ of $\beta$-carotene, lutein, and lycopene (mg/100 g DW) of hydroponically grown (GH) and store-bought (SB) cherry tomato, beefsteak tomato, cucumber, arugula, and bibb lettuce evaluated using high pressure liquid chromatography (HPLC).

\begin{tabular}{|c|c|c|c|c|}
\hline Crops & Varieties & $\beta$-Carotene & Lutein & Lycopene \\
\hline \multicolumn{5}{|c|}{ Cherry tomato } \\
\hline $\mathrm{GH}$ & Apero & $166.16^{\mathrm{d}}$ & $4.03^{\mathrm{b}}$ & $73.55^{\mathrm{c}}$ \\
\hline $\mathrm{GH}$ & Apero- $6^{*}$ & $107.43^{\mathrm{e}}$ & $2.56^{\mathrm{b}}$ & $60.74^{\mathrm{c}}$ \\
\hline GH & Favorita & $235.53^{c}$ & $5.00^{\mathrm{ab}}$ & $119.75^{\mathrm{ab}}$ \\
\hline $\mathrm{GH}$ & Favorita-6 & $152.43^{\mathrm{d}}$ & $5.49^{\mathrm{ab}}$ & $75.00^{c}$ \\
\hline $\mathrm{GH}$ & Juanita & $171.30^{\mathrm{d}}$ & $4.18^{\mathrm{b}}$ & $76.60^{c}$ \\
\hline $\mathrm{GH}$ & Juanita-6 & $147.70^{\mathrm{d}}$ & $4.07^{\mathrm{b}}$ & $83.80^{c}$ \\
\hline SB & Jardino & $146.55^{\mathrm{d}}$ & $3.95^{\mathrm{b}}$ & $72.36^{\mathrm{c}}$ \\
\hline SB & Cherries & $390.34^{\mathrm{a}}$ & $9.12^{\mathrm{a}}$ & $139.74^{\mathrm{a}}$ \\
\hline \multirow[t]{2}{*}{ SB } & Fruiterie & $311.53^{\mathrm{b}}$ & $6.52^{\mathrm{ab}}$ & $89.56^{\mathrm{bc}}$ \\
\hline & Mean & $203.22^{\mathrm{B}}$ & $4.99^{\mathrm{C}}$ & $87.90^{\mathrm{A}}$ \\
\hline \multicolumn{5}{|c|}{ Beefsteak tomato } \\
\hline $\mathrm{GH}$ & Arbason & $54.25^{\mathrm{e}}$ & $3.65^{\mathrm{a}}$ & $39.00^{\mathrm{b}}$ \\
\hline $\mathrm{GH}$ & Caramba & $146.88^{\mathrm{ab}}$ & $5.79^{\mathrm{a}}$ & $66.07^{\mathrm{a}}$ \\
\hline $\mathrm{GH}$ & Geronimo & $111.99^{\mathrm{bcd}}$ & $4.69^{\mathrm{a}}$ & $45.92^{\mathrm{b}}$ \\
\hline $\mathrm{GH}$ & Trust & $86.56^{\mathrm{de}}$ & $3.35^{\mathrm{a}}$ & $67.00^{\mathrm{a}}$ \\
\hline SB & Kaliroy & $107.23^{\mathrm{cd}}$ & $2.85^{\mathrm{a}}$ & $32.17^{\mathrm{b}}$ \\
\hline SB & BionatureL & $139.89^{\mathrm{abc}}$ & $2.98^{\mathrm{a}}$ & $40.74^{\mathrm{b}}$ \\
\hline \multirow[t]{2}{*}{ SB } & BionatureP & $153.32^{\mathrm{a}}$ & $3.62^{\mathrm{a}}$ & $32.03^{\mathrm{b}}$ \\
\hline & Mean & $114.30^{\mathrm{C}}$ & $3.88^{\mathrm{C}}$ & $46.13^{\mathrm{B}}$ \\
\hline \multicolumn{5}{|c|}{ Cucumber } \\
\hline $\mathrm{GH}$ & Diva & $37.09^{\mathrm{cd}}$ & $10.74^{\mathrm{bc}}$ & $-\$$ \\
\hline $\mathrm{GH}$ & Diva-3 & $22.25^{\mathrm{d}}$ & $5.26^{\mathrm{c}}$ & - \\
\hline $\mathrm{GH}$ & Diva-6 & $33.11^{\mathrm{d}}$ & $13.63^{\mathrm{bc}}$ & - \\
\hline SB & Cool Cukes & $56.29^{c}$ & $23.38^{\mathrm{a}}$ & - \\
\hline SB & Lebanese & $93.19^{b}$ & $19.11^{\mathrm{ab}}$ & - \\
\hline \multirow[t]{2}{*}{ SB } & Mini Cucumber & $139.05^{\mathrm{a}}$ & $22.95^{\mathrm{a}}$ & - \\
\hline & Mean & $63.50^{\mathrm{C}}$ & $15.89^{\mathrm{B}}$ & - \\
\hline \multicolumn{5}{|c|}{ Arugula } \\
\hline $\mathrm{GH}$ & Astro & $445.22^{\mathrm{b}}$ & $33.76^{c}$ & - \\
\hline $\mathrm{GH}$ & Astro-6 & $615.75^{\mathrm{b}}$ & $58.22^{\mathrm{bc}}$ & - \\
\hline SB & $\mathrm{ADO}$ & $1365.03^{\mathrm{a}}$ & $75.47^{\mathrm{ab}}$ & - \\
\hline SB & BW & $842.91^{\mathrm{ab}}$ & $72.14^{\mathrm{ab}}$ & - \\
\hline \multirow[t]{2}{*}{ SB } & PRO & $1080.80^{\mathrm{ab}}$ & $95.22^{\mathrm{a}}$ & - \\
\hline & Mean & $869.94^{\mathrm{A}}$ & $66.96^{\mathrm{A}}$ & - \\
\hline \multicolumn{5}{|c|}{ Bibb lettuce } \\
\hline $\mathrm{GH}$ & RexMT0 & $223.77^{\mathrm{b}}$ & $19.97^{\mathrm{b}}$ & - \\
\hline $\mathrm{GH}$ & RexMT0-6 & $85.70^{c}$ & $9.89^{c}$ & - \\
\hline SB & $\mathrm{ADO}$ & $55.00^{\mathrm{d}}$ & $14.78^{\mathrm{bc}}$ & - \\
\hline \multirow[t]{2}{*}{ SB } & IGA & $290.27^{\mathrm{a}}$ & $28.38^{\mathrm{a}}$ & - \\
\hline & Mean & $163.69^{\mathrm{BC}}$ & $18.26^{\mathrm{B}}$ & - \\
\hline
\end{tabular}

${ }^{1}$ LS means were compared using Scheffe's Multiple Comparison Test. Small case superscripts within species and large case superscripts between species not sharing the same letter are significantly different $(P \leq 0.05)$. ${ }^{*}$ Produce (based on availability) was fridge-stored $\left(4^{\circ} \mathrm{C}\right)$ for 3 and/or 6 days. $-\$$ : not detected.

acid levels compared with SB 'Cool Cukes' and 'Mini Cucumber' but was not different from 'Lebanese.' No difference occurred in ascorbic acid content between the GH arugula 'Astro' and the SB 'BW' and 'PRO.' Cultivar ADO had the least vitamin $\mathrm{C}$ content. For bibb lettuce, no differences were found in vitamin $\mathrm{C}$ content between 'ADO,' 'RexMT0,' and 'IGA.'
Based on average vitamin $\mathrm{C}$ content of cultivars within each crop, beefsteak tomato had the greatest vitamin $\mathrm{C}$ content (198.76 mg/100 g DW) followed by cherry tomato (129.45), arugula (73.72), bibb lettuce (67.17), and finally cucumber (37.82). Curiously, fridge-storage of GH 'Apero' and 'Juanita' for $6 \mathrm{~d}$ increased vitamin $\mathrm{C}$ concentrations but 
TABLE 11: LS mean values ${ }^{1}$ of organic acids (mg/100 g DW) of hydroponically grown (GH) and store-bought (SB) cherry tomato, beefsteak tomato, cucumber, arugula, and bibb lettuce evaluated using high pressure liquid chromatography (HPLC).

\begin{tabular}{|c|c|c|c|c|c|}
\hline Crops & Varieties & Ascorbic acid & Malic acid & Citric acid & Fumaric acid \\
\hline \multicolumn{6}{|c|}{ Cherry tomato } \\
\hline $\mathrm{GH}$ & Apero & $108.15^{\mathrm{c}}$ & $25.48^{\mathrm{a}}$ & $2.04^{b c}$ & $0.14^{\mathrm{ab}}$ \\
\hline $\mathrm{GH}$ & Apero- $6^{*}$ & $317.52^{\mathrm{a}}$ & $5.30^{\mathrm{ef}}$ & $5.60^{\mathrm{a}}$ & $0.24^{\mathrm{a}}$ \\
\hline GH & Favorita & $85.01^{\mathrm{cd}}$ & $11.93^{\mathrm{def}}$ & $4.10^{\mathrm{ab}}$ & $0.16^{\mathrm{ab}}$ \\
\hline $\mathrm{GH}$ & Favorita-6 & $44.94^{\mathrm{d}}$ & $4.45^{\mathrm{ef}}$ & $2.01^{\mathrm{bc}}$ & $0.13^{\mathrm{ab}}$ \\
\hline $\mathrm{GH}$ & Juanita & $81.74^{\mathrm{cd}}$ & $18.99^{\text {cde }}$ & $4.82^{\mathrm{ab}}$ & $0.19^{\mathrm{ab}}$ \\
\hline GH & Juanita-6 & $241.30^{\mathrm{b}}$ & $3.21^{\mathrm{f}}$ & $1.60^{\mathrm{bc}}$ & $0.15^{\mathrm{ab}}$ \\
\hline SB & Jardino & $82.82^{\mathrm{cd}}$ & $37.44^{\mathrm{b}}$ & $4.20^{\mathrm{ab}}$ & $0.24^{\mathrm{a}}$ \\
\hline SB & Cherries & $119.29^{c}$ & $58.92^{\mathrm{a}}$ & $1.59^{\mathrm{bc}}$ & $0.09^{\mathrm{b}}$ \\
\hline \multirow[t]{2}{*}{ SB } & Fruiterie & $84.28^{\mathrm{cd}}$ & $32.98^{\mathrm{bc}}$ & $0.50^{c}$ & $0.16^{\mathrm{ab}}$ \\
\hline & Mean & $129.45^{\mathrm{B}}$ & $22.08^{\mathrm{B}}$ & $2.97^{\mathrm{B}}$ & $0.17^{\mathrm{B}}$ \\
\hline \multicolumn{6}{|c|}{ Beefsteak tomato } \\
\hline $\mathrm{GH}$ & Arbason & $117.72^{\mathrm{cd}}$ & $4.33^{\mathrm{b}}$ & $2.59^{\mathrm{abc}}$ & $0.26^{\mathrm{a}}$ \\
\hline $\mathrm{GH}$ & Caramba & $125.16^{\mathrm{cd}}$ & $6.38^{\mathrm{b}}$ & $2.71^{\mathrm{ab}}$ & $0.26^{\mathrm{a}}$ \\
\hline $\mathrm{GH}$ & Geronimo & $46.46^{\mathrm{d}}$ & $109.65^{\mathrm{a}}$ & $0.09^{\mathrm{d}}$ & $0.16^{\mathrm{abc}}$ \\
\hline GH & Trust & $178.78^{\mathrm{c}}$ & $4.11^{\mathrm{b}}$ & $1.04^{\mathrm{cd}}$ & $0.21^{\mathrm{ab}}$ \\
\hline SB & Kaliroy & $497.97^{\mathrm{a}}$ & $6.34^{\mathrm{b}}$ & $3.54^{\mathrm{ab}}$ & $0.10^{\mathrm{bc}}$ \\
\hline SB & BionatureL & $306.23^{\mathrm{b}}$ & $10.14^{\mathrm{b}}$ & $3.92^{\mathrm{a}}$ & $0.18^{\mathrm{abc}}$ \\
\hline \multirow[t]{2}{*}{ SB } & BionatureP & $119.00^{\mathrm{cd}}$ & $1.21^{\mathrm{b}}$ & $2.10^{\mathrm{bc}}$ & $0.08^{\mathrm{c}}$ \\
\hline & Mean & $198.76^{\mathrm{A}}$ & $20.31^{\mathrm{B}}$ & $2.29^{\mathrm{B}}$ & $0.18^{\mathrm{AB}}$ \\
\hline \multicolumn{6}{|c|}{ Cucumber } \\
\hline $\mathrm{GH}$ & Diva & $55.41^{\mathrm{b}}$ & $85.43^{\mathrm{ab}}$ & $14.15^{\mathrm{ab}}$ & $0.50^{\mathrm{a}}$ \\
\hline $\mathrm{GH}$ & Diva-3 & $4.92^{\mathrm{d}}$ & $102.27^{\mathrm{a}}$ & $16.22^{\mathrm{a}}$ & $0.02^{\mathrm{c}}$ \\
\hline $\mathrm{GH}$ & Diva-6 & $87.50^{\mathrm{a}}$ & $19.67^{\mathrm{b}}$ & $4.72^{\mathrm{c}}$ & $0.14^{\mathrm{c}}$ \\
\hline SB & Cool Cukes & $20.32^{\mathrm{cd}}$ & $104.46^{\mathrm{a}}$ & $18.11^{\mathrm{a}}$ & $0.30^{\mathrm{abc}}$ \\
\hline SB & Lebanese & $43.18^{\mathrm{bc}}$ & $93.04^{\mathrm{a}}$ & $11.04^{\mathrm{abc}}$ & $0.34^{\mathrm{ab}}$ \\
\hline \multirow[t]{2}{*}{ SB } & Mini Cucumber & $15.60^{\mathrm{d}}$ & $108.31^{\mathrm{a}}$ & $7.67^{\mathrm{bc}}$ & $0.01^{\mathrm{c}}$ \\
\hline & Mean & $37.82^{\mathrm{D}}$ & $85.53^{\mathrm{B}}$ & $11.98^{\mathrm{A}}$ & $0.22^{\mathrm{A}}$ \\
\hline \multicolumn{6}{|c|}{ Arugula } \\
\hline $\mathrm{GH}$ & Astro & $87.07^{\mathrm{ab}}$ & $67.20^{\mathrm{b}}$ & $1.21^{\mathrm{a}}$ & $0.06^{\mathrm{b}}$ \\
\hline $\mathrm{GH}$ & Astro-6 & $56.91^{b c}$ & $183.18^{\mathrm{a}}$ & $0.15^{\mathrm{b}}$ & $0.01^{\mathrm{c}}$ \\
\hline SB & $\mathrm{ADO}$ & $31.45^{\mathrm{c}}$ & $12.18^{\mathrm{c}}$ & $1.21^{\mathrm{b}}$ & $0.02^{\mathrm{C}}$ \\
\hline SB & BW & $112.97^{\mathrm{a}}$ & $4.81^{\mathrm{c}}$ & $0.25^{\mathrm{b}}$ & $0.004^{\mathrm{c}}$ \\
\hline \multirow[t]{2}{*}{ SB } & PRO & $80.21^{\mathrm{ab}}$ & $82.89^{\mathrm{b}}$ & $0.08^{\mathrm{b}}$ & $0.14^{\mathrm{a}}$ \\
\hline & Mean & $73.72^{\mathrm{C}}$ & $70.05^{\mathrm{B}}$ & $0.36^{\mathrm{C}}$ & $0.05^{\mathrm{C}}$ \\
\hline \multicolumn{6}{|c|}{ Bibb lettuce } \\
\hline $\mathrm{GH}$ & RexMT0 & $65.72^{\mathrm{ab}}$ & $221.80^{\mathrm{b}}$ & $0.04^{\mathrm{b}}$ & $0.02^{\mathrm{a}}$ \\
\hline $\mathrm{GH}$ & RexMT0-6 & $85.29^{\mathrm{a}}$ & $814.06^{\mathrm{ab}}$ & $0.08^{\mathrm{ab}}$ & $0.06^{\mathrm{a}}$ \\
\hline SB & $\mathrm{ADO}$ & $54.30^{\mathrm{b}}$ & $1028.70^{\mathrm{a}}$ & $0.11^{\mathrm{ab}}$ & $0.12^{\mathrm{a}}$ \\
\hline \multirow[t]{2}{*}{ SB } & IGA & $63.38^{\mathrm{ab}}$ & $1323.56^{\mathrm{a}}$ & $0.14^{\mathrm{a}}$ & $0.07^{\mathrm{a}}$ \\
\hline & Mean & $67.17^{\mathrm{C}}$ & $847.03^{\mathrm{A}}$ & $0.09^{\mathrm{C}}$ & $0.07^{\mathrm{C}}$ \\
\hline
\end{tabular}

${ }^{1}$ LS means were compared using Scheffe's Multiple Comparison Test. Small case superscripts within species and large case superscripts between species not sharing the same letter are significantly different $(P \leq 0.05)$. ${ }^{*}$ Produce (based on availability) was fridge-stored $\left(4^{\circ} \mathrm{C}\right)$ for 3 and/or 6 days.

these were decreased in 'Favorita.' Similarly, storing 'Diva' for $6 \mathrm{~d}$ increased the ascorbic acid content compared with fresh cucumber. The observed increased vitamin $\mathrm{C}$ content with storage could be due to an increase in ascorbic acid synthesis. No effect of $6 \mathrm{~d}$ storage occurred on the vitamin $\mathrm{C}$ content of arugula 'Astro' or bibb lettuce 'RexMT0' compared with fresh produce.

3.10.2. Malic Acid. Malic acid contributes a sour taste to vegetables and tends to be present in greater concentrations in 
unripe fruit. Organic acids, especially malic and citric acids, were reported as the major organic acids in tomato [52]. For cherry tomato, the GH 'Apero' and the SB 'Cherries' had similar malic acid contents that were greater than all other cherry tomato cultivars (Table 11). For beefsteak tomato, 'Geronimo' had the greatest malic acid content while no differences occurred between the other GH and SB cultivars. For cucumber, no differences were found between GH and $\mathrm{SB}$ varieties. The $\mathrm{GH}$ arugula 'Astro-6' had greater malic acid content compared with SB 'ADO' and 'BW' but was similar to PRO. The reverse trend was found in bibb lettuce where the GH cultivars had less malic acid than the SB cultivars. Malic acid concentration was greatest in bibb lettuce $(847.03 \mathrm{mg} / 100 \mathrm{~g} \mathrm{DW})$ while it was $10 \%$ of this level and similar for cucumber (85.53) and arugula (70.05) and only $2 \%$ of this level in beef-steak tomato (20.31) and cherry tomato (22.08).

Surprisingly, fridge-storage (6 d) of GH arugula 'Astro' and bibb lettuce 'RexMT0' increased the concentration of malic acid by 172.60 and $267.02 \%$, respectively. In contrast, fridge-storage of $\mathrm{GH}$ cherry tomato $(6 \mathrm{~d})$ did not make any difference in terms of malic acid content for 'Favorita' (Table 11). However, for 'Apero' and 'Juanita,' storage dramatically decreased the concentration of malic acid by 79.20 and $83.10 \%$, respectively. Similarly, storage of the cucumber 'Diva' for $6 \mathrm{~d}$ decreased the content of malic acid by $66.64 \%$.

3.10.3. Citric Acid. Citric acid is a natural preservative and often used as a food additive for its flavor. It contributes to vegetables' acidity, color, and taste [48]. Citric acid contents of vegetable crops and fruits arranged in descending order were cucumber $(11.98 \mathrm{mg} / 100 \mathrm{DW})$, cherry tomato (2.97) and beefsteak tomato (2.29), and arugula (0.36), and bibb lettuce (0.09) (Table 11). Cherry tomatoes 'Favorita,' 'Jardino,' and 'Juanita' had greater citric acid content compared with 'Apero,' 'Cherries,' and 'Fruiterie.' There were no differences in the citric acid concentration of GH cultivars of cherry tomato. For beefsteak tomato, 'BionatureL,' 'Kaliroy', 'Caramba', and 'Arbason' had similar citric acid content, which was greater than 'Geronimo.' Cucumber 'Cool Cukes' had more citric acid than 'Mini Cucumber' that was not different from 'Diva' and 'Lebanese.' Citric acid content of hydroponically grown arugula 'Astro' was greater than SB cultivars, which were similar in citric acid content. For bibb lettuce, 'ADO,' 'IGA,' and 'RexMT0-6' had similar citric acid levels.

As with malic acid, different trends occurred in the citric acid content of hydroponically grown vegetables that were stored for $6 \mathrm{~d}$ (Table 11). Stored cherry tomato 'Apero' had increased citric acid content (174.5\%) but 'Favorita' and 'Juanita' were unaffected. Also, storage of cucumber 'Diva' and arugula 'Astro' showed decreased citric acid content of $66.6 \%$ and $87.6 \%$, respectively. Fridge-storage doubled citric acid content in bibb lettuce 'RexMT0'.

3.10.4. Fumaric Acid. Fumaric acid (trans-butenedioic acid) is an acidulent agent that contributes a sour taste to food. Vegetable crops had different fumaric acid content (mg/100 g DW) (Table 11). Cucumber (0.22) had relatively greater fumaric acid concentrations compared with beef-steak (0.18) and cherry tomato (0.17) which were greater than the two leafy greens arugula (0.05) and bibb lettuce (0.07) (Table 11). Cherry tomato 'Jardino' had greater fumaric acid than 'Cherries' but was not different from 'Apero,' 'Favorita,' 'Juanita,' and 'Fruiterie.' Greenhouse-grown beefsteak tomato varieties Arbason, Caramba, Geronimo, and Trust and SB 'BionatureL' had similar fumaric acid contents that were greater than the SB 'BionatureP'. The fumaric acid content of 'Trust,' 'BionatureL', and 'Kaliroy' was similar.

For cucumber, GH 'Diva' had greater fumaric acid content than 'Mini Cucumber' but similar content to 'Cool Cukes' and 'Lebanese' (Table 11). The SB arugula 'PRO' had the greatest fumaric acid content. 'Astro' had greater fumaric acid than 'ADO' and 'BW', which were similar. Fumaric acid content of all bibb lettuce cultivars was the same (0.02$0.12 \mathrm{mg} / 100 \mathrm{~g} \mathrm{DW})$.

The effect of fridge-storage on fumaric acid content was inconsistent between $\mathrm{GH}$ vegetables as seen with other organic acids (Table 11). There was no effect of storage on fumaric acid content of cherry tomatoes. However, storage of cucumber for 3 or $6 \mathrm{~d}$ decreased its fumaric acid content. Storage for $6 \mathrm{~d}$ increased the fumaric acid content of the arugula 'Astro' but did not affect the fumaric acid content of the bibb lettuce 'RexMT0.'

3.11. Effect of Storage on Nutritional Characteristics of Fresh Produce. Fridge-storage of cherry tomato for $6 \mathrm{~d}$ resulted in increased content of Fe and vitamin $\mathrm{C}$ in 'Juanita' and As, TAC, vitamin C, and citric acid content in 'Apero' while levels of Se, vitamin $\mathrm{C}$, and lycopene were reduced in 'Favorita.' Generally storage of GH cherry tomato depressed the content of $\beta$-carotene. Malic acid was decreased by 79.20 and $83.10 \%$ in 'Apero' and 'Juanita,' respectively.

Also, fridge-storage of the cucumber 'Diva' for 3 or $6 \mathrm{~d}$ increased its mineral content. It increased the TAC of cucumber 'Diva' after $3 \mathrm{~d}$ in storage but decreased it again after $6 \mathrm{~d}$ storage. Six-day storage of 'Diva' increased its the ascorbic acid content and decreased its hydrophilic and total ABTS scavenging activity, the content of malic acid (by $66.64 \%$ ), citric acid (by 66.6\%), and fumaric acid content.

Fridge-storage for $6 \mathrm{~d}$ of $\mathrm{GH}$ arugula 'Astro' resulted in greater $\mathrm{Ca}$ and $\mathrm{Fe}$ but $\mathrm{Cr}$ and $\mathrm{Pb}$ were not detected in stored produce but decreased the total carbohydrate and TAC levels. Storage of GH arugula 'Astro' for $6 \mathrm{~d}$ increased the concentration of malic and fumaric acids but dramatically decreased malic (by 79.20\%) and citric acids (by $87.6 \%$ ). Storage of GH bibb lettuce 'RexMT0' for $6 \mathrm{~d}$ had reduced $\mathrm{Al}, \mathrm{Cd}, \mathrm{Mg}, \mathrm{Zn}$, and $\beta$-carotene levels. On the other hand, it increased the concentration of malic acid and doubled citric acid content.

The observed variations in plant metabolites and antioxidant capacity following storage can be attributed to a variety of factors that include biosynthesis during storage, as well as losses due to degradation caused by enzymatic (i.e., polyphenoloxidase, ascorbate oxidase) and nonenzymatic oxidation reactions. Additionally, a slight drop in tissue dry weight during storage could account for slightly more efficient extraction, particularly minerals. 
TABLE 12: Drop-list. Nonsignificant variables (sensory and phytonutrient) that were excluded after the first statistical selection step because these variables do not differentiate among tested varieties of each select crop.

\begin{tabular}{|c|c|}
\hline Crop & Variables (ANOVA $P$ value) \\
\hline Cherry tomato & $\begin{array}{l}\text { Sensory: ripeness }(0.4340) \text {, sweetness }(0.1785) \text {, and mouth feeling }(0.1652) \text {. } \\
\text { Phytonutrient: chromium }(0.4172) \text {, total phenolics }(0.4853) \text {, antioxidant scavenging activity using ABTS } \\
\text { (hydrophilic) (TEACH 0.4706), lipophilic (TEACL 0.2781), total (TEACT 0.4095), DPPH scavenging assay } \\
\text { (0.5468), total carotenoids (lipophilic extract) }(0.5467) \text {, ascorbic acid (0.0651), and total dietary fiber }(0.1593) \\
\text { and lutein }(0.0712) \text {. }\end{array}$ \\
\hline Beefsteak tomato & $\begin{array}{l}\text { Sensory: sweetness }(0.5524) \text {, juiciness }(0.2993) \text {, mouth feeling }(0.4957) \text {, fruit ripeness }(0.0641) \text {, and general } \\
\text { acceptability }(0.5228) \text {. } \\
\text { Phytonutrient: total antioxidant capacity using ABTS (hydrophilic) (TEACH }(0.7314)) \text {, lipophilic (TEACL } \\
(0.0782)) \text {, total (TEACT }(0.7914)) \text {, DPPH scavenging assay }(0.9069) \text {, total carotenoids (lipophilic extract) } \\
(0.9069) \text {, and total dietary fiber }(0.1219) \text {. }\end{array}$ \\
\hline Cucumber & $\begin{array}{l}\text { Sensory: Flesh aroma (0.2351). } \\
\text { Phytonutrient: calcium (0.4110), iron (0.3572), magnesium (0.1290), chromium (0.2893), ABTS antioxidant } \\
\text { assay (lipophilic) (TEACL 0.9522), DPPH scavenging assay (0.9488), total carotenoids (lipophilic extract) } \\
(0.9489) \text {, dry matter }(0.1990) \text {, malic acid }(0.2847) \text {, and total dietary fiber }(0.1446) \text {. }\end{array}$ \\
\hline Arugula & $\begin{array}{l}\text { Sensory: overall quality }(0.1453) \text {. } \\
\text { Phytonutrient: calcium }(0.1130) \text {, magnesium }(0.2069) \text {, selenium }(0.6852) \text {, total antioxidant capacity (ABTS) } \\
\text { (hydrophilic) (TEACH }(0.4296)) \text {, lipophilic (TEACL }(0.0938)) \text {, total (TEACT }(0.2823)) \text {, and total Dietary Fiber } \\
(0.1790) \text {. }\end{array}$ \\
\hline Bibb lettuce & $\begin{array}{l}\text { Sensory: sogginess and freshness }(0.2596) \text {, odor }(0.6512) \text {, and overall quality }(0.1781) \text {. } \\
\text { Phytonutrient: calcium }(0.4926) \text {, potassium }(0.8910) \text {, phosphorous }(0.0850) \text {, antioxidant capacity using ABTS } \\
\text { (Total) (TEACT }(0.5871)) \text {, DPPH scavenging assay }(0.0684) \text {, total carotenoids (lipophilic extract) }(0.0684) \text {, } \\
\text { ascorbic acid }(0.4451) \text {, and total dietary fiber }(0.5905) \text {. }\end{array}$ \\
\hline
\end{tabular}

3.12. Ruling Out Nondiscriminant Variables (Compiling a Drop-List). Assessing traits that contribute to define the most nutritious variety is of great importance for long-term breeding programs for vegetables. The graphical representation of the interrelationships among various sensory and phytonutrient parameters is useful to visualize essential relationships [39]. It is important to rule out nondifferentiating traits. It was interesting that many of the sensory evaluation criteria were on the drop-list (Table 12), with a few important exceptions. These included criteria that called on panelists to make an overall assessment of relative crop quality (general acceptability). Most sensory evaluation criteria that are usually used for these crops (pooled from the literature) do not directly discriminate between cultivars. However, they in some cases, such as for cherry tomato, are necessary to enable reflective answers to overall ranking of general acceptability. Also, a few dominant criteria, such as astringency, or degree of bitterness in arugula, or juiciness in cherry tomato, were relatively more useful to discriminate between cultivars than the other criteria used, which could perhaps be eliminated in favor of new ones (Table 12).

Based on the output after running ANOVA for each of the tested populations separately (cherry tomato, beefsteak tomato cucumber, arugula, and bibb lettuce), a first selection process among assayed variables was done (Table 12). It was clear that the estimation of total dietary fiber did not differentiate among varieties of tested crops. Also, measurement of the antioxidant capacity of vegetables and fruit produce using the ABTS (either hydrophilic of lipophilic phases) was useful for discrimination among cucumber varieties but did not distinguish among varieties of cherry tomato, beef-steak tomato, arugula, or bibb lettuce. Similar to ABTS, the DPPH and total carotenoid (lipophilic extract) assays were not suitable to distinguish between varieties of cherry tomato, beefsteak tomato, cucumber, or bibb lettuce (Table 12).

Similarly, some mineral elements were not different in varieties of $\mathrm{SB}$ and $\mathrm{GH}$ produce (Table 12). For example, chromium $(\mathrm{Cr})$ was the same in all cherry tomato varieties. In cucumber, calcium $(\mathrm{Ca})$, iron $(\mathrm{Fe})$, magnesium $(\mathrm{Mg})$, and $\mathrm{Cr}$ were not discriminating mineral elements among assayed varieties. In arugula, $\mathrm{Ca}, \mathrm{Mg}$, and selenium (Se) were the same in SB and GH varieties. For bibb lettuce, $\mathrm{Ca}$, potassium $(\mathrm{K})$, and phosphorous $(\mathrm{P})$ were the same in $\mathrm{SB}$ and $\mathrm{GH}$ produce. Other assays generated similar results for specific vegetable or fruit produce varieties including total phenolics, ascorbic acid, and lutein content and fruit ripeness, sweetness, and the mouth feeling of cherry tomato (Table 12).

Taste test components including fruit ripeness, sweetness, juiciness, mouth feeling, and general acceptability of beefsteak tomato were similar. Dry matter, malic acid, and flesh aroma were not able to distinguish varieties of cucumber. The overall quality term could not distinguish arugula varieties. Ascorbic acid and the sensory variables, odor, sogginess and freshness, and overall quality, were not discriminating variables among bibb lettuce varieties (Table 12). The largescale similarity among tested varieties might be due to the fact that they were selected carefully to have similar characteristics for better comparison between the hydroponic production system and store-bought produce.

\subsection{Dominant Variables for Fruit and Vegetables}

3.13.1. Dominant Variables for Cherry Tomato. Figure 1 shows that $100 \%$ of the total variation was explained using 9 clusters. 


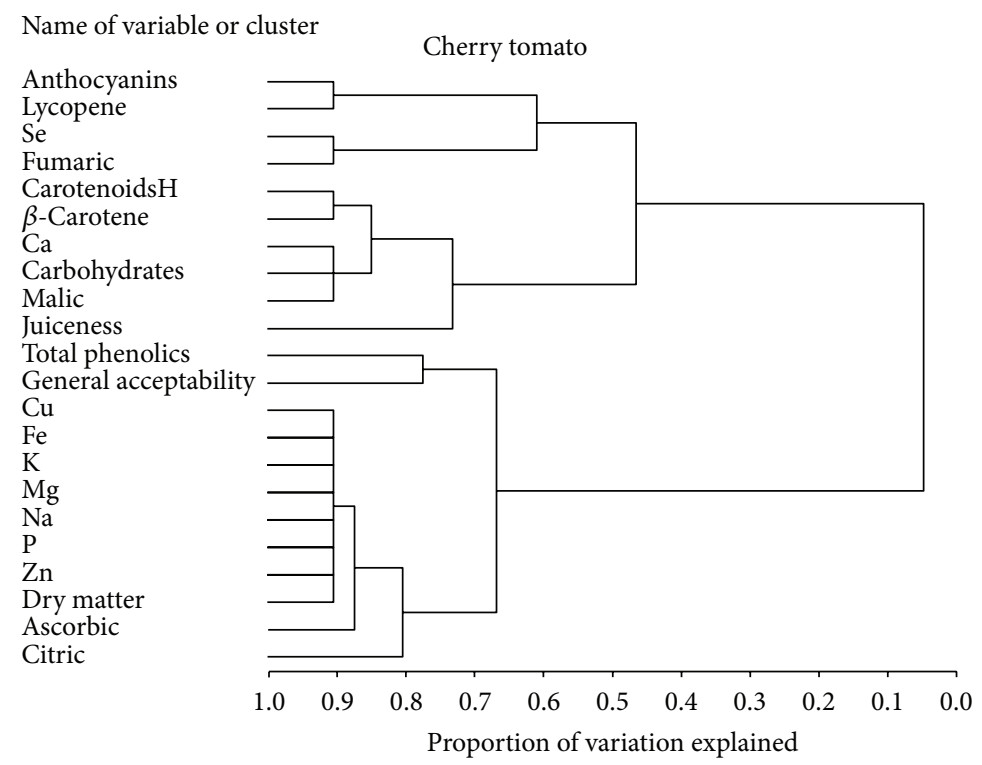

FIGURE 1: Tree dendrogram of the clustering patterns and their proportion of explained variance ( 9 clusters explained $100 \%$ of the variation) using VARCLUS procedure for phytonutrient variables that were used to differentiate among cherry tomato store-bought and greenhousegrown varieties. CarotenoidsH: carotenoids, hydrophilic fraction.

The VARCLUS method showed that separation of dependent variables into 9 clusters resulted in the best classification. Based on results illustrated in Figures 1, 6, and 11, we identified two sensory criteria (fruit juiciness and general acceptability) and 11 phytonutrient factors $(\mathrm{Ca}, \mathrm{Cu}, \mathrm{Fe}, \mathrm{K}$, $\mathrm{Mg}$, total carotenoids, lycopene, total phenolics, citric acid, fumaric acid, and total carbohydrates) as the most influential for discrimination among cherry tomato varieties.

The PLS and PCA output showed that the eigenvalues of the first 2 components (PLS factors 1 and 2 and PCA components 1 and 2) were responsible for $76.4 \%$ of the variance and $69.5 \%$ of the covariance, so plotting PLS 1 versus PLS 2 (Figure 11) and PCA 1 versus PCA 2 (86.4\%) (Figure 6) identified variables that contributed more than others to the variance. Correlation loading plot (Figure 11) shows that plotting factors PLS 1 and 2 of $X$ and $Y$ scores reveal $76.4 \%$ and $69.5 \%$ of $X$ and $Y$ variability, respectively, which illustrates the best dimensional rotation and visualization of the variance components.

Figures 6 and 11 confirm that the variables with the most weight in the variance were fruit juiciness, general acceptability, some minerals ( $\mathrm{Ca}, \mathrm{Cu}, \mathrm{Fe}, \mathrm{K}$, and $\mathrm{Mg}$ ), total carotenoids, lycopene, total phenolics, citric acid, fumaric acid, and total carbohydrates. It is also interesting to note that certain variables were negatively correlated with general acceptability and malic acid, including anthocyanins, total phenolics, lycopene, citric acid, and fumaric acid.

3.13.2. Dominant Variables for Beefsteak Tomato. Results in Figure 2 show that $100 \%$ of the variation was explained using 9 clusters. The VARCLUS method indicated that the best classification was obtained through separation of dependent variables into 9 clusters. Based on results illustrated in Figures 2, 7, and 12, we identified 15 phytonutrient factors $(\mathrm{Ca}$,
$\mathrm{Cu}, \mathrm{Fe}, \mathrm{K}, \mathrm{Mg}, \mathrm{P}, \mathrm{Zn}, \beta$-carotene, lutein, lycopene, total phenolics, total anthocyanins, citric acid, fumaric acid, and total carbohydrates) as the most influential for discrimination among beefsteak tomato varieties. Biological network analysis was used to interrelate sensory and phytonutrient traits as discriminating factors of tomato and strong associations were reported between citric acid with tomato aroma, glycine with tomato aroma, and granulosity with dry matter [39]. Similar to our results, sugar and organic acids contributed the most to the flavor of tomato [53-55].

The PLS and PCA output showed that the eigenvalues of the first 2 components (PLS factors 1 and 2 and PCA factors 1 and 2) are responsible for $87.92 \%$ of the variance, so plotting PLS 1 versus PLS 2 (Figure 12) and PCA 1 versus PCA 2 (Figure 7) identified variables that contribute more than others to the variance. Correlation loading plot (Figure 12) shows that plotting factors PLS 1 and PLS 2 of $X$ and $Y$ scores reveal $51.2 \%$ and $63.7 \%$ of $X$ and $Y$ variability, respectively, which illustrate the best dimensional rotation and visualization of the variance components. Figures 7 and 12 confirm the most important variables to distinguish between greenhousegrown and store-purchased produce were minerals $(\mathrm{Ca}, \mathrm{Cu}$, $\mathrm{Fe}, \mathrm{K}, \mathrm{Mg}, \mathrm{P}$, and $\mathrm{Zn}$ ), carotenoids ( $\beta$-carotene, lutein, and lycopene), total phenolics, total anthocyanins, citric acid, fumaric acid, and total carbohydrates. Playing a major role in the general acceptability of beef-steak tomato and similar to observations with cherry tomato were the variables total phenolics and anthocyanins; both were negatively correlated with fumaric acid and total carbohydrate contents.

3.13.3. Dominant Variables for Cucumber. Data presented in Figure 3 show that $100 \%$ of the total variation was explained using 11 clusters. Based on the VARCLUS method, separation of dependent variables into 11 clusters was the 


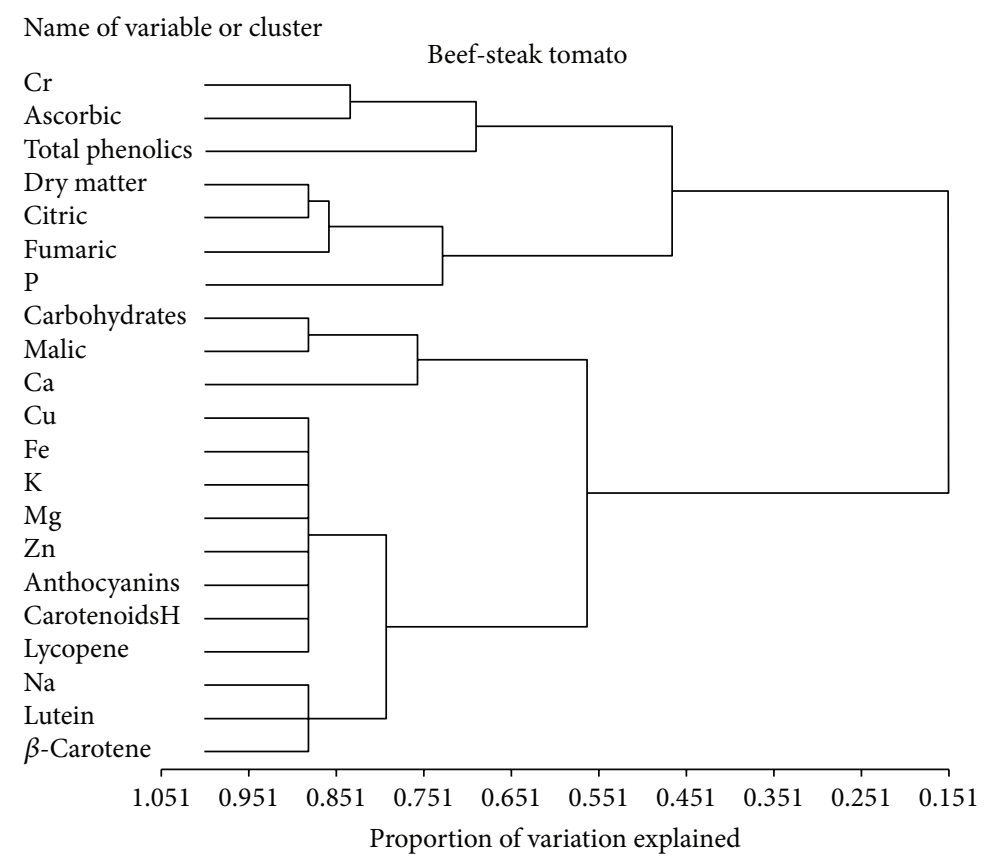

FiguRE 2: Tree dendrogram of the clustering patterns and their proportion of explained variance ( 9 clusters explained $100 \%$ of the variation) using VARCLUS procedure for phytonutrient variables that were used to differentiate among beefsteak tomato store-bought and greenhousegrown varieties. CarotenoidsH: carotenoids, hydrophilic fraction.

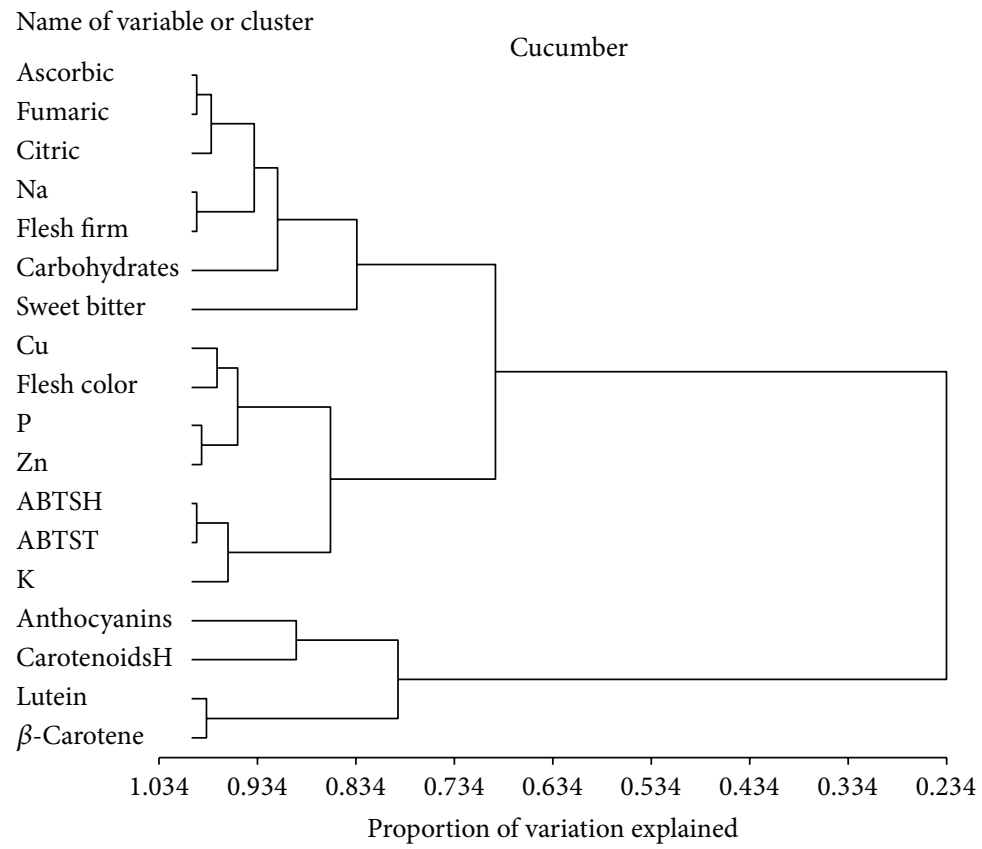

FIGURE 3: Tree dendrogram of the clustering patterns and their proportion of explained variance (11 clusters explained $100 \%$ of the variation) using VARCLUS procedure for phytonutrient variables that were used to differentiate among cucumber store-bought and greenhousegrown varieties. CarotenoidsH: carotenoids, hydrophilic fraction; ABTSH: ABTS, hydrophilic fraction; ABTST: ABTS, total hydrophilic and lipophilic fractions. 


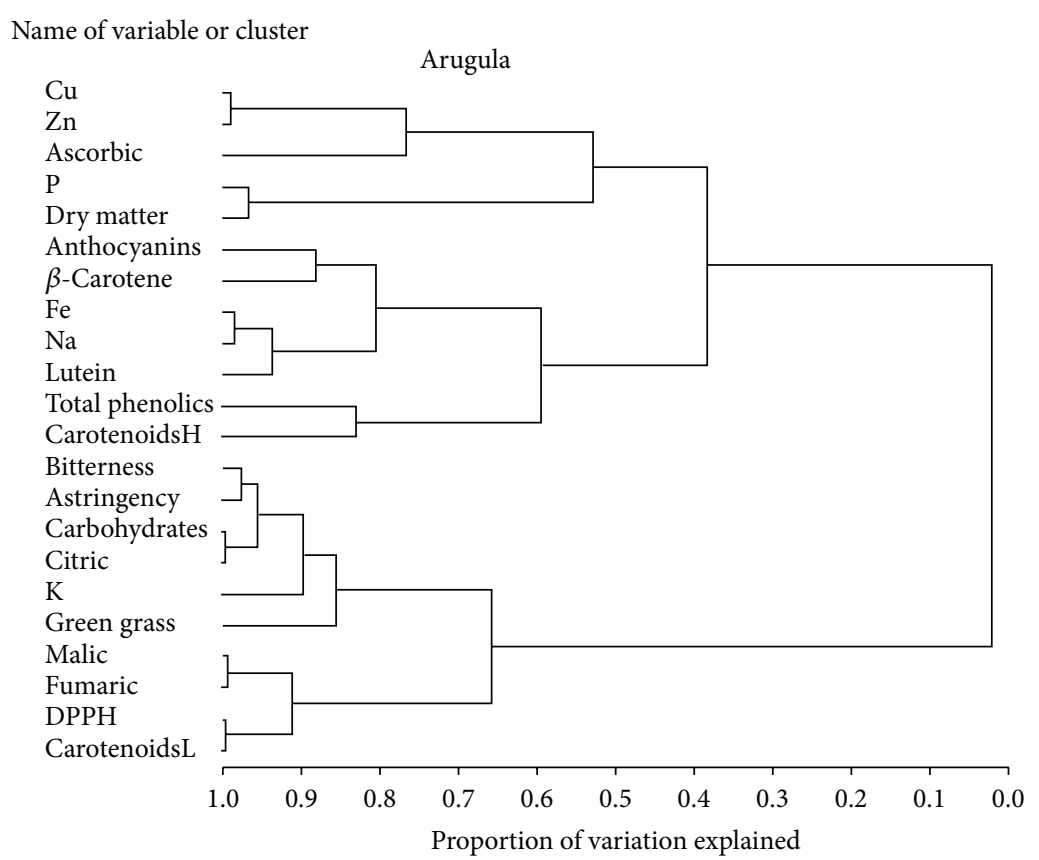

FIGURE 4: Tree dendrogram of the clustering patterns and their proportion of explained variance (13 clusters explained $100 \%$ of the variation) using VARCLUS procedure for phytonutrient variables that were used to differentiate among arugula store-bought and greenhouse-grown varieties. CarotenoidsH: Carotenoids, hydrophilic fraction; CarotenoidsL: carotenoids, lipophilic fraction.

best classification (Figure 3). Based on results illustrated in Figures 3, 8, and 13, we identified two sensory criteria (fruit sweetness and flesh firmness) and 10 phytonutrient factors $(\mathrm{Cu}, \mathrm{K}, \mathrm{P}$, total carotenoids (hydrophilic extract), ABTS, lutein, ascorbic acid, fumaric acid, total carbohydrates, and total anthocyanins) as the most influential for discrimination among cucumber varieties. Ascorbic acid content was an important trait where cucumber had similar levels to carrot [56].

The PLS and PCA output showed that the eigenvalues of the first 2 components (PLS factors 1 and 2 and PCA factors 1 and 2) are responsible for $100 \%$ of the variance and $85.4 \%$ of the covariance, so plotting PLS 1 versus PLS 2 (Figure 13) and PCA 1 versus PCA 2 (100.0\%) (Figure 8) would identify variables that contribute more than others to the variance. Correlation loading plot (Figure 13) shows that plotting factors PLS 1 and PLS 2 of $X$ and $Y$ scores reveal $100 \%$ and $85.4 \%$ of $X$ and $Y$ variability, respectively, which illustrates the best dimensional rotation and visualization of the variance components. It was clear from data presented in Figures 8 and 13 that firmness and sweetness were positively correlated with minerals $(\mathrm{Cu}, \mathrm{Fe}, \mathrm{P}$, and $\mathrm{Zn})$ and fumaric and ascorbic acids. These variables collectively were negatively correlated with total carbohydrate, total anthocyanins, and total carotenoids. Those 12 variables express almost all of the variance reported.

3.13.4. Dominant Variables for Arugula. Approximately 13 clusters explained close to $100 \%$ of variation among arugula varieties (Figure 4). These clusters were visualized in a tree dendrogram obtained using the VARCLUS and PCA procedures. Plots of the correlation loading (out of PLS analysis) and the multidimensional preference analysis plots showed similar groupings of the variables (Figures 9 and $14)$ used in the variable selection. Plotting $X$-scores (scales) and $Y$-scores explained 66.6 and $46.8 \%$, respectively, of the variance and covariance (Figure 14) and PC1 versus PC2 illustrates $91.66 \%$ of the covariance (Figure 9). Two sensory components (astringent taste and green/grassy color) and 11 phytonutrient factors ( $\mathrm{Fe}, \mathrm{Cu}, \mathrm{P}, \mathrm{K}$, citric acid, malic acid, ascorbic acid, total carotenoids, $\beta$-carotene, total phenolics, and total anthocyanins) were the most influential for discrimination among arugula varieties. It was reported in the literature that arugula is a rich source of $\beta$-carotene either fresh or processed $[21,51]$. It was reported that main compounds that affect the aroma of arugula were isothiocyanates and derivatives of butane, hexane, octane, and nonane. Specifically, 4-methylthiobutyl isothiocyanate (14.2\%), cis-3-hexen-1-ol (11.0\%), cis-3-hexenyl butanoate (10.8\%), 5-methylthiopentyl isothiocyanate (9.3\%), cis-3-hexenyl 2-methylbutanoate (5.4\%), and 5-methylthiopentanenitrile (5.0\%) were found in concentrations higher than $5.0 \%$ [57]. From Figures 9 and 14, a strong positive association was noticed between the astringent taste and green/grassy color, $\mathrm{K}$, citric acid, and total carbohydrates, while negative correlation occurred between astringent taste, green/grassy color, $\mathrm{P}, \mathrm{K}$, citric acid, carbohydrates, malic acid, fumaric acid, carotenoids, $\beta$-carotene, and total phenolics. Also, contributions from ascorbic acid and total anthocyanins into total variance were limited. 


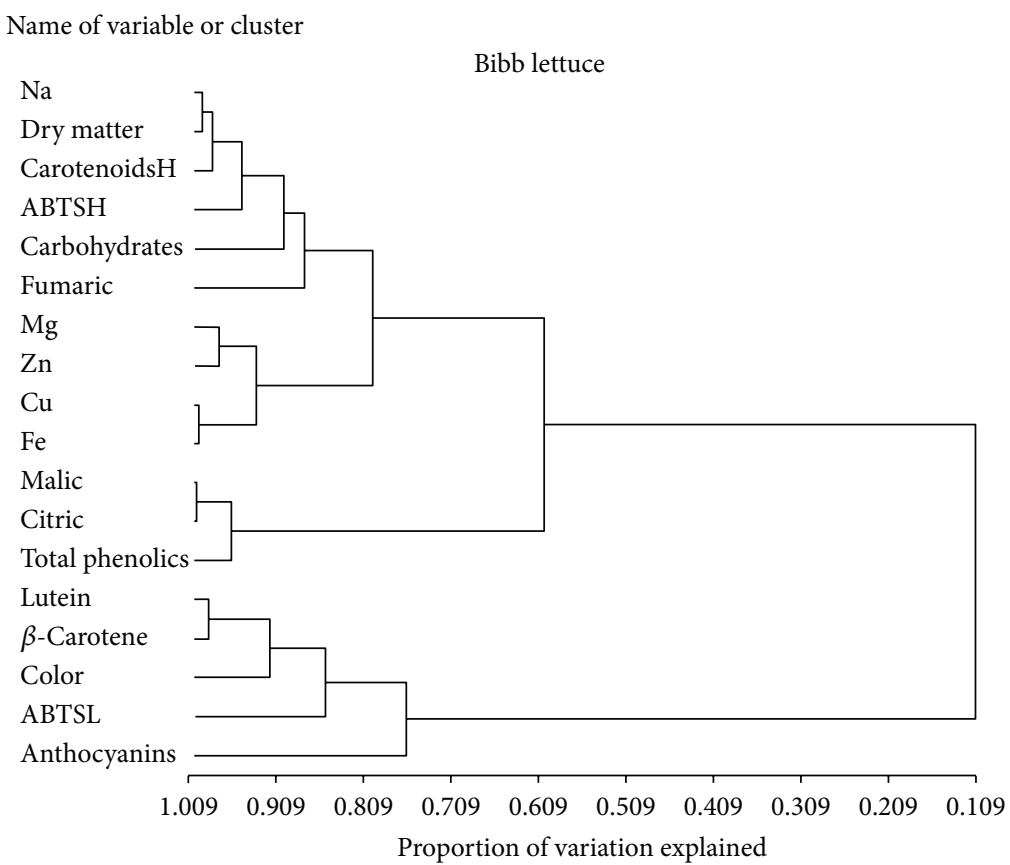

FIgURE 5: Tree dendrogram of the clustering patterns and their proportion of explained variance (13 clusters explained $100 \%$ of the variation) using VARCLUS procedure for phytonutrient variables that were used to differentiate among bibb lettuces store-bought and greenhousegrown varieties. CarotenoidsH: carotenoids, hydrophilic fraction; ABTSL: ABTS, lipophilic fraction.

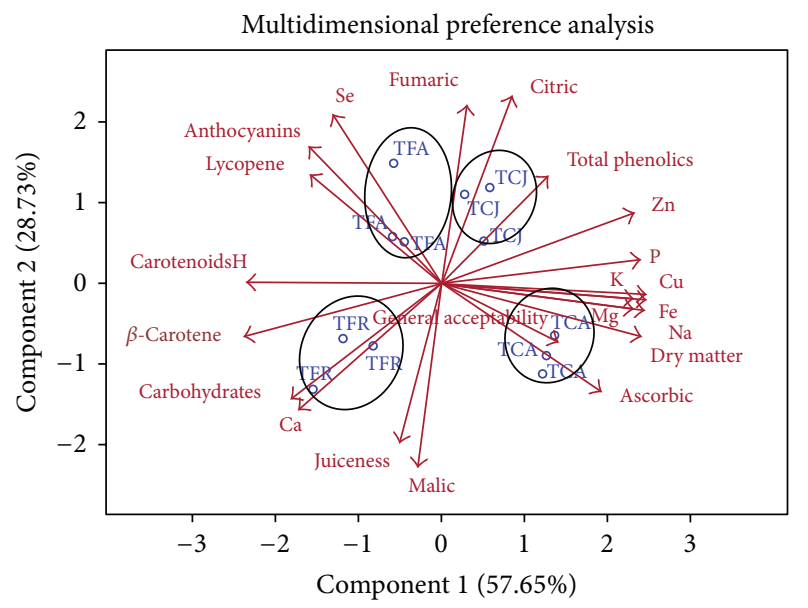

FIGURE 6: Multidimensional preference analysis plot of the PCA procedure. A visual illustration tool that shows similarity classification of the dependent and independent variables but in different space dimension for variables used to differentiate cherry tomato varieties: greenhouse cvs TFA: Favorita, TCJ: Juanita, and TCA: Apero, and the store-bought cv TFR: Fruiterie.

3.13.5. Dominant Variables for Bibb Lettuce. Of all of the sensory variables, the fresh leaf color was the most dominant factor, which clearly differentiated the three tested bibb lettuce varieties (Figure 5). The PLS and PCA output showed that the eigenvalues of the first 2 components (PLS factors 1 and 2 and PCA factors 1 and 2) were responsible for $99.61 \%$ of the variance, so plotting PLS 1 versus PLS 2 (Figure 15) and PCA 1 versus PCA 2 (Figure 10) identified variables that

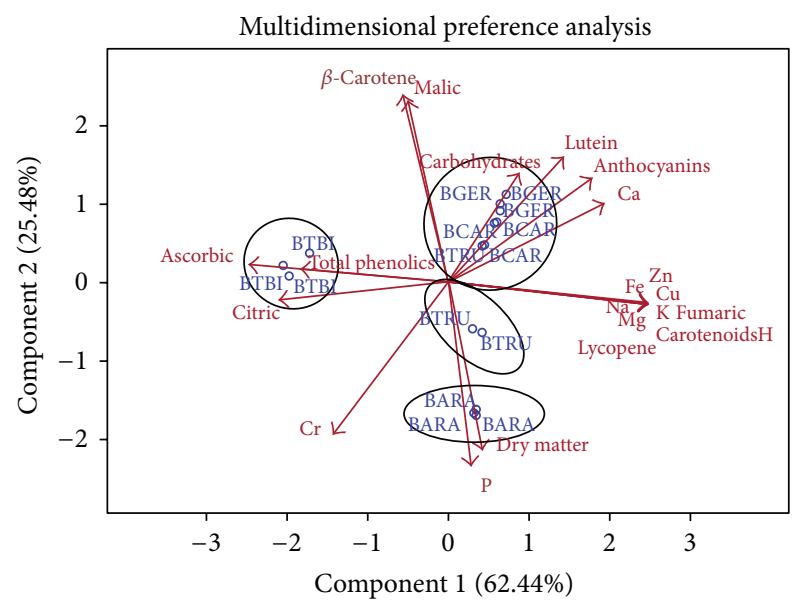

FIgURE 7: Multidimensional preference analysis plot of the PCA procedure. A visual illustration tool that shows similarity classification of the dependent and independent variables but in different space dimension for variables used to differentiate beefsteak tomato varieties: greenhouse cvs BGER: Geronimo, BCAR: Caramba, BTRU: Trust, and BARA: Arbason, and the store-bought cv BTBI: BionatureL.

contributed more than others to the variance. The correlation loading plot (PLS) and the multidimensional preference analysis plot (PCA) showed basically similar classification of the dependent and independent variables. Correlation loading plot (Figure 15) showed that plotting factors PLS 1 and PLS 2 of $X$ and $Y$ scores revealed $100 \%$ and $82 \%$ of $X$ and $Y$ variability, respectively, which illustrates the best dimensional rotation and visualization of the variance components. 


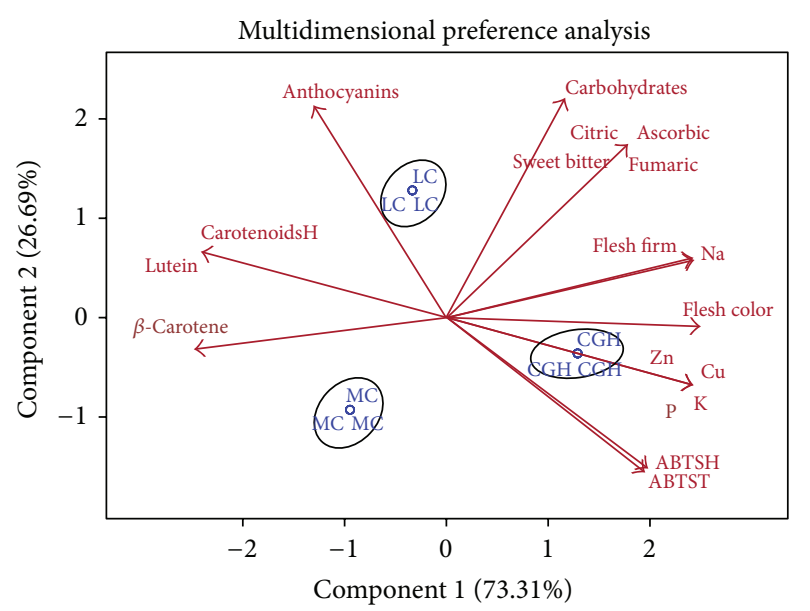

FIgURE 8: Multidimensional preference analysis plot of the PCA procedure. A visual illustration tool that shows similarity classification of the dependent and independent variables but in different space dimension for variables used to differentiate cucumber varieties greenhouse cv CGH: Diva and store-bought cvs LC: Labenese, and MC: Mini Cucumber.

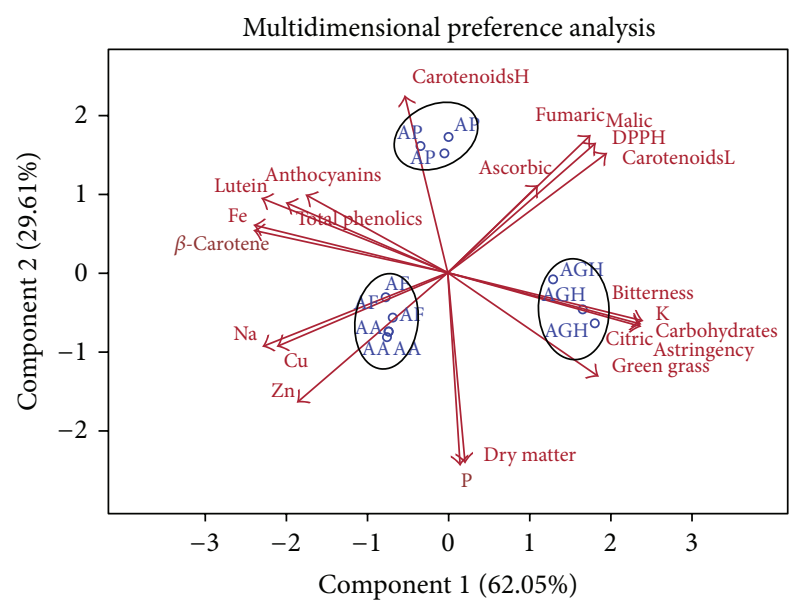

Figure 9: Multidimensional preference analysis plot of the PCA procedure. A visual illustration tool that shows similarity classification of the dependent and independent variables but in different space dimension for variables used to differentiate arugula varieties: greenhouse cv AGH: Astro and store-bought cvs AP: PRO, AF: BW, and AA: ADO.

Figure 5 shows that $100 \%$ of the total variation was explained using 13 clusters. The VARCLUS method indicated that separation of dependent variables into 13 clusters resulted in the best classification (Figure 5). Based on results illustrated in Figure 5 and Table 6 it was clear that 11 phytonutrient factors $(\mathrm{Cu}, \mathrm{Zn}, \mathrm{Mg}$, ABTS, total carotenoids (hydrophilic extract), $\beta$-carotene, total phenolics, total anthocyanins, citric acid, fumaric acid, and total carbohydrates) were the most influential for discrimination among bibb lettuce varieties.

For bibb lettuce, total anthocyanins, total phenolics, total carbohydrates, citric acid, malic acids, fumaric acid, lutein, and $\beta$-carotene were the dominant variables in differentiating between greenhouse-grown and store-bought lettuce. Also,

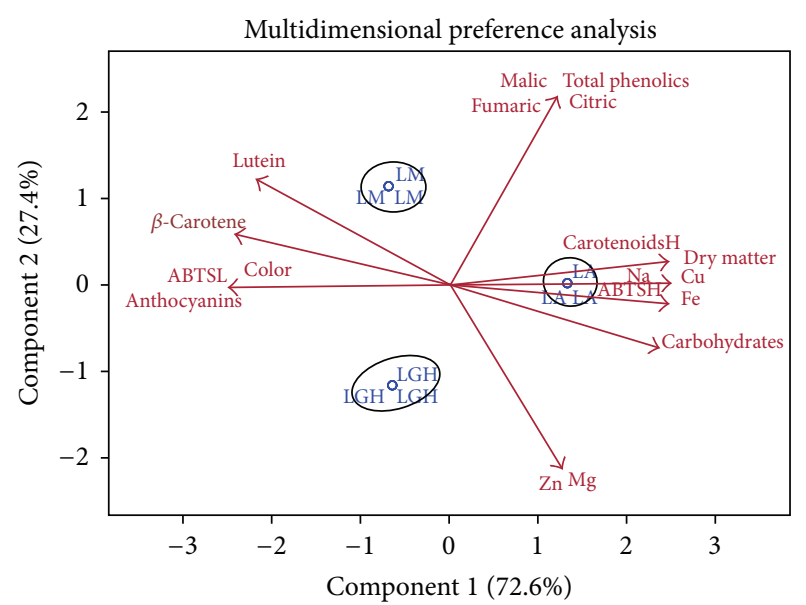

FIGURE 10: Multidimensional preference analysis plot of the PCA procedure. A visual illustration tool that shows similarity classification of the dependent and independent variables but in different space dimension for variables used to differentiate bibb lettuce varieties: greenhouse cv LGH: RexMT and store-bought cvs LM: IGA and LA: ADO.

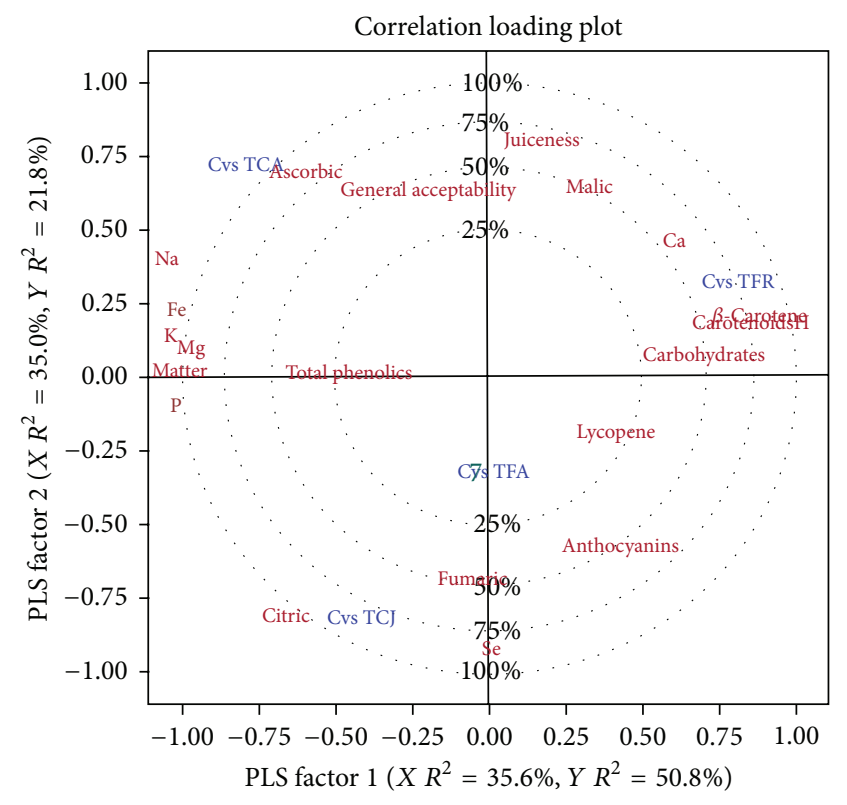

FIGURE 11: Correlation loading plot of the PLS procedure. A visual illustration tool that shows similarity classification of the dependent and independent variables but in different space dimension for variables used to differentiate cherry tomato varieties: greenhouse cvs TFA: Favorita, TCJ: Juanita, and TCA: Apero and the storebought cV TFR: Fruiterie.

these were the variables that contributed the most to taste and acceptability (Figures 10 and 15).

\section{Conclusions}

In this study, we examined the possibility of discriminating cultivars of several crop species, both hydroponically grown and store-bought, based on taste panels' sensory analysis, 


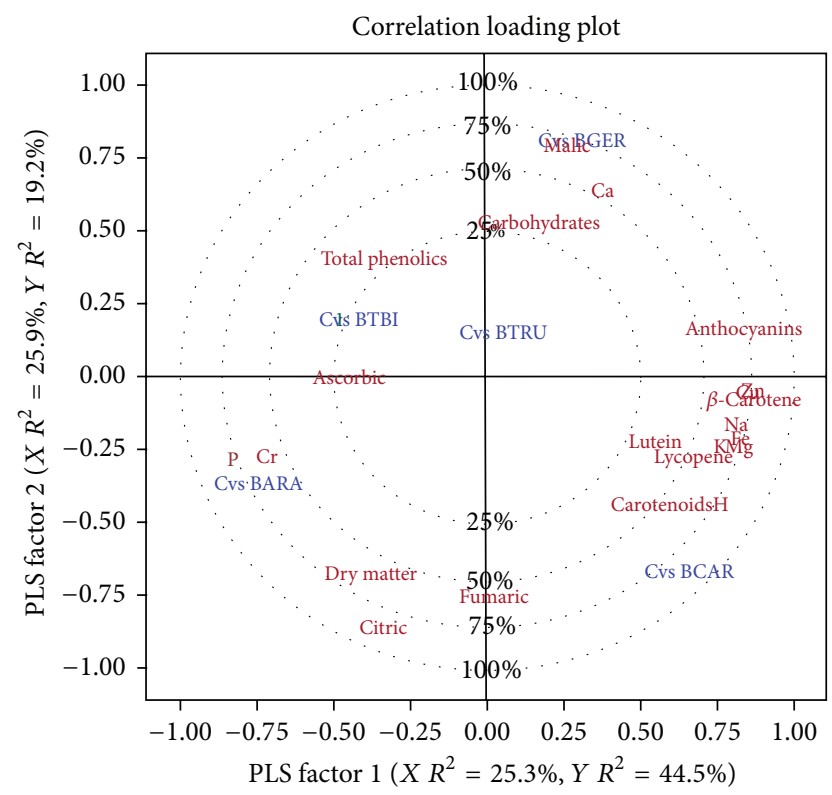

FIGURE 12: Correlation loading plot of the PLS procedure. A visual illustration tool that shows similarity classification of the dependent and independent variables but in different space dimension for variables used to differentiate beefsteak tomato varieties: greenhouse cvs BGER: Geronimo, BCAR: Caramba, BTRU: Trust, and BARA: Arbason and the store-bought cv BTBI: BionatureL.

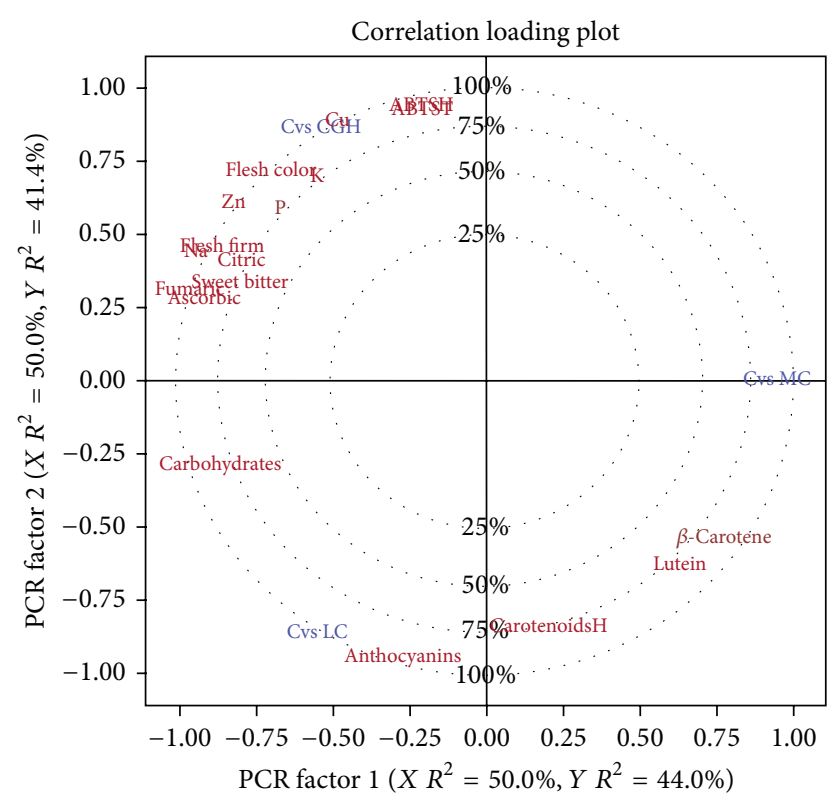

FIGURE 13: Correlation loading plot of the PLS procedure. A visual illustration tool that shows similarity classification of the dependent and independent variables but in different space dimension for variables used to differentiate cucumber varieties greenhouse $\mathrm{cv}$ CGH: Diva and store-bought cvs LC: Lebanese and MC: Mini Cucumber.

phytonutrient analysis of a long list of phytonutrients, and complex statistical analysis. Our hope was that this strategy could provide plant breeders with sufficient information to

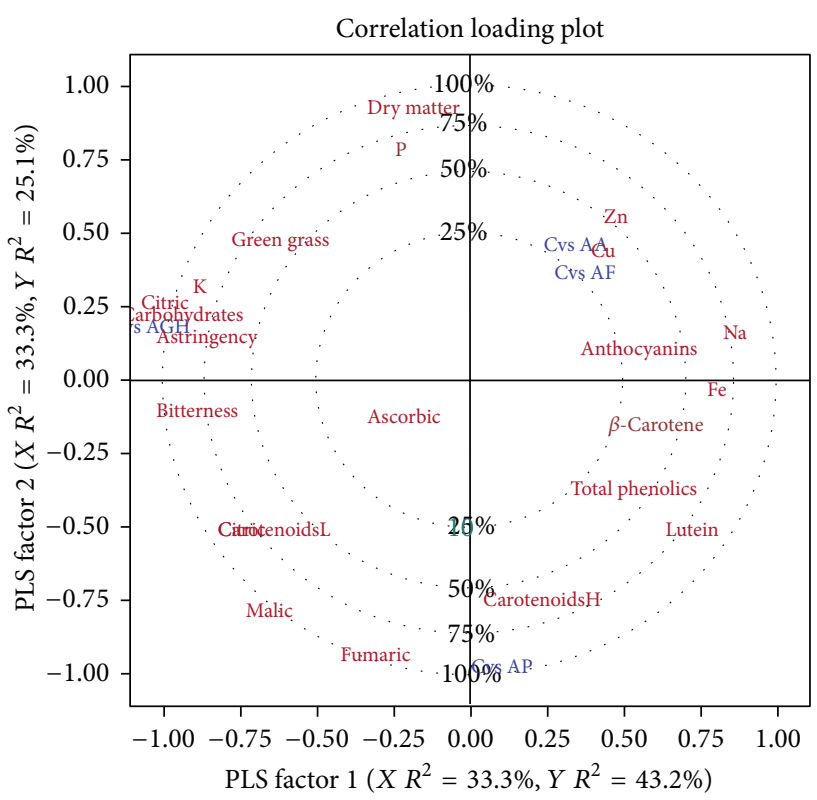

FIGURE 14: Correlation loading plot of the PLS procedure. A visual illustration tool, which shows similarity classification of the dependent and independent variables but in different space dimension for variables used to differentiate arugula varieties: greenhouse cv AGH: Astro and store-bought cvs AP: PRO, AF: BW, and AA: ADO.

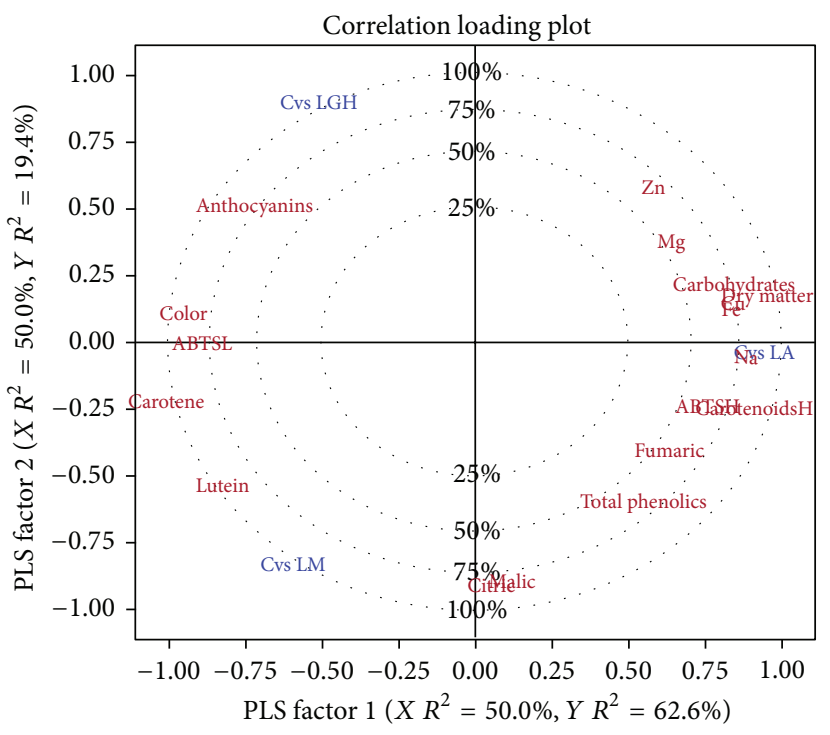

FIGURE 15: Correlation loading plot of the PLS procedure. A visual illustration tool, which shows similarity classification of the dependent and independent variables but in different space dimension for variables used to differentiate bibb lettuce varieties: greenhouse $\mathrm{cv}$ LGH: RexMT and store-bought cvs LM: IGA and LA: ADO.

both choose the best varieties and design long-term strategies to improve crop breeding programs towards improved human health.

Based on our panelists' responses, the variables we chose for cultivar selection among greenhouse-grown crops (also between these and store-bought crops) were in most cases 
insufficiently robust to help distinguish between cultivars. The exceptions were the more dominant sensory characteristics such as the "astringent" and "grassy" traits of arugula cultivars, the "juiciness" and "general acceptability" of cherry tomato cultivars, and the "freshness" and "sweetness" of cucumber cultivars. These dominant characteristics could form the core of a consolidated number of criteria in a more discriminating sensory evaluation test.

Among the phytonutrient tests, mineral analysis was powerful for crop cultivar differentiation; in particular, the minerals $\mathrm{Cu}, \mathrm{Fe}, \mathrm{K}, \mathrm{Mg}$, and $\mathrm{P}$ were more useful than others to discriminate between cultivars within each crop. Total carotenoids, particularly $\beta$-carotene, lycopene, and lutein, were also strong determinants for cultivar selection. Previous literature reported that hydrophilic antioxidant activity (ABTS), ascorbic acid, $\beta$-carotene, and lutein were major phytonutrient components of tomato varieties and ascorbic acid was the main antioxidant component [58]. We found that total carbohydrate was a strong variable for cultivar selection within each crop except arugula. Organic acids, including ascorbic, citric, and fumaric acids, were good traits for cultivar selection within each crop. Total phenolics and total anthocyanins were strong factors to differentiate between cultivars within each crop except cucumber.

Our data supports the use of hierarchical cluster analysis, used efficiently in past studies to compare between different types of foods through the analysis of data sets $[39,59]$. This statistical approach enabled overall conclusions regarding hydroponically grown in comparison to store-bought produce and helped determine the effect of "freshness" on phytonutrient parameters. Overall, some hydroponic produce was superior in phytonutrient parameters to SB produce, but this was not necessarily apparent with all hydroponic produce or all of these parameters. For example, the cherry tomato cultivar Apero exceeded SB varieties in content of most minerals (Mg, Na, P, K, Fe, and $\mathrm{Zn}$ ), percent dry matter, and malic acid content. Cultivar Geronimo exceeded SB cultivars in $\mathrm{Ca}, \mathrm{Cu}, \mathrm{K}, \mathrm{Fe}, \mathrm{Mg}, \mathrm{Na}$, Se, $\mathrm{Zn}$, total anthocyanins, and malic acid content. In addition, cultivar Trust had greater content of $\mathrm{Ca}, \mathrm{Cu}, \mathrm{K}, \mathrm{Fe}, \mathrm{Mg}, \mathrm{Na}, \mathrm{Zn}$, total anthocyanins, and lycopene compared with $\mathrm{SB}$ varieties.

The effect of fridge-storage under ideal circumstances (picked fresh, packed into zip-lock plastic bags, and placed at $4^{\circ} \mathrm{C}$ for 3 or $6 \mathrm{~d}$ ) did not have a dramatic effect on phytonutrient status. As long as produce is handled well after harvest, it seems that it does not deteriorate too much during this time frame. There are various implications of this to consider. Foremost is that while "fresh-picked" is perceived by consumers to be very important, "freshness" under ideal storage conditions, such as the $6 \mathrm{~d}$ of fridge-storage used in our study, did not affect phytonutrient quality. It is apparent that the effect of cultivar is more important than the effect of short-term storage under ideal storage conditions. This is reassuring for suppliers and customers who may be concerned about relative freshness of their produce. For example, the effects of various phenolic and organic acids that were affected by storage in some cultivars are taste-related components that could have an impact on sensory quality.
There are many unknowns related to the effects of storage on sensory parameters (this was not done) and phytonutrient characteristics, which could now be explored. Apart from $\mathrm{GH}$ arugula that had relatively more intense bitter flavor, $\mathrm{GH}$ produce generally had rankings of sensory traits that were either superior or equal to SB produce. The importance of cultivar selection towards improved sensory traits is evident for cherry tomatoes, where 'Apero' showed consistently better sensory characteristics relative to the other GH cherry tomatoes in addition to the SB produce. The advantage of $\mathrm{GH}$ cucumbers relative to the two other tested SB produce is apparent for flesh color and flesh firmness indicating a superior product in terms of sensory characteristics.

The current study provides new information concerning key relationships and correlation among sensory analysis, phytonutrient content, and data mining statistics of arugula, bibb lettuce, cucumber, and tomato (beef-steak and cherry) to enable better visualization of essential relationships among vegetable and fruit traits. Plant breeders can use this study to select the more discriminating sensory criteria and strategize to find others and to better select among phytochemical assays and eliminate the often costly analyses with lesser utility for discrimination between genotypes. Ultimately, consumers will benefit by identification and promotion of cultivars with superior phytonutrient content and antioxidant capacity.

\section{Conflict of Interests}

The authors have no conflict of interests to declare regarding the publication of this paper.

\section{Acknowledgments}

Thanks are due to Ms. Lauren Rathmell of Lufa Farms for help growing the hydroponic greenhouse produce in the Macdonald campus research greenhouse, purchasing the store-bought produce and other materials for the taste tests, and assisting with plate preparation and other matters during the taste tests. The authors also thank Drs. Z. Farook and M. Baig (Arid Agriculture University, Rawalpindi, Pakistan) for their assistance with the taste and phytonutrient tests and paper review. Thanks are due to Mr. Simon Hebert and his staff for their assistance with greenhouse help during the crop growth and harvesting phases. Thanks are also due to Dr. G. Marquis, Chair, and the other members of McGill's Ethics Board, for their helpful suggestions towards the detailed planning necessary to conduct the Taste Tests (McGill Ethics certificate REB File \#: 953-1110). The authors also thank the School of Dietetics \& Human Nutrition for use of their sensory analysis facility for conducting the taste tests. Thanks are also due to Drs. M. Lefsrud and Dr. S. Prasher (Bioresource Engineering Dept.), A. Mustafa (Animal Sciences Dept.), and J. Singh (Plant Science Dept.) for the use of the freeze-dryer, ICP OES, LECO, and $-80^{\circ} \mathrm{C}$ freezer, respectively. Authors D. J. Donnelly and S. Kubow are also grateful to the NSERC Discovery Grant program. 


\section{References}

[1] H. M. Resh, Hydroponic Food Production: A Definitive Guidebook of Soilless Food-Growing Methods, Newconcept Press, Princeton, NJ, USA, 6th edition, 2004.

[2] J. B. Jones Jr., Hydroponics: A Practical Guide for the Soilless Growers, CRC Press, 2nd edition, 2005.

[3] FAO, FAO STAT, 2011, http://faostat.fao.org/faostat/servlet.

[4] I. T. Johnson, "Antioxidant and antitumor properties," in Antioxidants in Food, J. Pokomy, J. N. Yanishlieva, and M. Gordon, Eds., pp. 100-123, Woodhead Publishing, Cambridge, UK, 2001.

[5] O. M. Atrooz, "The antioxidant activity and polyphenolic contents of different plant seeds extracts," Pakistan Journal of Biological Sciences, vol. 12, no. 15, pp. 1063-1068, 2009.

[6] Y.-F. Chu, J. Sun, X. Wu, and R. H. Liu, "Antioxidant and antiproliferative activities of common vegetables," Journal of Agricultural and Food Chemistry, vol. 50, no. 23, pp. 6910-6916, 2002.

[7] W. Song, C. M. Derito, M. K. Liu, X. He, M. Dong, and R. H. Liu, "Cellular antioxidant activity of common vegetables," Journal of Agricultural and Food Chemistry, vol. 58, no. 11, pp. 6621-6629, 2010.

[8] Statistics Canada, Food Statistics, SAS, Ed., Statisitics Canada, 2009.

[9] J. K. Campbell, K. Canene-Adams, B. L. Lindshield, T. W.M. Boileau, S. K. Clinton, and J. W. Erdman Jr., "Tomato phytochemicals and prostate cancer risk," Journal of Nutrition, vol. 134, no. 12, pp. 3486S-3492S, 2004.

[10] H. Gerster, "The potential role of lycopene for human health," Journal of the American College of Nutrition, vol. 16, no. 2, pp. 109-126, 1997.

[11] L. Arab, S. Steck, and A. E. Harper, "Lycopene and cardiovascular disease," The American Journal of Clinical Nutrition, vol. 71, pp. 1691S-1695S, 2000.

[12] A. V. Rao and S. Agarwal, "Role of antioxidant lycopene in cancer and heart disease," Journal of the American College of Nutrition, vol. 19, no. 5, pp. 563-569, 2000.

[13] W. Stahl and H. Sies, "Lycopene: a biologically important carotenoid for humans?" Archives of Biochemistry and Biophysics, vol. 336, no. 1, pp. 1-9, 1996.

[14] P. W. Simon, "Plant pigments for color and nutrition," HortScience, vol. 32, pp. 12-13, 1997.

[15] E. Giovannucci, "Tomatoes, tomato-based products, lycopene, and cancer: Review of the epidemiologic literature," Journal of the National Cancer Institute, vol. 91, no. 4, pp. 317-331, 1999.

[16] M. Rodriguez-Carmona, J. Kvansakul, J. Alister Harlow, W. Köpcke, W. Schalch, and J. L. Barbur, "The effects of supplementation with lutein and/or zeaxanthin on human macular pigment density and colour vision," Ophthalmic and Physiological Optics, vol. 26, no. 2, pp. 137-147, 2006.

[17] P. K. Mukherjee, N. K. Nema, N. Maity, and B. K. Sarkar, "Phytochemical and therapeutic potential of cucumber," Fitoterapia, vol. 84, no. 1, pp. 227-236, 2013.

[18] M. S. DuPont, Z. Mondin, G. Williamson, and K. R. Price, "Effect of variety, processing, and storage on the flavonoid glycoside content and composition of lettuce endive," Journal of Agricultural and Food Chemistry, vol. 48, no. 9, pp. 3957-3964, 2000.

[19] C. Nicolle, N. Cardinault, E. Gueux et al., "Health effect of vegetable-based diet: lettuce consumption improves cholesterol metabolism and antioxidant status in the rat," Clinical Nutrition, vol. 23, no. 4, pp. 605-614, 2004.

[20] R. Llorach, A. Martínez-Sánchez, F. A. Tomás-Barberán, M. I. Gil, and F. Ferreres, "Characterisation of polyphenols and antioxidant properties of five lettuce varieties and escarole," Food Chemistry, vol. 108, no. 3, pp. 1028-1038, 2008.

[21] E. M. M. Tassi and J. Amaya-Farfan, "Carotenoid uptake by human triacylglycerol-rich lipoproteins from the green leafy vegetable Eruca sativa," Ecology of Food \& Nutrition, vol. 47, no. 1, pp. 77-94, 2008.

[22] M. Kimura and D. B. Rodriguez-Amaya, "Carotenoid composition of hydroponic leafy vegetables," Journal of Agricultural and Food Chemistry, vol. 51, no. 9, pp. 2603-2607, 2003.

[23] J. Benton Jr., Hydroponics: A Practical Guide for the Soilless Grower, CRC Press, Boca Raton, Fla, USA, 2nd edition, 2005.

[24] S. Wold, N. Kettaneh, and L. Eriksson, "PLS in data mining and data integration," in Handbook of Partial Least Squares: Concepts, Methods and Applications, V. E. Vinzi, W. W. Chin, J. Henseler, and H. Wang, Eds., Springer Handbooks of Computational Statistics, Springer, Berlin, Germany, 2010.

[25] L. Munck, The Revolutionary Aspect of Exploratory Chemometric Technology. The Universe and the Biological Cell as Computers. A Plea for cognitive flexibility in mathematical modelling, Narayana Press, Gylling, Denmark, 2005.

[26] S. Wold, M. Sjöström, and L. Eriksson, "PLS-regression: a basic tool of chemometrics," Chemometrics and Intelligent Laboratory Systems, vol. 58, no. 2, pp. 109-130, 2001.

[27] A. M. K. Nassar, K. Sabally, S. Kubow, Y. N. Leclerc, and D. J. Donnelly, "Some canadian-grown potato cultivars contribute to a substantial content of essential dietary minerals," Journal of Agricultural and Food Chemistry, vol. 60, no. 18, pp. 4688-4696, 2012.

[28] A. M. K. Nassar, S. Kubow, Y. N. Leclerc, and D. J. Donnelly, "Somatic mining for phytonutrient improvement of 'Russet Burbank' potato," American Journal of Potato Research, vol. 91, no. 1, pp. 89-100, 2014.

[29] R. Chirinos, H. Rogez, D. Campos, R. Pedreschi, and Y. Larondelle, "Optimization of extraction conditions of antioxidant phenolic compounds from mashua (Tropaeolum tuberosum Ruíz \& Pavón) tubers," Separation and Purification Technology, vol. 55, no. 2, pp. 217-225, 2007.

[30] R. Re, N. Pellegrini, A. Proteggente, A. Pannala, M. Yang, and C. Rice-Evans, "Antioxidant activity applying an improved ABTS radical cation decolorization assay," Free Radical Biology \& Medicine, vol. 26, no. 9-10, pp. 1231-1237, 1999.

[31] L. E. Rodriguez-Saona and R. E. Wrolstad, "Extraction, isolation, and purification of anthocyanins," in Current Protocols in Food Analytical Chemistry, R. E. Wrolstad, T. E. Acree, H. An et al., Eds., John Wiley \& Sons, New York, NY, USA, 2001.

[32] C. R. Brown, R. Wrolstad, R. Durst, C.-P. Yang, and B. Clevidence, "Breeding studies in potatoes containing high concentrations of anthocyanins," American Journal of Potato Research, vol. 80, no. 4, pp. 241-250, 2003.

[33] G. A. Garzón, K. M. Riedl, and S. J. Schwartz, “Determination of anthocyanins, total phenolic content, and antioxidant activity in Andes berry (Rubus glaucus Benth)," Journal of Food Science, vol. 74, no. 3, pp. C227-C232, 2009.

[34] M. M. Giusti and R. E. Wrolstad, "Characterization and measurement of anthocyanins by UV-visible spectroscopy," in Current Protocols in Food Analytical Chemistry, pp. F1.2.1F1.2.13, John Wiley \& Sons, 2001. 
[35] A. R. Davis, J. Collins, W. W. Fish, Y. Tadmor, C. L. Webber III, and P. Perkins-Veazie, "Rapid method for total carotenoid detection in canary yellow-fleshed watermelon," Journal of Food Science, vol. 72, no. 5, pp. S319-S323, 2007.

[36] R. E. Wrolstad, T. E. Acree, E. A. Decker et al., Current Protocols in Food Analytical Chemistry, John Wiley \& Sons, New York, NY, USA, 2004.

[37] H. K. Lichtenthaler and C. Buschmann, "UNIT F4.3 chlorophylls and carotenoids: measurement and characterization by UV-VIS spectroscopy," in Current Protocols in Food Analytical Chemistry, pp. F4.3.1-F4.3.8, John Wiley \& Sons, New York, NY, USA, 2001.

[38] A. I. O. Barba, M. C. Hurtado, M. C. S. Mata, V. F. Ruiz, and M. L. S. de Tejada, "Application of a UV-vis detection-HPLC method for a rapid determination of lycopene and $\beta$-carotene in vegetables," Food Chemistry, vol. 95, no. 2, pp. 328-336, 2006.

[39] P. Carli, S. Arima, V. Fogliano, L. Tardella, L. Frusciante, and M. R. Ercolano, "Use of network analysis to capture key traits affecting tomato organoleptic quality," Journal of Experimental Botany, vol. 60, no. 12, pp. 3379-3386, 2009.

[40] M. Mecozzi, R. Acquistucci, M. Amici, and D. Cardarilli, "Improvement of an ultrasound assisted method for the analysis of total carbohydrate in environmental and food samples," Ultrasonics Sonochemistry, vol. 9, no. 4, pp. 219-223, 2002.

[41] S. S. Nelsen, "Phenol-sulfuric acid method for total carbohydrates," in Food Analysis Laboratory Manual, chapter 6, Springer, New York, NY, USA, 2010.

[42] M. L. Garbelotti, D. A. P. Marsiglia, and E. A. F. S. Torres, "Determination and validation of dietary fiber in food by the enzymatic gravimetric method," Food Chemistry, vol. 83, no. 3 , pp. 469-473, 2003.

[43] Association of Official Analytical Chemists, Official Method of Analysis. Cereal Foods Supplements, AOAC, Arlington, Va, USA, 1995.

[44] SAS, SAS/INSIGHT User's Guide, SAS Online Documents, Version 8, SAS Institute, Cary, NC, USA, 1999.

[45] J. A. Labate, S. Grandillo, T. Fulton et al., "Tomato," in Genome Mapping and Molecular Breeding in Plants, C. Kole, Ed., Springer, Berlin, Germany, 2007.

[46] C. F. I. Agency, "Guidelines for Highlighted Ingredients and Flavours," http://www.inspection.gc.ca/food/labelling/foodlabelling-for-industry/composition-and-qualityclaims/highlight -edconsultation/highlightedguidelines/eng/1339422936843/ 1339422996038 ? chap $=0$.

[47] J. Gajc-Wolska, H. Skapski, and J. A. Szymczak, "Physical and sensory characteristics of the fruits of eight cultivars of field grown tomato," Acta Physiologiae Plantarum, vol. 22, no. 3, pp. 365-369, 2000.

[48] L. F. D’Antuono, S. Elementi, and R. Neri, "Exploring new potential health-promoting vegetables: glucosinolates and sensory attributes of rocket salads and related Diplotaxis and Eruca species," Journal of the Science of Food and Agriculture, vol. 89, no. 4, pp. 713-722, 2009.

[49] B. George, C. Kaur, D. S. Khurdiya, and H. C. Kapoor, "Antioxidants in tomato (Lycopersium esculentum) as a function of genotype," Food Chemistry, vol. 84, no. 1, pp. 45-51, 2004.

[50] P. Y. Niizu and D. B. Rodriguez-Amaya, "New data on the carotenoid composition of raw salad vegetables," Journal of Food Composition and Analysis, vol. 18, no. 8, pp. 739-749, 2005.

[51] D. B. Rodriguez-Amaya, "Assessment of the provitamin A contents of foods-the Brazilian experience," Journal of Food Composition and Analysis, vol. 9, no. 3, pp. 196-230, 1996.
[52] M. Petro-Turza, "Flavor of tomato and tomato products," Food Reviews International, vol. 2, no. 3, pp. 309-351, 1986.

[53] R. A. Jones and S. J. Scott, "Improvement of tomato flavor by genetically increasing sugar and acid contents," Euphytica, vol. 32, no. 3, pp. 845-855, 1983.

[54] T. M. M. Malundo, R. L. Shewfelt, and J. W. Scott, "Flavor quality of fresh tomato (Lycopersicon esculentum Mill.) as affected by sugar and acid levels," Postharvest Biology and Technology, vol. 6, no. 1-2, pp. 103-110, 1995.

[55] K. K. Petersen, J. Willumsen, and K. Kaack, "Composition and taste of tomatoes as affected by increased salinity and different salinity sources," Journal of Horticultural Science and Biotechnology, vol. 73, no. 2, pp. 205-215, 1998.

[56] U. L. Opara and M. R. Al-Ani, "Antioxidant contents of prepacked fresh-cut versus whole fruit and vegetables," British Food Journal, vol. 112, no. 8, pp. 797-810, 2010.

[57] L. Jirovetz, D. Smith, and G. Buchbauer, "Aroma compound analysis of Eruca sativa (Brassicaceae) SPME headspace leaf samples using GC, GC-MS, and olfactometry," Journal of Agricultural and Food Chemistry, vol. 50, no. 16, pp. 4643-4646, 2002.

[58] Z. Kotíková, J. Lachman, A. Hejtmánková, and K. Hejtmánková, "Determination of antioxidant activity and antioxidant content in tomato varieties and evaluation of mutual interactions between antioxidants," LWT-Food Science and Technology, vol. 44, no. 8, pp. 1703-1710, 2011.

[59] E. A. F. da Silva Torres, M. L. Garbelotti, and J. M. Moita Neto, "The application of hierarchical clusters analysis to the study of the composition of foods," Food Chemistry, vol. 99, no. 3, pp. 622-629, 2006. 


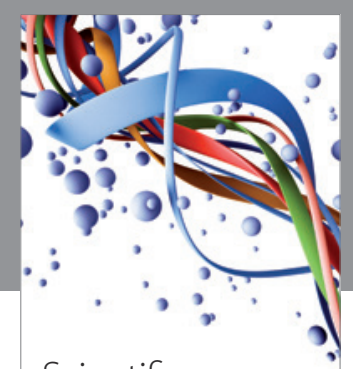

Scientifica
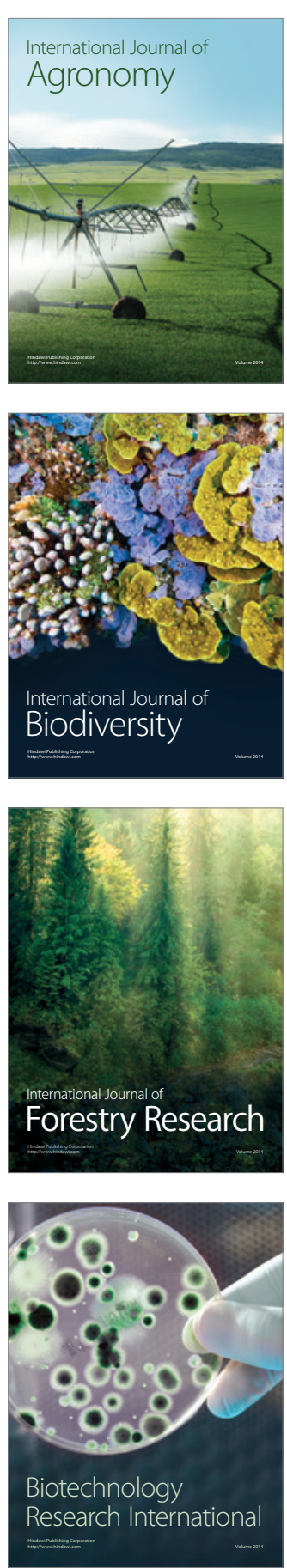
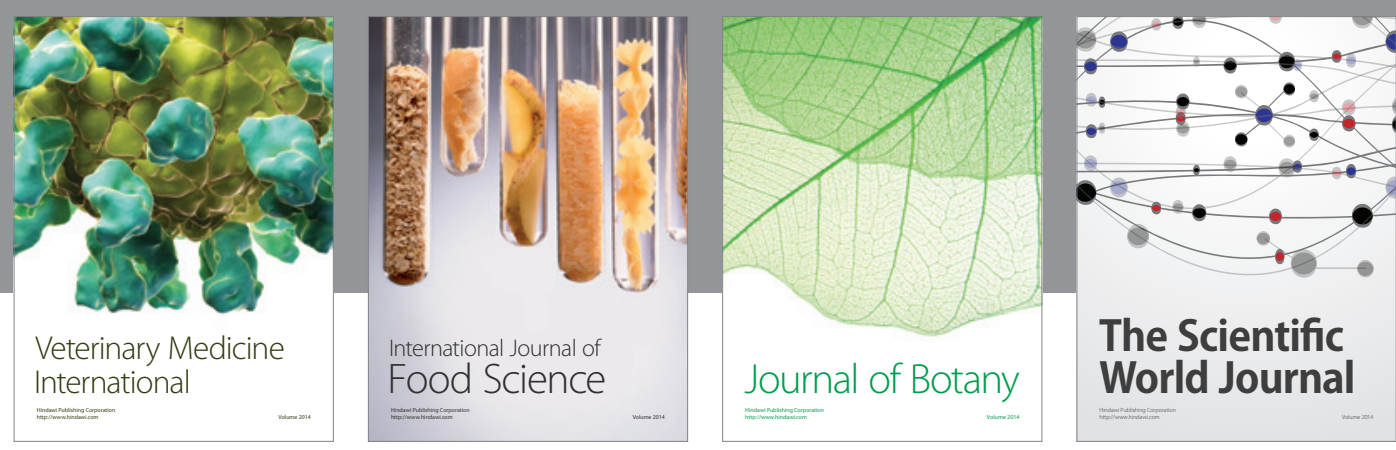

The Scientific World Journal
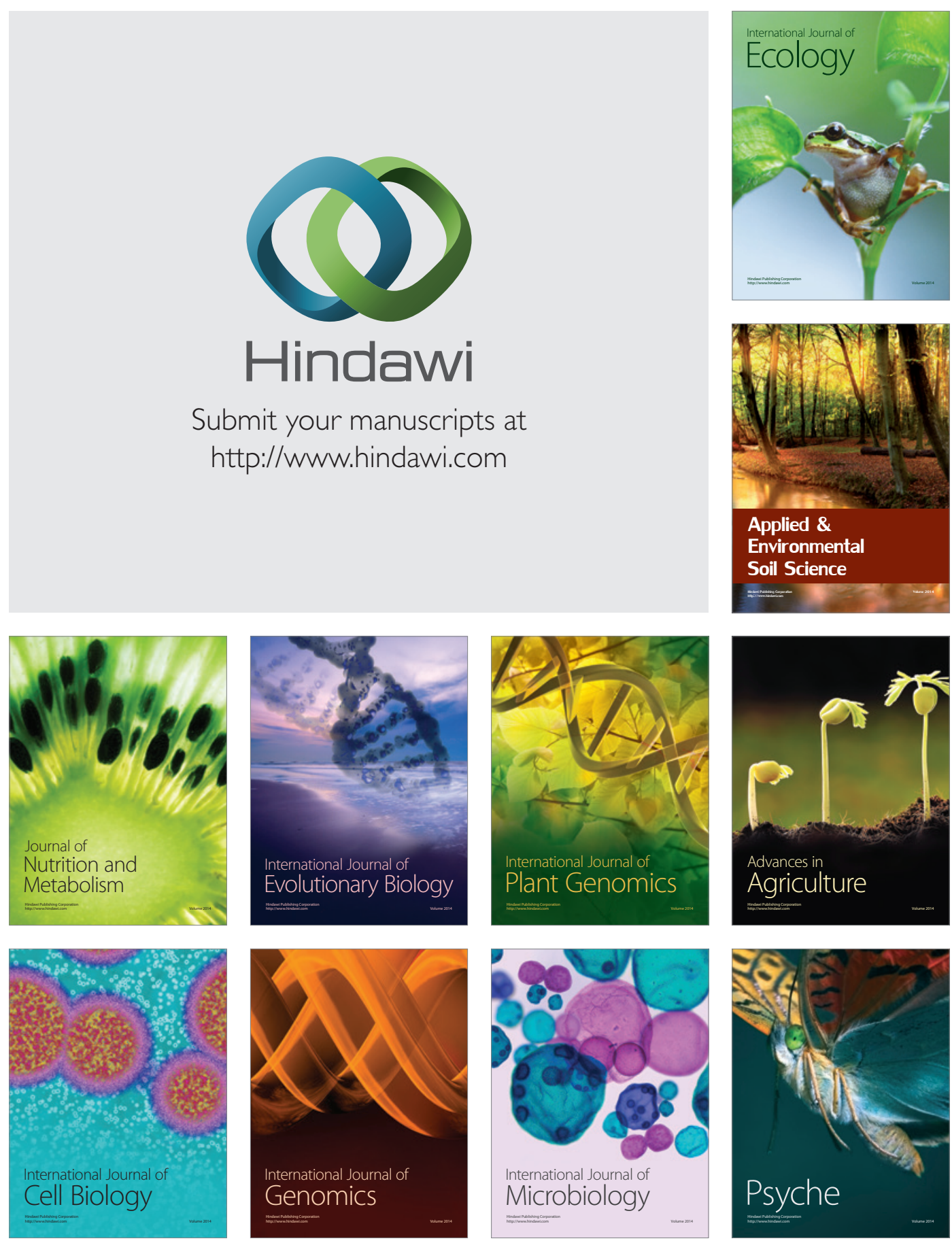